\title{
Microwave-assisted dry reforming of methane for syngas production: a review
}

\author{
T. T. Phuong Pham ${ }^{1,2} \cdot$ Kyoung S. Ro ${ }^{3} \cdot$ Lyufei Chen $^{4} \cdot$ Devinder Mahajan $^{4} \cdot$ Tan Ji Siang $^{5} \cdot$ U. P. M. Ashik ${ }^{6}$. \\ Jun-ichiro Hayashi ${ }^{6,7}$. Doan Pham Minh ${ }^{8,9}$. Dai-Viet N. Vo ${ }^{10}$
}

\begin{abstract}
Abatement of emissions of greenhouse gases such as methane and carbon dioxide is crucial to reduce global warming. For that, dry reforming of methane allows to convert methane and carbon dioxide into useful synthesis gas, named 'syngas', a gas mixture rich in hydrogen and carbon monoxide. However, this process requires high temperatures of about $900{ }^{\circ} \mathrm{C}$ to activate methane and carbon dioxide because dry reforming of methane reaction is highly endothermic. Therefore, a solid catalyst with appropriate thermal properties is needed for the reaction. As a consequence, efficient heating of the reactor is required to control heat transfer and optimize energy consumption. Microwave-assisted dry reforming of methane thus appears as a promising alternative to conventional heating. Here we review the recent research on microwave-assisted dry reforming of methane. We present thermodynamical aspects of the dry reforming of methane, and basics of microwave heating and apparatus. We analyse reformers that use microwave heating. Catalysts used in a microwave-assisted reformer are presented and compared with reactors using conventional heating. Finally, the energy balance is discussed.
\end{abstract}

Keyword Dry reforming of methane $\cdot$ Syngas $\cdot$ Microwave-assisted $\cdot$ Catalyst $\cdot$ Energy balance

\begin{tabular}{|c|c|c|c|}
\hline Abbreviations & Bi-reformino of methane & $\begin{array}{l}\mathrm{DRM} \\
\mathrm{eFe}\end{array}$ & $\begin{array}{l}\text { Dry reforming of methane } \\
\text { Steel-making slag }\end{array}$ \\
\hline btoe & Billion tonnes oil equivalent & FTIR & Fourier transform infrared \\
\hline CNTs-HPCFs & Carbon nanotubes-hollow & & spectroscopy \\
\hline & porous carbon fibres & IEA & International energy agency \\
\hline CQ & Metallurgical coke & Microwave-assisted DRM & Microwave-assisted dry \\
\hline $\mathrm{C} / \mathrm{MR}$ & Catalyst and microwave & & reforming of methane \\
\hline & receptor & MAE & Microwave-assisted extractio \\
\hline
\end{tabular}

Doan Pham Minh

phamminhdoan@duytan.edu.vn;

doan.phamminh@mines-albi.fr

1 Institute of Chemical Technology, Vietnam Academy of Science and Technology, 1 Mac Dinh Chi Str., Dist. 1, Ho Chi Minh City, Vietnam

2 Graduate University of Science and Technology, Vietnam Academy of Science and Technology, 18 Hoang Quoc Viet Street, Cau Giay District, Hanoi, Vietnam

3 Coastal Plains Soil, Water and Plant Research Center, USDA-ARS, 2611 West Lucas Street, Florence, SC 29501, USA

4 Advanced Energy Research and Technology and Materials Science and Chemical Engineering Department, Institute of Gas Innovation and Technology, Stony Brook University, Stony Brook, NY 11794-2275, USA
5 Faculty of Engineering, School of Chemical and Energy Engineering, Universiti Teknologi Malaysia (UTM), 81310 Johor Bahru, Johor, Malaysia

6 Institute for Materials Chemistry and Engineering, Kyushu University, 6-1, Kasuga Koen, Kasuga 816-8580, Japan

7 Transdisciplinary Research and Education Center of Green Technology, Kyushu University, Kasuga 816-8580, Japan

8 Institute of Research and Development, Duy Tan University, Da Nang 550000, Vietnam

9 Université de Toulouse, IMT Mines Albi, UMR CNRS 5302, Centre RAPSODEE, Campus Jarlard, 81013 Albi cedex 09, France

10 Center of Excellence for Green Energy and Environmental Nanomaterials (CE@GrEEN), Nguyen Tat Thanh University, 300A Nguyen Tat Thanh, District 4, Ho Chi Minh City 755414, Vietnam 


$\begin{array}{ll}\text { MPO } & \begin{array}{l}\text { Methane partial oxidation } \\ \text { MWCNT }\end{array} \\ & \begin{array}{l}\text { Multi-walled carbon } \\ \text { nanotubes } \\ \text { MWH }\end{array} \\ \text { M/GR } & \text { MWCNT/layered graphene } \\ & \text { composite } \\ \text { M/CSCNT } & \text { MWCNT/cup-stacked CNT } \\ & \text { composite } \\ \text { OMR } & \text { Oxy-CO }{ }_{2} \text { methane reforming } \\ \text { PSA } & \text { Pressure swing adsorption } \\ \text { PTO } & \text { Lead titanate } \\ \text { PZT } & \text { Ferroelectric lead zirconate } \\ & \text { titanate } \\ \text { SEM } & \text { Scanning electron microscopy } \\ \text { SMR } & \text { Steam methane reforming } \\ \text { TEM } & \text { Transmission electron } \\ \text { VHSV } & \text { microscopy } \\ \text { WGSR } & \text { Volume hourly space velocity } \\ & \text { Water-gas-shift reaction }\end{array}$

\section{Introduction}

Global energy consumption steadily increased from 8.8 billion tonnes oil equivalent (btoe) in 1990 to 13.865 btoe in 2018 (BP Statistical Review of World Energy). Despite the progress made in the development of alternative sources over the past decades, fossil fuels including coal, oil and natural gas still account for approximately $84.7 \%$ of the total global energy consumption in 2019 (BP Statistical Review of World Energy). Among fossil fuels, natural gas burns the cleanest and as such, is considered the bridge fuel to renewables (Védrine 2005). Natural gas can be directly used to heat buildings and used as a feedstock to produce fuels and chemicals (Védrine 2005). For natural gas conversion, the most common route is via conversion to synthesis gas or syngas, which is a mixture of varying amount of hydrogen, carbon monoxide, and carbon dioxide. Syngas is an important platform for chemical gas mixture because it is commercially used for the production of ammonia, methanol, mixed alcohols, oxygenates, and hydrocarbons via Fischer-Tropsch synthesis (Liu et al. 2009). According to Higman (2017), total syngas usage increased $11 \%$ from 120.9 million $\mathrm{Nm}^{3} / \mathrm{h}$ in 2016 to 134.3 million $\mathrm{Nm}^{3} / \mathrm{h}$ in 2017 for all end-use products. Two major syngas production processes are gasification using coal, gas, petcoke, petroleum, biomass and waste as primary feedstocks (Raje and Davis 1997) and methane reforming. In 2017, gasification accounted for about $42 \%$ or $173 \mathrm{GWh}$, and methane reforming accounted for the remaining $58 \%$ or $240 \mathrm{GWh}$ power generation (Higman 2017). At the industrial scale, methane reforming includes steam methane reforming (SMR, Eq. 1) and methane partial oxidation (MPO, Eq. 2). Steam methane reforming is still the dominant process in the syngas production industry. Overall, there are several major disadvantages of steam methane reforming (Tsang et al. 1995). It needs excessive superheated steam for the process at high temperature, causing high operating cost. Also, steam methane reforming is a highly endothermic reaction and the process requires temperature typically above 800-900 ${ }^{\circ} \mathrm{C}$, which can hasten catalyst deactivation. The energy to meet the endothermicity requirement is usually supplied from the combustion of a fuel resulting in a large $\mathrm{CO}_{2}$ emission. The methane partial oxidation reaction occurs at a typical high temperature around $1400 \mathrm{~K}$. The operating temperature can be greatly reduced as low as $1023 \mathrm{~K}$ for high yields of syngas production with the use of a catalyst (York et al. 2003). However, there are several drawbacks related to methane partial oxidation that limits its application (York et al. 2003) (Tsang et al. 1995; York et al. 2003). First, hot-spot may occur in the catalyst bed which causes safety and efficiency reductions issues. Second, the purification of product syngas related to $\mathrm{O}_{2}$ removal is expensive. Finally, coke formation on catalyst surface needs to be addressed.

Steam methane reforming:

$\mathrm{CH}_{4}+\mathrm{H}_{2} \mathrm{O} \rightleftharpoons \mathrm{CO}+3 \mathrm{H}_{2} \quad \Delta \mathrm{H}_{298 \mathrm{~K}}=+206 \mathrm{~kJ} / \mathrm{mol}$

Methane partial oxidation:

$\mathrm{CH}_{4}+1 / 2 \mathrm{O}_{2} \rightleftharpoons \mathrm{CO}+2 \mathrm{H}_{2} \quad \Delta \mathrm{H}_{298 \mathrm{~K}}=-36 \mathrm{~kJ} / \mathrm{mol}$

Dry reforming of methane:

$\mathrm{CH}_{4}+\mathrm{CO}_{2} \rightleftharpoons 2 \mathrm{CO}+2 \mathrm{H}_{2} \quad \Delta \mathrm{H}_{298 \mathrm{~K}}=+274 \mathrm{~kJ} / \mathrm{mol}$

Of particular interest is methane oxidation using a wellknown greenhouse gas, $\mathrm{CO}_{2}$, known as dry reforming of methane (Eq. 3). Both reactants of the dry reforming of methane reactions are the main compounds of natural gas and biogas which is considered as an important renewable resource (Jain et al. 2019). The dry reforming of methane reaction also needs a catalyst to control the kinetic and the selectivity of the reaction. Nickel-based catalysts are the most used for the dry reforming of methane reaction (Alia et al. 2020; Meloni et al. 2020). However, the major issue is catalyst deactivation by coke and carbon formation on catalysts' surface and by thermal sintering (Fischer and Tropsch 1928; Chen et al. 2012). In fact, according to Eq. 3, the dry reforming of methane reaction is highly endothermal and requires high reaction temperature (above $700{ }^{\circ} \mathrm{C}$ ), which can speed up both catalyst thermal sintering and local "cold-spot" inside catalyst beds (Chen et al. 2012). So, heat transfer control also plays important role in dry reforming of methane. This latter can be achieved by using microwaveassisted technology.

Microwave-assisted chemical processes using commercial microwave ovens were reported by Giguere et al. (1986). 
Since then, this technique has shown promise as an alternative technique in extraction (Eskilsson and Björklund 2000; Mandal et al. 2007), environmental engineering (Jones et al. 2002a, b), synthesis (Nüchter et al. 2004), pyrolysis (Motasemi and Afzal; 2013) and reforming (Fidalgo et al. 2008). Compared to conventional heating, the microwave heating offers several advantages including: higher heating rate, better heating control, reduction of equipment size, time and energy savings, etc. (Jones et al. 2002a, b; Motasemi and Afzal 2013).

To date, the dry reforming of methane reaction performed with a conventional heating system has actively studied during the last decades, as illustrated by several recent reviews in the literature (Abdulrasheed et al. 2019; Aramouni et al. 2018; Arora and Prasad 2016; Jang et al. 2019; Lavoie 2014; Muraza and Galadima 2015). Some of these studies evoked microwave-assisted technology as a novel approach for the dry reforming of methane reaction (Shah and Gardner 2014). However, microwave-assisted dry reforming of methane (DRM) was only recently reviewed by Nguyen et al. (2020), and this latter did not cover all the aspects of microwaveassisted DRM such as the thermodynamics of the process, the influence of operating conditions, the energy consumption versus conventional heating. So, the objective of this paper is to address a comprehensive synthesis of research work dedicated to microwave-assisted DRM with focus on challenges and opportunities of this process.

\section{Thermodynamics of dry reforming of methane}

Dry reforming of methane reaction produces $\mathrm{CO}$ and $\mathrm{H}_{2}$ as the main products from $\mathrm{CH}_{4}$ and $\mathrm{CO}_{2} . \mathrm{CH}_{4}$ and $\mathrm{CO}_{2}$ are chemically stable because of their high bonding energy. Their transformation needs severe temperature conditions to activate them. Thus, thermodynamic study on the equilibria of the dry reforming of methane reaction is useful to determinate the thermodynamic limit of the process. In the literature, work has been done on the thermodynamic equilibrium of this process (Chein et al. 2015; Li et al. 2008; Nematollahi et al. 2012; Nikoo and Amin 2011; Pashchenko 2017; Pham Minh et al. 2018; Protasov et al. 2012). The common feature of these studies relates to the basis of Gibbs free energy minimization method. The principle of this method has been detailed in previous studies ( $\mathrm{Li}$ et al. 2008; Nematollahi et al. 2012; Nikoo and Amin 2011; Protasov et al. 2012). Different parameters of the dry reforming of methane have been investigated in particular: (1) the influence of the temperature and pressure on the conversion of $\mathrm{CH}_{4}$ and $\mathrm{CO}_{2}$ and the selectivity in $\mathrm{CO}$ and $\mathrm{H}_{2}$; (2) the influence of the composition of the initial mixture of $\mathrm{CH}_{4}$ and $\mathrm{CO}_{2}$; and (3) the formation of by-products like $\mathrm{C}_{\mathrm{s}}$ and water, and also light hydrocarbons.
The dry reforming of methane reaction generates $\mathrm{CO}$ and $\mathrm{H}_{2}$ as the main gaseous products, but other by-products such as solid carbon $\left(\mathrm{C}_{\mathrm{s}}\right)$, water and light hydrocarbons are also formed. Among them, light hydrocarbons are formed at the very low quantity (Nikoo and Amin 2011). In addition to the main dry reforming of methane reaction (Eq. 3), the following reactions can also take place:

Boudouard reaction:

$2 \mathrm{CO} \rightleftharpoons \mathrm{C}_{\mathrm{s}}+\mathrm{CO}_{2} \quad \Delta \mathrm{H}_{298 \mathrm{~K}}=-172 \mathrm{~kJ} / \mathrm{mol}$

Methane cracking :

$\mathrm{CH}_{4} \rightleftharpoons \mathrm{C}_{\mathrm{s}}+2 \mathrm{H}_{2} \quad \Delta \mathrm{H}_{298 \mathrm{~K}}=+75 \mathrm{~kJ} / \mathrm{mol}$

Water - gas - shift:

$\mathrm{CO}+\mathrm{H}_{2} \mathrm{O} \rightarrow \mathrm{CO}_{2}+\mathrm{H}_{2} \quad \Delta \mathrm{H}_{298 \mathrm{~K}}=-41 \mathrm{~kJ} / \mathrm{mol}$

Steam reforming of carbon:

$\mathrm{C}_{\mathrm{s}}+\mathrm{H}_{2} \mathrm{O} \rightarrow \mathrm{CO}+\mathrm{H}_{2} \quad \Delta \mathrm{H}_{298 \mathrm{~K}}=+131 \mathrm{~kJ} / \mathrm{mol}$

Using FactSage software, which bases also on the Gibbs free energy minimization method (Pham Minh et al. 2018), the thermodynamic equilibrium of different $\mathrm{CH}_{4}$ and $\mathrm{CO}_{2}$ mixtures under different physicochemical conditions could be obtained as presented below. According to Pham Minh et al. (2020), Fig. 1 shows the results obtained for an equimolar mixture of $\mathrm{CH}_{4}$ and $\mathrm{CO}_{2}$ at 1 bar. Below $550^{\circ} \mathrm{C}$, solid carbon $\left(\mathrm{C}_{\mathrm{s}}\right)$ and $\mathrm{H}_{2} \mathrm{O}$ are predominant species, together with $\mathrm{CH}_{4}$ and $\mathrm{CO}_{2}$. By increasing the temperature, all these species are converted to form syngas. At $900{ }^{\circ} \mathrm{C}$, the conversion of $\mathrm{CH}_{4}$ and $\mathrm{CO}_{2}$ can reach 98.1 and $97.3 \%$, respectively. Solid carbon can be practically negligible at this temperature from thermodynamic point of view.

From the stoichiometry of Eq. 3, it is evident that the dry reforming of methane reaction is favourable at low pressure. However, when the dry reforming of methane reaction is integrated into a multi-step process, the realization of this reaction at high pressure is sometimes necessary to optimize global energy balance. This is the case for the production of green hydrogen from landfill gas using steam reforming followed by the water-gas-shift reaction (WGSR) and pressure swing adsorption (PSA) steps (Grouset and Ridart 2018). Figure 2 shows the influence of the pressure on thermodynamic equilibrium of a mixture containing initially $1 \mathrm{~mol}$ of $\mathrm{CH}_{4}$ and $1 \mathrm{~mol}$ of $\mathrm{CO}_{2}$ at 800 and $900{ }^{\circ} \mathrm{C}$. Increasing the pressure from 1 to 30 bar strongly decreases the equilibrium amount of both $\mathrm{H}_{2}$ and $\mathrm{CO}$ at 800 and $900{ }^{\circ} \mathrm{C}$, which illustrates the negative impact of the pressure on this process (Fig. 2a, b). At $900{ }^{\circ} \mathrm{C}$, the conversion of $\mathrm{CH}_{4}$ and $\mathrm{CO}_{2}$ decreases from 98.1 and $97.3 \%$ at 1 bar to 76.0 and $71.3 \%$ at 30 bar (Fig. 2c). In parallel, the equilibrium amount of solid 
Equilibrium amount (mol)

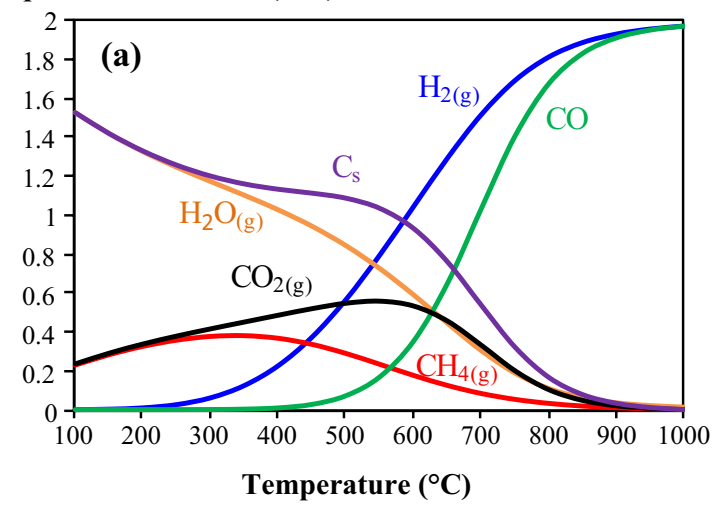

Fig. 1 Thermodynamic equilibrium of a mixture containing initially $1 \mathrm{~mol}$ of $\mathrm{CH}_{4}$ and $1 \mathrm{~mol}$ of $\mathrm{CO}_{2}$ at 1 bar (a); conversion of $\mathrm{CH}_{4}$ and $\mathrm{CO}_{2}$ and molar ratio of $\mathrm{H}_{2} / \mathrm{CO}$. The transformation of $\mathrm{CH}_{4}$ and $\mathrm{CO}_{2}$ into $\mathrm{H}_{2}$ and $\mathrm{CO}$ is only favoured at high temperature, e.g. above

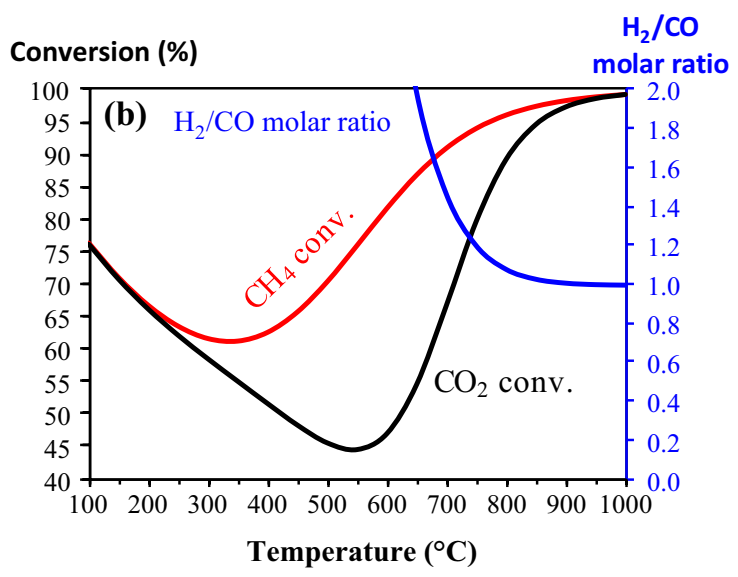

$800{ }^{\circ} \mathrm{C}$. The molar ratio of $\mathrm{H}_{2} / \mathrm{CO}$ could theoretically reach 1 at high temperature. Reprinted by permission from Springer Nature (Pham Minh et al. 2020), Copyright 2020
Fig. 2 Effect of the pressure on the thermodynamic equilibrium of a mixture containing initially $1 \mathrm{~mol}$ of $\mathrm{CH}_{4}$ and $1 \mathrm{~mol}$ of $\mathrm{CO}_{2}$ at 800 and $900{ }^{\circ} \mathrm{C}$. At high temperature of 800 and $900{ }^{\circ} \mathrm{C}$, the increase in the total pressure highly decreases the transformation of $\mathrm{CH}_{4}$ and $\mathrm{CO}_{2}$ into syngas and highly favours the formation of solid carbon
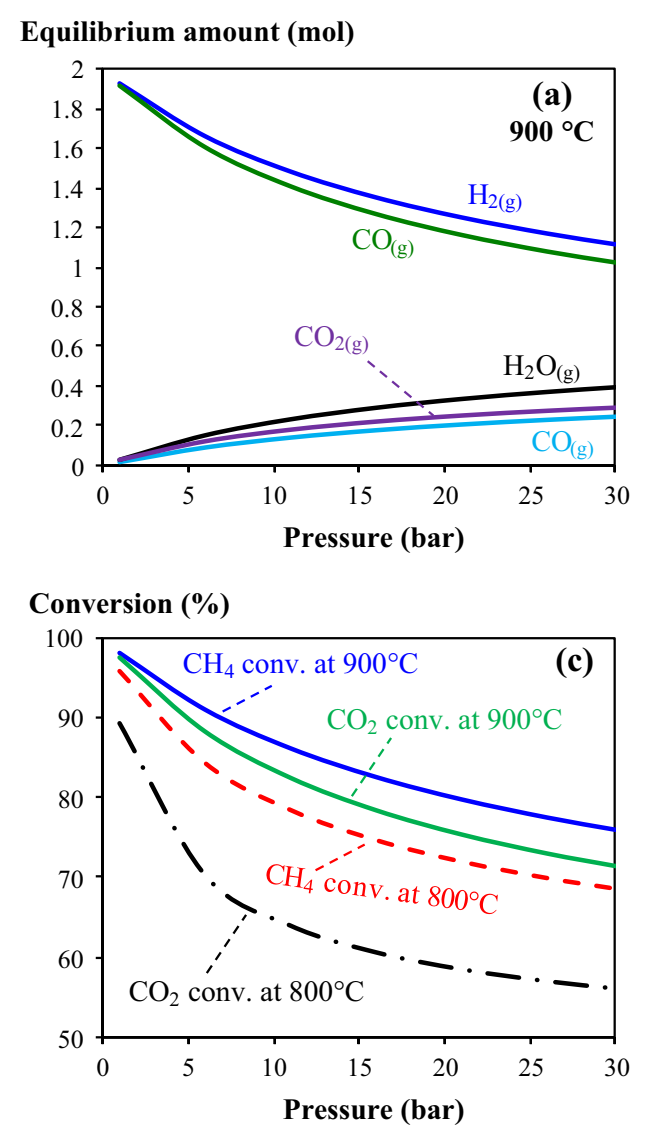

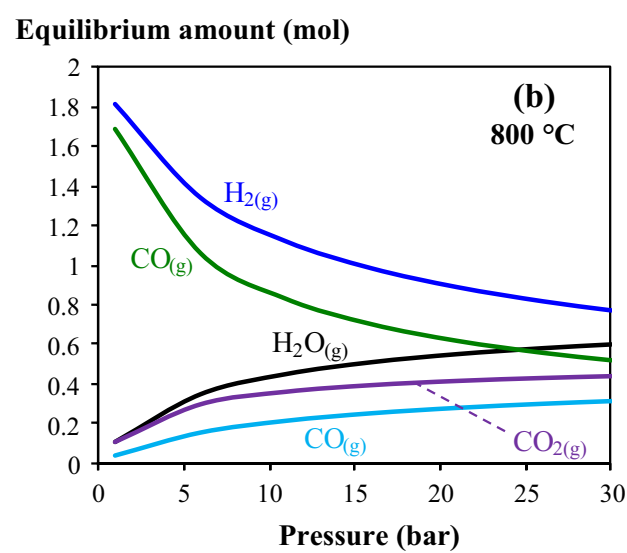

Selectivity in solid carbon (\%)

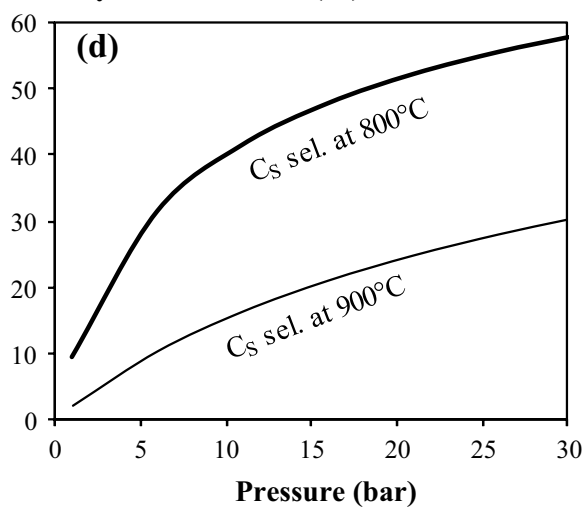

carbon quickly increases with the increase in the pressure (Fig. 2d). The selection of operating pressure for the dry reforming of methane at a large scale must be carefully examined taking into account other factors of the global process. It is worth noting that the steam reforming of methane is usually performed at around $900{ }^{\circ} \mathrm{C}$ and
15-30 bar with a molar ratio of steam/methane close to 3/1 (Grouset and Ridart 2018).

In the dry reforming of methane reaction, the formation of solid carbon $\left(\mathrm{C}_{\mathrm{s}}\right)$ highly impacts the stability of catalyst. This can be limited by adjusting the content of $\mathrm{CO}_{2}$ in the initial mixture of $\mathrm{CH}_{4}$ and $\mathrm{CO}_{2}$. Figure 3 shows the influence 
of the molar ratio of $\mathrm{CH}_{4} / \mathrm{CO}_{2}$ at two different pressures of 1 and 15 bar.

As expected, under a given pressure, increasing the content of $\mathrm{CO}_{2}$ is favourable for $\mathrm{CH}_{4}$ conversion (Fig. 3a). At 1 bar and $700{ }^{\circ} \mathrm{C}, \mathrm{CH}_{4}$ conversion can reach $97 \%$ at $\mathrm{CH}_{4} /$ $\mathrm{CO}_{2}=1 / 3$. To get this $\mathrm{CH}_{4}$ conversion at $\mathrm{CH}_{4} / \mathrm{CO}_{2}=1 / 2$ and 1 bar, the temperature must be equal to $750{ }^{\circ} \mathrm{C}$. Once again, increasing the pressure does not favour the methane conversion. At 15 bar and $900{ }^{\circ} \mathrm{C}$, which are the typical conditions used in steam reforming of methane, $\mathrm{CH}_{4}$ conversion can reach 92 and $97 \%$ at $\mathrm{CH}_{4} / \mathrm{CO}_{2}=1 / 2$ and $1 / 3$, respectively.

Figure $3 \mathrm{~b}$ shows $\mathrm{CO}_{2}$ conversion, but this is not really representative of real situations since $\mathrm{CO}_{2}$ is in large excess. Figure $3 c$, d presents the selectivity in $\mathrm{H}_{2}$ and $\mathrm{CO}$. The negative influence of increasing the pressure can be clearly observed. In addition, $\mathrm{CH}_{4} / \mathrm{CO}_{2}$ ratio strongly influences the formation of $\mathrm{H}_{2}$ and $\mathrm{CO}$ via the reserve water-gas shift (Eq. 6). Under a given experimental condition of pressure and $\mathrm{CH}_{4} / \mathrm{CO}_{2}$ ratio, and by increasing the temperature, there is a maximum in the formation of $\mathrm{H}_{2}$. In fact, $\mathrm{H}_{2}$ formation from the dry reforming of methane reaction is favourable by increasing the reaction temperature. Then, this $\mathrm{H}_{2}$ is consumed in Eq. 6 by reacting with $\mathrm{CO}_{2}$ which is in large excess

Figure $3 \mathrm{e}, \mathrm{f}$ presents the formation of $\mathrm{H}_{2} \mathrm{O}$ and $\mathrm{C}_{\mathrm{s}}$ as the two major undesirable by-products of the dry reforming of methane reaction. Within the temperature and pressure ranges simulated in this study, and regardless the $\mathrm{CH}_{4} / \mathrm{CO}_{2}$ ratio $=1 / 2$ or $1 / 3$, water formation is inevitable because of the omnipresence of the reserve water-gas shift (Eq. 6). As previously observed for $\mathrm{H}_{2}$ formation, under a given experimental condition of pressure and $\mathrm{CH}_{4} / \mathrm{CO}_{2}$ ratio, increasing the temperature leads to a minimum of $\mathrm{H}_{2} \mathrm{O}$ formation, i.e. close to $800{ }^{\circ} \mathrm{C}$ for the molar ratio of $\mathrm{CH}_{4} / \mathrm{CO}_{2}$ of $1 / 2$ and at 1 bar. The coke formation can be theoretically avoided by increasing the reaction temperature, since the steam reforming of carbon (Eq. 7) is highly endothermal. As an example, at 1 bar and with the molar ratio of $\mathrm{CH}_{4} / \mathrm{CO}_{2}$ equal to $1 / 3, \mathrm{C}_{\mathrm{s}}$ selectivity can be completely avoided above $700{ }^{\circ} \mathrm{C}$
Fig. 3 Influence of the molar ratio of $\mathrm{CH}_{4} / \mathrm{CO}_{2}$ on the dry reforming of methane reaction at 1 and 15 bar. At a given temperature and total pressure, the decrease of the molar ratio of $\mathrm{CH}_{4} / \mathrm{CO}_{2}$ allows increasing $\mathrm{CH}_{4}$ conversion and decreasing coke formation
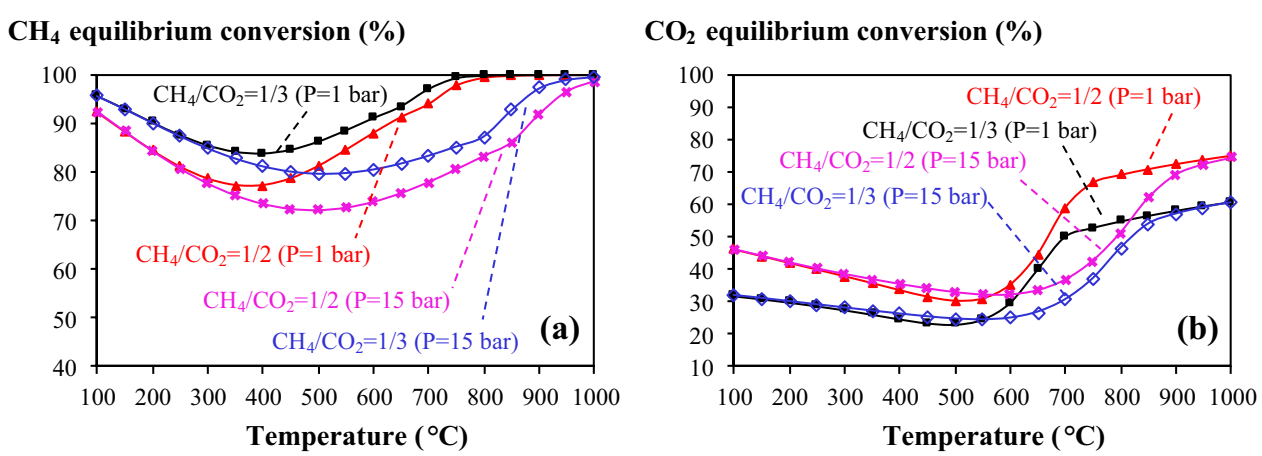

$\mathrm{H}_{2}$ equilibrium selectivity $(\%)$
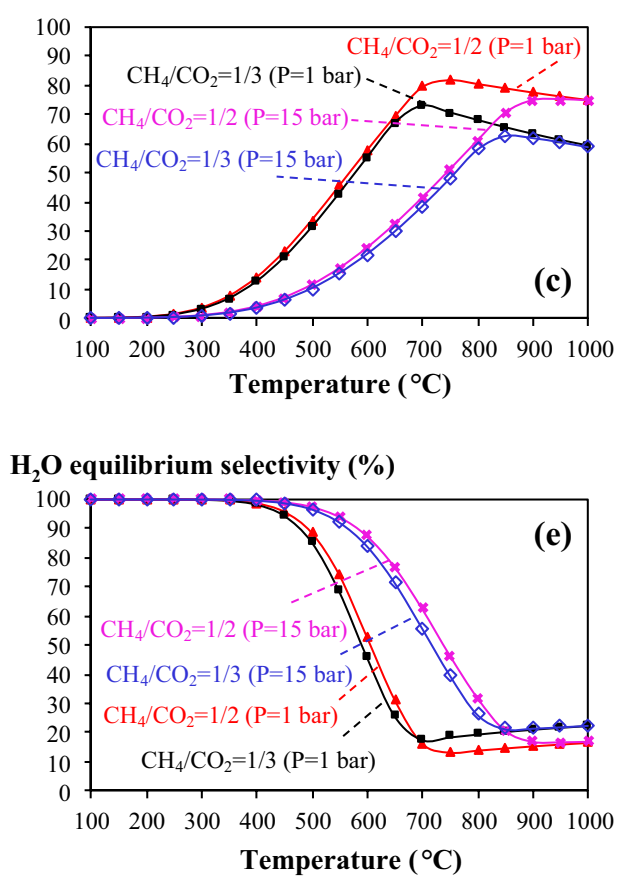

CO equilibrium selectivity (\%)

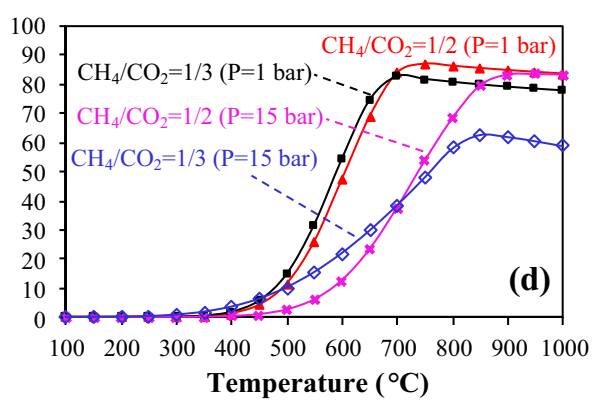

Coke equilibrium selectivity (\%)

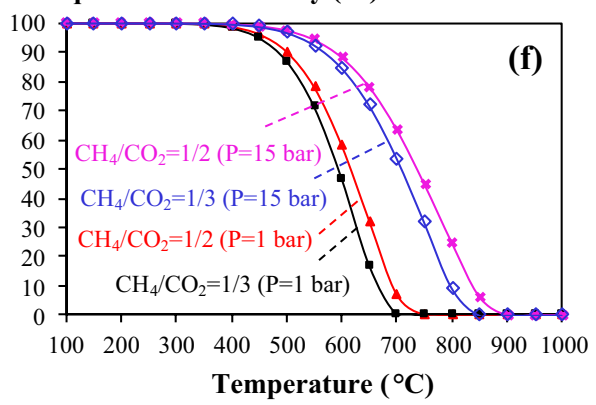


In all cases, the formation of light hydrocarbons (C2 to C4) is possible but only at traces amounts as previously observed (Nikoo and Amin 2011).

As a partial conclusion, the reaction of $\mathrm{CH}_{4}$ with $\mathrm{CO}_{2}$ is complex with the presence of different chemical equilibria. In general, the dry reforming of methane reaction is favourable at high temperature, low pressure, and the low molar ratio of $\mathrm{CH}_{4} / \mathrm{CO}_{2}$. However, when working with low $\mathrm{CH}_{4} / \mathrm{CO}_{2}$ ratio, the temperature must be carefully selected to avoid the detrimental effect on the formation of $\mathrm{H}_{2}$.

\section{Microwave heating technology}

\section{Principles of microwave heating}

Microwaves are electromagnetic radiations whose wavelength range is from 1 to $1 \mathrm{~mm}$ corresponding to a frequency range of 0.3-300 GHz. Generally, microwave heating $(\mathrm{MWH})$ is conducted at 0.9 or $2.45 \mathrm{GHz}$ to avoid or minimize any possible interference with the communication applications (Meredith 1998). Unlike conventional heating that is basically relied on the heat transfer of hot medium, microwave heating is created through the interactions of the objects with the electric and magnetic fields. Thus, microwave heating offers several advantages comparing to conventional one, including (1) non-contacting, quick and selectable heating; (2) rapid starting and stopping of the heating; and (3) more safety and easier automation (Jones et al. 2002a, b; Menéndez et al. 2010; Zhang and Hayward 2006). Consequently, applying microwaves causes reducing in the equipment size and processing time. Therefore, microwave heating is now not only applied for industrial wood drying, food processing, and rubber vulcanization, but also studied in various areas, such as, ceramic and polymer processing (Komarneni et al. 1992; Hoogenboom and Schubert 2007; Wiesbrock et al. 2004), environmental applications (Jones et al. 2002a, b; Verma and Samanta 2018; Zhang and Hayward 2006; Zlotorzynski 1995), biofuels and chemical productions (Aravind et al. 2020; Hassan et al. 2020), and metallurgy and mineral processing (Jones et al. 2002a, b; Kingman et al. 2004). Particularly, there is an increasing interest in the study of heterogeneous gas-phase catalysis under microwave heating (Zhang and Hayward 2006; Durka et al. 2009), such as $\mathrm{NH}_{3}$ decomposition (Guler et al. 2017), $\mathrm{CH}_{4}$ decomposition (Domínguez et al. 2007a, b; Zhang et al. 2003), $\mathrm{H}_{2} \mathrm{~S}$ decomposition ( $\mathrm{Xu}$ et al. 2017a, b), $\mathrm{NO}_{x}$ and $\mathrm{SO}_{2}$ reduction (Peng et al. 2017; Zhang et al. 2001), $\mathrm{CO}_{2}$ reforming of $\mathrm{CH}_{4}$ (Fidalgo and Menéndez 2013; Lim and Chun 2017; Zhang et al. 2003) and recently steam reforming of alcohols (Durka et al. 2011; Gündüz and Dogu 2015; Sar1yer et al. 2019). It was found that microwave heating apparently induces higher reactants conversions and product yields compared to conventional heating at the same operating temperature due to the formation of hot spots (Fidalgo et al. 2008, 2010; Fidalgo and Menéndez 2012; Zhang et al. 2003).

Practically, both components of the high-frequency electromagnetic radiation are responsible for microwave heating. However, dielectric heating caused by the electric field component is often used to represent microwave heating, whereas the heating effect induced by the magnetic one is seldom mentioned due to insufficient knowledge (Sun et al. 2016). Dielectric heating occurs when the dipoles collide with each other while trying to align themselves with the high-frequency electric field by rotation. Accordingly, the heating ability of a dielectric is described by its dielectric loss tangent $(\tan \delta)$ as given in Eq. 8:

$\tan \delta_{\varepsilon}=\varepsilon^{\prime \prime} / \varepsilon^{\prime}$

The real $\left(\varepsilon^{\prime}\right)$ and imaginary $\left(\varepsilon^{\prime \prime}\right)$ parts of permittivity represent the abilities to propagate microwaves into the object and to generate heat by dissipation of microwave power, respectively (Jones et al. 2002a, b; Menéndez et al. 2010). It is widely accepted that a good microwave absorber must have loss tangent value greater than 0.1 (Beneroso and Fidalgo 2016; Metaxas and Meredith 1983; Rossi et al. 2017). Dielectric properties of a specific sample rely upon its anisotropy, homogeneity, surface roughness, and the applied temperature and frequency (Janezic et al. 2001). Ignoring the effect of factors related to its nature and the applied frequency, the loss tangent of a sample generally increases with its temperature at a frequency of $900 \mathrm{MHz}$ or $2.45 \mathrm{GHz}$ (Gabriel et al. 1998; Janezic et al. 2001; Westphal and Sils 1972; Zhang et al. 2002). Many solid materials, such as alumina and silica (Nightingale 2001; Westphal and Sils 1972) which are commonly used as effective catalyst supports, are classified as very low-lossy material at room temperature. However, their heating ability rises rapidly when the temperature is above certain point as can be seen in Table 1. Besides, some moderate lossy materials, such as carbon-coated on $\mathrm{SiO}_{2}\left(\mathrm{C}-\mathrm{SiO}_{2}\right)$ and platinum-coated on carbon (Pt/C), exhibit a double increase in their dielectric loss tangent at over $800{ }^{\circ} \mathrm{C}$ compared to that at room temperature. Practically, these materials could be employed in microwave-assisted DRM application due to its high operating temperature which favours the ability to absorb microwave (Zhang et al. 2018a, b, c). Thus, understanding the dielectric properties of a catalytic/supporting material in its expected operating temperature range is essential. Unfortunately, the available studies usually focused on the dielectric properties of the materials in the wide frequency range without considering the response to temperature since their target application is for microwave absorption, not for heating (Benedito et al. 2012; Bhattacharya and Basak 2016; 
Table 1 Dielectric loss tangent $\left(\tan \delta_{\varepsilon}\right.$ ) of common substances

\begin{tabular}{|c|c|c|c|c|c|c|}
\hline \multirow[t]{2}{*}{ Material } & \multirow[t]{2}{*}{ Temperature $\left({ }^{\circ} \mathrm{C}\right)$} & \multirow{2}{*}{$\begin{array}{l}\text { Frequency } \\
(\mathrm{GHz})\end{array}$} & \multicolumn{3}{|c|}{ Dielectric properties } & \multirow[t]{2}{*}{ References } \\
\hline & & & $\varepsilon^{\prime}$ & $\varepsilon^{\prime \prime}$ & $\tan \delta_{\varepsilon}$ & \\
\hline \multicolumn{7}{|l|}{ Microwave transparent } \\
\hline Vacuum & 25 & 2.54 & 1.00 & 0 & 0 & Durka et al. (2009) \\
\hline Air & 25 & 2.54 & 1.0006 & 0 & 0 & Durka et al. (2009) \\
\hline n-hexane & 20 & 2.54 & & & 0.02 & Zhu and Chen (2014) \\
\hline Styrofoam & 25 & 3 & 1.03 & 0.0001 & 0.0001 & Durka et al. (2009) \\
\hline PTFE & 25 & 10 & 2.08 & 0.0008 & 0.0004 & Durka et al. (2009) \\
\hline Titanium oxide & 25 & 2.54 & 50 & 0.25 & 0.005 & Durka et al. (2009) \\
\hline Magnesium oxide & 25 & 2.54 & 9 & 0.0045 & 0.0005 & Durka et al. (2009) \\
\hline Glass (pyrex) & 25 & 3 & 4.82 & 0.026 & 0.0054 & Durka et al. (2009) \\
\hline \multirow[t]{2}{*}{ Fused silica } & 25 & 5.5 & & & $<0.0003$ & Durka et al. (2009) \\
\hline & 1165 & & & & 0.01 & \\
\hline Fused quartz & 25 & 2.54 & 3.78 & $<0.001$ & 0.00025 & Gupta and Leong (2008) \\
\hline Silicon & 25 & 1 & 4.3 & $<0.05$ & $<0.0116$ & Meredith (1998) \\
\hline \multirow[t]{3}{*}{ Alumina (dynallox 100) } & 590 & 2.54 & 10.37 & 0.027 & 0.0026 & Bhattacharya and Basak (2016) \\
\hline & 980 & & 11.06 & 0.15 & 0.01356 & \\
\hline & 1340 & & 11.64 & 0.74 & 0.06412 & \\
\hline \multirow[t]{2}{*}{ Glass-ceramics $\left(\mathrm{Li}_{2} \mathrm{O}-\mathrm{Al}_{2} \mathrm{O}_{3}-\mathrm{SiO}_{2}\right)$} & 20 & 9.37 & & & 0.011 & McMillan and Partridge (1972) \\
\hline & 400 & & & & 0.021 & \\
\hline \multicolumn{7}{|l|}{ Microwave absorber } \\
\hline Water & 20 & 2.54 & 77.4 & 9.48 & 0.122 & Gabriel et al. (1998) \\
\hline \multirow[t]{2}{*}{ Methanol } & 20 & 0.9 & 32.1 & 8.49 & 0.265 & \\
\hline & 20 & 2.54 & 21.9 & 14.6 & 0.665 & \\
\hline Ethanol & 20 & 2.54 & 24.3 & 22.86 & 0.941 & \\
\hline \multirow[t]{2}{*}{ Hexanol } & 20 & 0.9 & 3.96 & 2.25 & 0.568 & \\
\hline & 20 & 2.54 & 3.43 & 1.17 & 0.341 & \\
\hline \multirow[t]{2}{*}{ Glycerol } & 20 & 0.9 & 8.41 & 6.39 & 0.759 & \\
\hline & 20 & 2.54 & 6.33 & 3.42 & 0.540 & \\
\hline \multirow[t]{2}{*}{ Nitrobenzene } & 20 & 0.9 & 33.7 & 7.73 & 0.229 & \\
\hline & 20 & 2.54 & 25.2 & 14.7 & 0.584 & \\
\hline Zirconium oxide & 25 & 2.54 & 20 & 2 & 0.1 & Durka et al. (2009) \\
\hline Zinc oxide & 25 & 2.54 & 3 & 3 & 1 & Durka et al. (2009) \\
\hline \multirow[t]{2}{*}{ Silicon carbide } & 25 & 3 & & & 0.58 & Westphal and Sils (1972) \\
\hline & 20 & 2.45 & 30 & 11 & 0.3667 & Meredith (1998) \\
\hline \multirow[t]{2}{*}{$\mathrm{C}-\mathrm{SiO}_{2}$} & 25 & 2.54 & 13.7 & 6 & 0.437 & Hamzehlouia et al. (2018) \\
\hline & $>800$ & 2.54 & $<15$ & 12 & $>0.8$ & \\
\hline \multirow[t]{2}{*}{$\mathrm{Pt} / \mathrm{C}$} & 20 & 2.54 & & & $<0.27$ & Gangurde et al. (2017) \\
\hline & 850 & 2.54 & & & $<0.4$ & \\
\hline
\end{tabular}

Horikoshi et al. 2012; Wang et al. 2019; Xiong et al. 2017; Zhang et al. 1999).

In the case of conductor materials, an electric current will be created under the effect of the high-frequency electric field, causing heating due to the collisions of the charged particles with their neighbouring atoms and molecules (Meredith 1998). These losses dominate in conductors, whereas the dielectric losses dominate in lossy dielectrics such as water, polar solvent, glass, and ceramic. However, in some cases such as microwave heating of electrolyte solutions
(Horikoshi et al. 2012) or carbonaceous materials (Menéndez et al. 2010), both mechanisms are involved to heat the objects in the high-frequency electric field, resulting in an enhancement of heating rate.

To date, the microwave magnetic heating has been rarely ascribed although its superior advantages over the electric heating for several ferrites and powder conductive materials such as $\mathrm{Fe}_{3} \mathrm{O}_{4}, \mathrm{WC}, \mathrm{Fe}$, and Co were experimentally proved by Cheng et al. $(2001,2002)$. A microwave-assisted synthesis method was then demonstrated to prepare some 
ferrites that have new crystal structure such as $\mathrm{ZnFe}_{2} \mathrm{O}_{4}$, $\mathrm{NiFe}_{2} \mathrm{O}_{4}, \mathrm{BaFe}_{12} \mathrm{O}_{19}, \mathrm{CoFe}_{2} \mathrm{O}_{4}$, and $\mathrm{Fe}_{3} \mathrm{O}_{4}$ from stoichiometric mixtures of constituent oxides (Roy et al. 2002). The authors observed that the major changes in the structural phase of the produced ferrites and their magnetic properties are mainly caused by the magnetic field component. The crystallization of ferroelectric lead zirconate titanate (PZT) (Bhaskar et al. 2007) and lead titanate (PTO) (Zhang et al. 2018a, b, c) on substrates was reported to be able to occur at only $450{ }^{\circ} \mathrm{C}$ in the predominant magnetic field region of a single-mode microwave applicator, whereas $\mathrm{SiC}$ rods need to be employed as a microwave susceptor if the crystallization of ferroelectric lead zirconate titanate is performed in a multi-mode one where the predominant magnetic field regions cannot be determined (Antunes et al. 2018). At this moment, there are enough studies to conclude that the magnetic losses contribute significantly to the microwave heating of not only magnetic materials but also conductors, semiconductors and other composite materials (Bhattacharya and Basak 2016; Cao et al. 2010; Haneishi et al. 2017; Rosa et al. 2016; Wen et al. 2011; Zhang et al. 1999); thus, it deserves to receive more attention.

Similar to the dielectric heating, the magnetic heating ability of a material is described by its magnetic loss tangent $\left(\tan \delta_{\mu}\right)$ as given by Eq. 9:

$\tan \delta_{\mu}=\mu^{\prime \prime} / \mu^{\prime}$

The real $\left(\mu^{\prime}\right)$ and imaginary $\left(\mu^{\prime \prime}\right)$ parts of permeability represent the amount of energy stored and lost, respectively (Durka et al. 2009; Sun et al. 2016). Table 2 shows that a ferrite could not be considered as a good microwave absorber with respect to only its dielectric loss tangent. However, with respect to both values, all of them are suited for microwave heating applications.
In addition to the above-mentioned factors, the heating efficiency is also affected by the penetration depth in which the microwave power decreases to $37 \%$ of its value at the object's surface (Durka et al. 2009; Sun et al. 2016). The penetration depth apparently decreases with increasing frequency, dielectric and magnetic losses. In the heating applications where the frequencies of $900 \mathrm{MHz}$ and $2.45 \mathrm{GHz}$ are commonly used, a material that has a high heating ability exhibits a low penetration depth whereas low-lossy materials such as high purity quartz, Teflon, and other plastic can be almost transparent to microwaves (Barbosa-Canovas and Ibarz 2014; Menéndez et al. 2010). Both experimental (Cao et al. 2010; Yoshikawa et al. 2006) and theoretical (Hotta et al. 2011) studies revealed that bulk metals totally reflect microwaves and can only undergo surface heating, due to the so-called skin effect. Meanwhile, powdered metals can be considered as good microwave absorbers if their particles are fine enough compared to their penetration depths in order to be effectively heated in the electromagnetic fields. Table 3 shows the estimated penetration depth of common bulk metals. Detailed calculation method for estimating the penetration depth can be found in literatures (Atwater and Wheeler 2004; Gupta and Leong 2008).

\section{Microwave susceptors}

It has been known that low-lossy or transparent materials could not be rapidly heated to elevated temperatures which are required to conduct the dry reforming of methane reaction efficiently. All reactants and most common catalysts used in the dry reforming of methane reaction such as Ni-based catalysts supported on $\mathrm{SiO}_{2}, \mathrm{Al}_{2} \mathrm{O}_{3}$ or other mesoporous materials (Wang et al. 2018; Abdullah et al. 2017; Lovell et al. 2015) showed relatively low microwave absorption due to their low dielectric loss tangent (Fidalgo et al. 2011). A long warm-up time
Table 2 Dielectric and magnetic properties of some ferrites at $25^{\circ} \mathrm{C}$ and $2.45 \mathrm{GHz}$ (Bhattacharya and Basak 2016)

\begin{tabular}{lcllllll}
\hline Material & \multicolumn{3}{l}{ Dielectric properties } & & \multicolumn{3}{l}{ Magnetic properties } \\
\cline { 2 - 3 } & $\varepsilon^{\prime}$ & $\varepsilon^{\prime \prime}$ & $\tan \delta_{\varepsilon}$ & & $\mu^{\prime}$ & $\mu^{\prime \prime}$ & $\tan \delta_{\mu}$ \\
\hline $\mathrm{Fe}_{3} \mathrm{O}_{4}$ & 12.51 & 0.25 & 0.02 & & 1.51 & 0.3 & 0.199 \\
$\mathrm{BaFe}_{12} \mathrm{O}_{19}$ & 1.465 & 0.052 & 0.036 & & 1.105 & 0.071 & 0.064 \\
$\mathrm{CuFe}_{2} \mathrm{O}_{4}$ & 1.507 & 0.091 & 0.06 & & 1.029 & 0.106 & 0.103 \\
$\mathrm{CuZnFe}_{4} \mathrm{O}_{4}$ & 1.595 & 0.089 & 0.056 & & 1.038 & 0.209 & 0.201 \\
$\mathrm{NiZnFe}_{4} \mathrm{O}_{4}$ & 1.313 & 0.123 & 0.094 & & 1.080 & 0.201 & 0.186 \\
\hline
\end{tabular}

Table 3 Calculated penetration depth of some metals $25^{\circ} \mathrm{C}$ and $2.45 \mathrm{GHz}$ (Atwater and Wheeler 2004; Bhattacharya and Basak 2016; Stefanidis et al. 2014)

\begin{tabular}{lllllllllll}
\hline Metals & $\mathrm{Mg}$ & $\mathrm{Al}$ & $\mathrm{Zn}$ & $\mathrm{Au}$ & $\mathrm{Cu}$ & $\mathrm{Ag}$ & $\mathrm{Fe}$ & $\mathrm{Zr}$ & $\mathrm{Ni}$ & $\mathrm{Co}$ \\
\hline Penetration depth $(\mu \mathrm{m})$ & 2.2 & 1.7 & 2.5 & 1.5 & 1.3 & 1.3 & 3.2 & 6.7 & 2.7 & 2.5 \\
\hline
\end{tabular}


is necessary for the transparent materials to be heated to the desired temperature when they start absorbing microwaves. In some cases, these materials even could not be heated to such point without using a microwave susceptor which must be a highly lossy material (Fidalgo et al. 2011; Horikoshi et al. 2018). There are two ways to overcome this critical issue: (1) enhancing the microwave absorbing ability of the material by doping with or coating on other microwave absorbers or susceptors; and (2) using the external microwave susceptors to heat the material by thermal radiation (Bhattacharya and Basak 2016). Both techniques have their own advantages and drawbacks so choosing one depends on what would be expected. The former invasive route alters the physicochemical properties of the original material, but it is more effective in assisting them to be directly heated by microwaves. On the contrary, simply incorporating with the susceptors does not affect the material but heating by thermal radiation is obviously less effective comparing to direct heating by microwave radiation. However, as the material becomes more lossy to be able to absorb microwaves at a higher temperature, it then undergoes a two-way heating: conventional heating from the surface by susceptor-generated thermal radiation and microwave heating from the centre, resulting in a more uniform heating.

\section{Carbon-based susceptor}

Except for coal, carbonaceous materials such as graphite, activated carbon, carbon nanotube, and bio-char have already been demonstrated to be effective susceptor for many microwave heating applications because of their high conductivity and dielectric loss tangent as can be seen in Table 4. It is well known that a larger amount of delocalized $\pi$-electrons presented in the carbonaceous materials results in a larger microwave absorbing ability (Beneroso and Fidalgo 2016). Therefore, low-lossy coal has been reported to become a highly lossy material at the end of the carbonization process (Peng et al. 2012).

Actually, carbonaceous materials could be used as the active catalysts for the dry reforming of methane reaction (Li et al. 2019). However, as indicated in the following section, they are definitely consumed by $\mathrm{CO}_{2}$ gasification that takes place during the reforming process (Fidalgo and Menéndez 2013). That's why they are rarely employed as external susceptors for microwave-assisted DRM, while they are commonly used in other microwave heating applications (Antunes et al. 2018; Horikoshi et al. 2018). Li et al. (2017) reported an unstable activity of a heterogeneous mixture of Ni-based catalyst and bio-char on the dry reforming of methane reaction which is mainly caused by $\mathrm{CO}_{2}$ gasification reaction. It was observed that the production of syngas and its composition decreased significantly with time on stream during only 120 min of operation. Recently, Hamzehlouia et al. (2018) develop a novel C-SiO $\mathrm{S}_{2}$ microwave susceptor which has excellent loss tangent comparing to the conventional receptor particle. Carbon was coated by $\mathrm{SiO}_{2}$ resulting in no reverse impact on the performance of $\mathrm{Ni} / \mathrm{Al}_{2} \mathrm{O}_{3}$ catalyst; however, this approach is quite complicated. Therefore, carbonaceous materials have been preferably investigated as either catalyst supports or active catalysts, and related studies were reviewed in the next section.
Table 4 Dielectric properties of carbon-based materials at $25{ }^{\circ} \mathrm{C}$ and $2.45 \mathrm{GHz}$

\begin{tabular}{|c|c|c|c|c|}
\hline Carbon material & $\begin{array}{l}\text { Dielectric } \\
\text { constant }\left(\varepsilon^{\prime}\right)\end{array}$ & Loss factor $\left(\varepsilon^{\prime \prime}\right)$ & $\begin{array}{l}\text { Loss tangent } \\
\left(\tan \delta_{\varepsilon}\right)\end{array}$ & References \\
\hline Long-flame coal & 3.06 & 0.02 & 0.006 & Liu et al. (2018) \\
\hline Brown coal & 7.41 & 0.10 & 0.013 & Liu et al. (2018) \\
\hline Bituminous coal & 3.48 & 0.13 & 0.037 & Peng et al. (2012) \\
\hline Carbonized bituminous coal $^{\mathrm{a}}$ & 120 & 88 & 0.733 & Peng et al. (2012) \\
\hline Bio-char ${ }^{b}$ & 2.82 & 0.24 & 0.085 & Salema et al. (2013) \\
\hline Pyrolysis bio-char ${ }^{\mathrm{c}}$ & 6.00 & 1.22 & 0.203 & Ellison et al. (2017) \\
\hline Carbon black & 9.29 & 1.75 & 0.188 & Hotta et al. (2011) \\
\hline Activated carbon & 1.94 & 1.76 & 0.907 & Yin et al. (2018) \\
\hline Graphite $^{\mathrm{d}}$ & 17.61 & 5.01 & 0.28 & Hotta et al. (2011) \\
\hline CNTs-HPCFs & 13.4 & 5.11 & 0.381 & Qiu and Qiu (2015) \\
\hline
\end{tabular}

CNTs-HPCFs Carbon nanotubes-hollow porous carbon fibres

${ }^{a}$ Dielectric properties of bituminous coal was determined during pyrolysis in which the sample was stepheated to $750{ }^{\circ} \mathrm{C}$ with ramp rate of $5^{\circ} \mathrm{C} / \mathrm{min}$

${ }^{\mathrm{b}} \mathrm{Bio}-\mathrm{char}$ is made of oil palm shell

${ }^{\mathrm{c}}$ Pyrolysis char is made of live oak

${ }^{\mathrm{d}}$ Pure carbon 


\section{Non-carbon based susceptor}

Although the non-carbon-based susceptors usually showed lower heating efficiencies comparing to the carbonaceous ones (Benedito et al. 2012; Bhattacharya and Basak 2016), they have been preferably used in the microwave-assisted DRM applications because of unavoidable activity of the carbon-based susceptor on the dry reforming of methane reaction (Fidalgo and Menéndez 2013). In addition to the most common used non-carbon-based susceptors in microwave heating applications such as $\mathrm{SiC}$ and $\mathrm{CuO}$, some metals, which have good microwave absorbing ability at small particle size, and ferrites have been recently introduced as potential susceptors for various microwave heating applications (Bhattacharya and Basak 2016). However, only SiC has been employed as catalyst supports (Bhattacharya and Basak 2016). However, only $\mathrm{SiC}$ has been employed as catalyst supports (Zhang et al. 2018a, b) to enhance the coupling effect between the microwaves and catalysts used in the dry reforming of methane reaction. $\mathrm{SiC}$ is an inert material, thus does not interfere with any reactions, and consequently, a stable performance of $\mathrm{SiC}$ supported catalyst on microwaveassisted DRM was observed during $50 \mathrm{~h}$ of reaction (Zhang et al. 2018b). Since commercially available silicon carbide has a low specific surface area, it cannot be employed as an effective support for any catalyst. Zhang et al. (2018a) synthesized $\mathrm{SiC}$-based supports composed of $\mathrm{SiC} \cdot \mathrm{SiO}_{2}$ and $\mathrm{Al}_{2} \mathrm{O}_{3} \cdot \mathrm{SiC}$ ceramic foams. Although $\mathrm{Al}_{2} \mathrm{O}_{3}$ has been shown to be superior to $\mathrm{SiO}_{2}$ as support of nickel catalyst for the conventional dry reforming of methane with respect to both activity and stability (Xu et al. 2019), the catalytic activity of $\mathrm{Fe} /\left(\mathrm{SiC} \cdot \mathrm{SiO}_{2}\right)$ in microwave-assisted DRM was reported to be higher than that of $\mathrm{Fe} /\left(\mathrm{Al}_{2} \mathrm{O}_{3} \cdot \mathrm{SiC}\right)$ due to its greater microwave absorbing capability.

While supported nickel-based catalysts have been widely investigated for the dry reforming of methane (Wang et al. 2018), using Ni supported on $\mathrm{SiC}$ catalyst for microwaveassisted DRM has not been demonstrated. Hawangchu et al. (2010) observed that $\mathrm{Ni} / \mathrm{SiC}$ bed reached a much lower temperature compared to the bare $\mathrm{SiC}$ after being heated for $5 \mathrm{~min}$ in the microwave at the same power level. This observation was simply explained by consideration of the microwave reflection behaviour of Ni metal particles. In fact, metallic magnetic Ni-based material can behave either as a microwave reflector or absorber depending on its particle size and penetration depth at certain working conditions such as temperature and frequency (Bhattacharya and Basak 2016). Due to its high magnetic loss tangent, coating nickel on the surface of a high lossy dielectric material may enhance its microwave absorption capability (Zhao et al. 2015). Therefore, Ni supported on $\mathrm{SiC}$ with a proper layer thickness would be a promising catalyst for microwaveassisted DRM. Another approach that should be tried is mixing the supported Ni-based catalysts with $\mathrm{SiC}$. Chen et al. reported that simply covering each thin layer of lowlossy sawdust with a thin layer of $\mathrm{SiC}$ microwave absorber can deliver uniform heating for pyrolysis of sawdust samples (Chen et al. 2008).

In addition, there are many promising approaches that were successfully demonstrated in other microwave heating applications that have not been investigated for microwaveassisted DRM yet. The perovskite-type mixed oxide, such as $\mathrm{BaMn}_{0.2} \mathrm{Cu}_{0.8} \mathrm{O}_{3}$ was proved to be an effective external susceptor for improving the activity of $\mathrm{NiS} / \mathrm{Al}_{2} \mathrm{O}_{3}$ and $\mathrm{CoS} /$ $\mathrm{Al}_{2} \mathrm{O}_{3}$ catalyst in microwave-assisted decomposition of $\mathrm{H}_{2} \mathrm{~S}$ (Xu et al. 2017b). Zhang et al. (1999) observed that the loss tangent of $\gamma-\mathrm{Al}_{2} \mathrm{O}_{3}$ increased significantly by either coating or mixing it with $\mathrm{MoS}_{2}$, which is a good microwave absorber, leading to an enhanced activity for the decomposition of $\mathrm{H}_{2} \mathrm{~S}$ under microwave radiation. Based on these results, $\mathrm{Xu}$ et al. (2017a) prepared a mechanical mixture of $\mathrm{CoS}, \mathrm{MoS}_{2}$, and $\gamma-\mathrm{Al}_{2} \mathrm{O}_{3}$ which work as a catalyst, as a catalyst and microwave susceptor and as a porous support, respectively. Consequently, the outstanding catalytic activity of $\mathrm{CoS}-\mathrm{MoS}_{2} / \gamma-\mathrm{Al}_{2} \mathrm{O}_{3}$ for decomposition of $\mathrm{H}_{2} \mathrm{~S}$ under microwave radiation has been attributed to the synergistic effects of all components. Similarly, these approaches could be employed in the microwave-assisted DRM. For example, Ni-WC $\mathrm{W}_{x}$ was proposed as an active bi-functional catalyst for the conventional dry reforming of methane (Zhang et al. 2015), whereas WC was reported as a good microwave absorber (Cheng et al. 2001 2002). Thus, Ni-WC ${ }_{x}$ catalyst may exhibit enhanced activity in microwave-assisted DRM. Besides, perovsikites and ferrites are deserved to be investigated as both catalysts and susceptors in microwave-assisted DRM due to their excellent microwave absorbing ability as well as catalytic activity (Benrabaa et al. 2013; Caprariis et al. 2015; Sheshko et al. 2017).

\section{Microwave heating apparatus}

Basically, a microwave heating system consist of four parts: (1) power source, (2) microwave generator, (3) applicator or cavity in which the target material is put, and (4) waveguide for transporting microwaves generated to inside the cavity (Haque 1999). However, the main differences between the studied microwave-assisted catalytic systems arise from the temperature controlling method and the design of the microwave cavity. The power output of magnetron could be controlled by either simply on-off mode ( $\mathrm{Li}$ et al. 2011) or by varying the electrical power input to the high-voltage transformer unit (Fidalgo et al. 2008). In the former case, the desired average power will be obtained by periodically turning on/off the power supply with full load. Meanwhile, in the latter case, the more precise power output can be controlled by altering the 
voltage or current amplitude. In order to control reaction temperature precisely, there is also a need for choosing the correct temperature measurement solution, which is not a straightforward task. An inconel-sheathed thermocouple was reported to be able to continuously record inside temperature without electrical noise and arcing by earthing the sheathed thermocouple through the microwave oven casing (Hogan and Mori 1990). However, this thermocouple was only used to measure up to the boiling point of water; thus, employing such thermocouples under much more extreme conditions can definitely cause arcing between the sample and metallic probe and lead to failure in thermocouple performance. Fibre-optic sensors can measure only up to $400{ }^{\circ} \mathrm{C}$, whereas the dry reforming of methane reaction must be performed at the temperature of at least $700{ }^{\circ} \mathrm{C}$. Meanwhile, although the applicable temperature range of the optical pyrometers is suited for the dry reforming of methane, it only measures the surface temperature, which differs from the interior of catalyst particles (Haque 1999; Thostenson and Chou 1999; Will et al. 2004). Moreover, even using a sensor that was known to be insensible to microwave can cause a modification of the temperature profile inside as shown in Fig. 4 (Estel et al. 2017).
The design of the microwave cavity, or applicator, is vital to ensure the efficiency in microwave heating. The distribution of temperature within the object and of the electromagnetic fields within the cavity are basically linked to each other. Consequently, it depends on the type of applicators which are classified as single mode and multi-mode. As can be seen in Fig. 5a, a, single-mode applicator in which focusing microwave field at a given location is generated is only suitable to work with small amounts of materials that need to be heated; otherwise, non-uniform temperature distribution may occur. On the other hand, a multimode applicator is capable of more even distribution; thus, it is the most common processing device used in industrial applications (Fidalgo and Menéndez 2013; Thostenson and Chou 1999). So far, there are two different designs of the multi-mode applicator, one with the turntable and one with the mode stirrer as can be seen in Fig. 5b. The turntable which is now widely used in a domestic microwave oven rotates to allow the target to contact more evenly with microwave transported from the magnetron. The applicator without a turntable uses a rotating reflector (mode stirrer) just under the outlet of a waveguide to distribute the microwave more evenly.

Fig. 4 Effect of inserting a

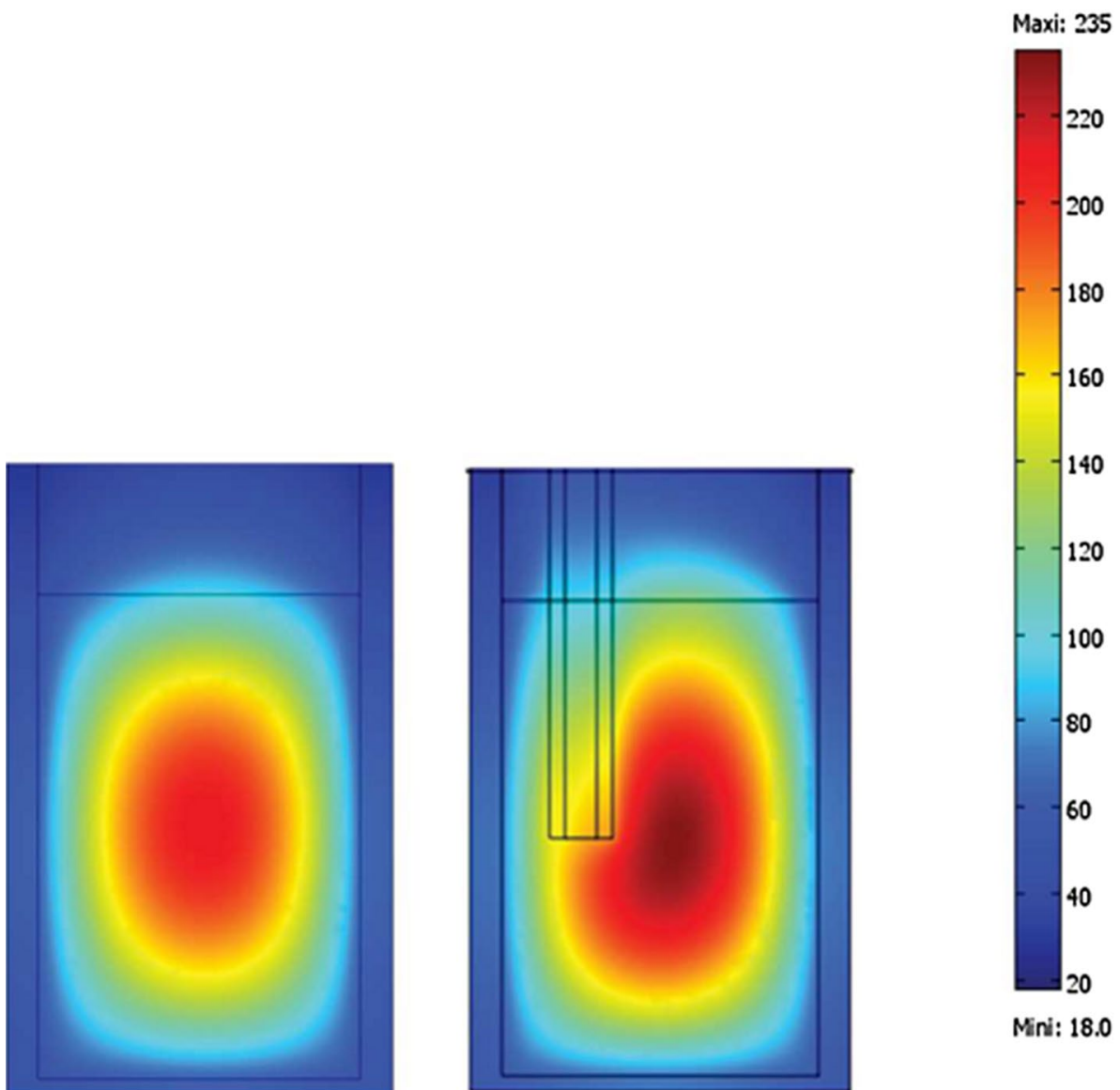


Fig. 5 Illustration of a a singlemode cavity and $\mathbf{b}$ multimode one. The multimode was illustrated with both the turntable and the mode stirrer. Reprinted by permission from Horikoshi et al. (2018), Copyright (2018) Springer Nature

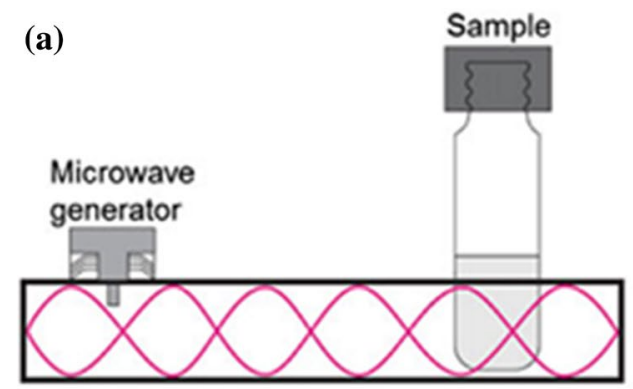

(b) Mode stir

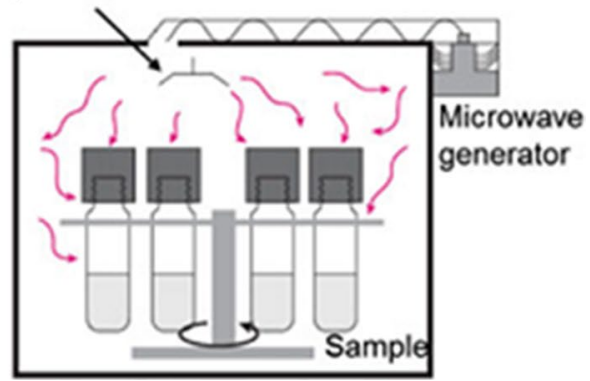

According to Fig. 6, it is not difficult to recognize that neither applicator is perfect as there are always dead points or overheating points, although the mutimode one exhibits a more uniform distribution of electromagnetic fields. The larger frequency is applied in the same cavity or the larger cavity is used at the same frequency; the higher uniformity can be obtained. However, due to the predictable field distributions, the separated effects of electric and magnetic field components on a specific object can only be investigated in a suitable single-mode cavity (Cheng et al. 2001, 2002; Rosa et al. 2016).

\section{Microwave-enhanced reformers}

The extremely endothermic nature of the dry reforming of methane requires an accurate measurement of the reaction. However, as stated above, this task is not easy due to the challenges of microwave heating such as non-uniform temperature distribution and the risk of interaction between the electromagnetic field and the metals which must be used to make up the high-temperature thermocouples. In order to overcome this critical issue, the metal sheathed thermocouples must be protected by a microwave-transparent quartz tube and connected with a grounded filter capacitor before inserting it into the radiated catalyst bed (Li et al. 2017, 2018a, b; Zhang et al. 2018a, b, c). This method does not only help to protect the thermocouples
Fig. 6 Simulation of the distribution of a the electric and magnetic fields in a single-mode cavity, and $\mathbf{b}$ electric field in a $30 \times 30 \times 30 \mathrm{~cm}$ multimode one at 2.54 and $5.8 \mathrm{GHz}$. Electric and magnetic fields are observed to be separated from each other in a single-mode cavity, while they cannot be distinguished in a multimode one. At the same size of multimode cavity, higher frequency results greater uniformity. Reprinted by permission from Horikoshi et al. (2018), Copyright (2018) Springer Nature (a)
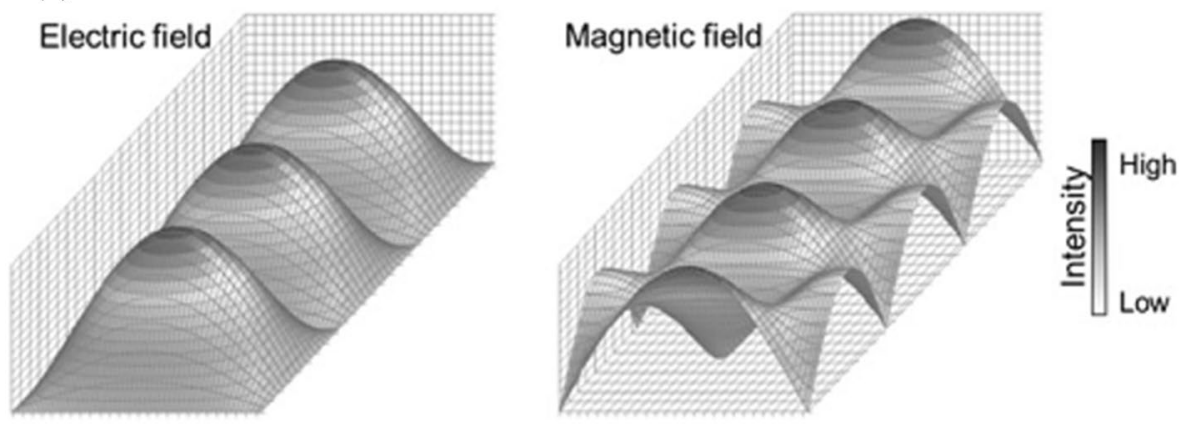

(b)

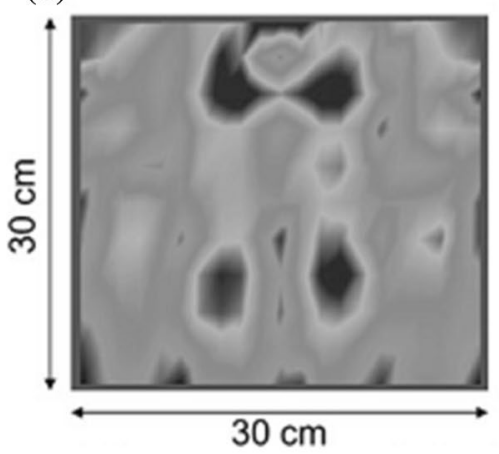

$2.54 \mathrm{GHz}$

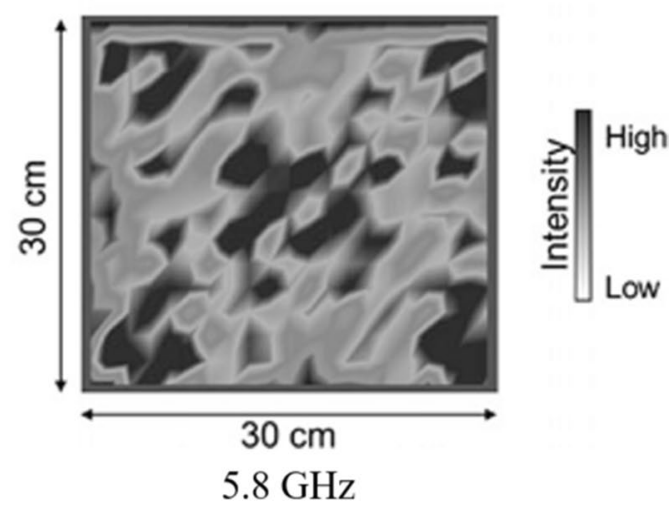


from metal-microwave interaction but also eliminates the breakdown discharge and electrical noise. Recently, Gangurde et al. $(2017,2018)$ proposed a non-contact method for continuously monitoring of the $2 \mathrm{D}$ temperature distribution in a microwave-enhanced reactor by using a thermal camera. They employed both optical fibres and N-type thermocouples to measure the temperature profile along the radial

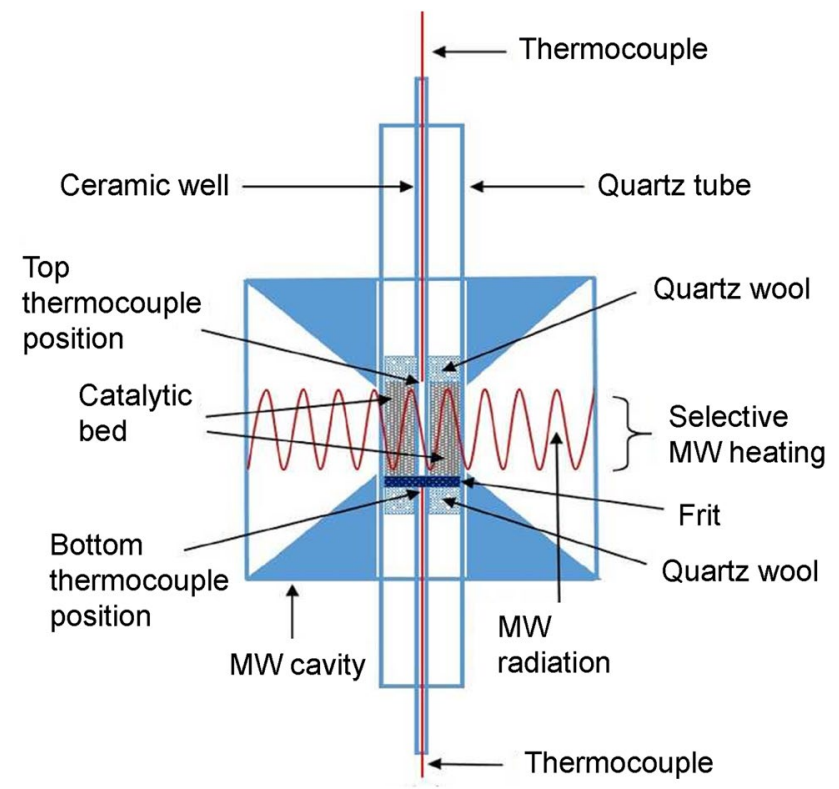

Fig. 7 Modified single-mode cavity for continuously monitoring of the $2 \mathrm{D}$ temperature distribution in a microwave-enhanced reactor using a non-contact thermal camera calibrated with contact thermocouples that must be placed outside the radiated regions. Reprinted with permission from Gangurde et al. (2017), Copyright (2017) American Chemical Society direction of the reactor and temperature of the lower and upper parts of the catalyst bed for calibration. The N-type thermocouples could not be placed in the radiated regions to avoid dangers from microwave-metal interaction; thus, the single-mode cavity had to be modified as seen in Fig. 7. It was reported that hot spot generation could be detected by the thermal camera; however, using it alone does not ensure the correct measurement due to its complex dependence on many factors. Thus, at least one contact temperature sensor must be additionally employed for calibration.

Due to its excellent microwave-transparent and heat resistance properties, quartz has been used to make the reaction tube for almost microwave-enhanced reformer. Both single- and multimode applicators have been introduced for microwave-assisted DRM although the single-mode one has rarely employed due to its low energy efficiency (Fidalgo and Menéndez 2013). As shown in Fig. 8, the water sinks must be installed in front and behind of the reaction quartz tube in order to dissipate non-absorbed microwave, resulting in a lot of wasted energy in the case of using single-mode applicator (Fidalgo et al. 2008). In addition, a simulation work demonstrated that the temperature gradient in the radial direction can reach up to $210^{\circ} \mathrm{C}$ (Julian et al. 2019). Practically, the rotation of the reactor was proven to be effective in reducing this gradient as shown in Fig. 9, but this modification would be very complicated (Julian et al. 2019). Consequently, the multimode applicator has been the most common choice in both laboratory-scale (Li et al. 2018a, b) and pilot-scale (Fidalgo and Menéndez 2012).

When a domestic microwave oven is utilized and modified to become a microwave-enhanced reactor, the turntable mode must be disabled due to the complex connection with outside parts as can be seen in Fig. 10. Microwave distribution is now only based on the multiple reflections from the

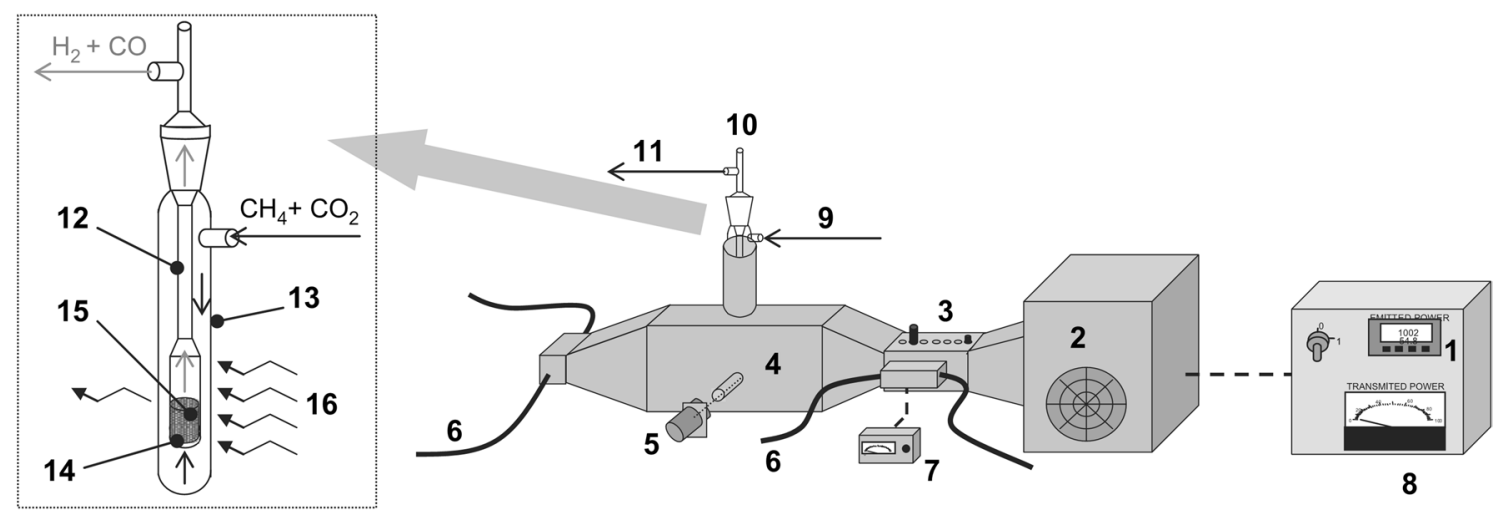

Fig. 8 Schematic drawing of the single-mode microwave-assisted DRM reactor where 1 is input power control unit, 2 is magnetron, 3 is manual two-tub unit, 4 is waveguide, 5 is optical pyrometer, 6 is water sink, 7 and 8 are reflected and transmitted power control, respectively, 9 is inflow gas line, and 10 is quartz reactor-jacket and catalyst/microwave receptor. The schematic drawing of object 10 is inserted at the left side where 11 is outflow gas line, 12 is quartz reactor, 13 is quartz jacket, 14 is porous plate, 15 is catalyst/microwave receptor bed, and 16 is microwave radiation. Reprinted from Fidalgo et al. (2008), Copyright (2008), with permission from Elsevier 

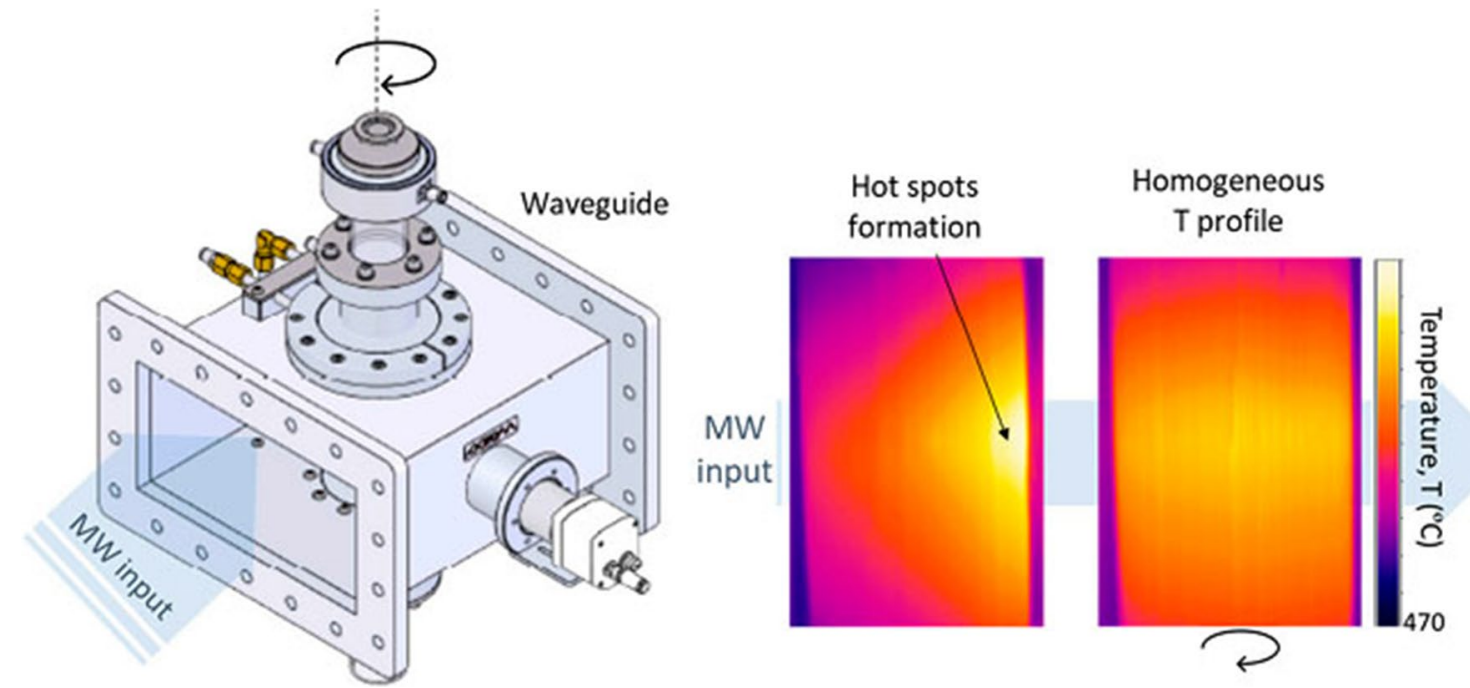

Fig. 9 Single-mode cavity coupled with rotatable reactor. Note that the temperature distribution in the cases of rotating configuration (right) is more uniform than in the case of standing (left). Adapted from (Julian et al. 2019)

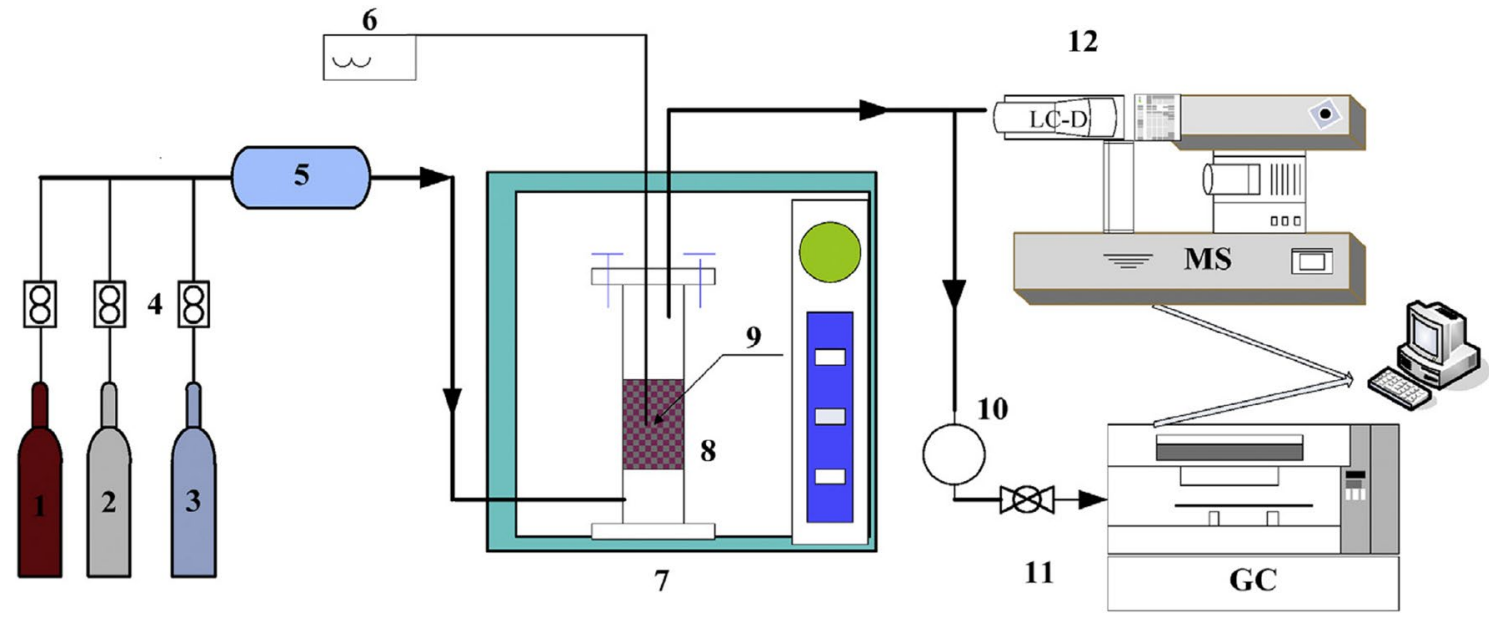

Fig. 10 Multi-mode microwave-assisted dry reforming of methane (DRM) reactor modified from domestic microwave oven where 1 to 3 are $\mathrm{CH} 4, \mathrm{CO} 2$ and argon cylinders, respectively, 4 are mass flow meters, 5 is gas mixing device, 6 is thermocouple, 7 is microwave

cavity walls, resulting in an inhomogeneous temperature profile within the catalyst bed ( $\mathrm{Li}$ et al. 2011; Salema et al. 2013; Zhang et al. 2018a, b, c). Zhu et al. (2017) proposed a multi-physics coupling model to simulate electric field distribution inside the multi-mode applicator under normal and rotary heating. Results showed that heating uniformity can be improved significantly by a rotating microwave radiation source.

Recently, a novel design of turntable multimode microwave device, which ensures the uniform distribution of electromagnetic fields inside the applicator was successfully developed (Nguyen et al. 2019). This approach is basically oven, 8 is quartz reactor, 9 is catalyst bed, 10 is gas collecting bag, 11 is gas chromatography (GC), and 12 is mass spectrometry (MS). Reprinted from Zhang et al. (2018a, b, c), Copyright (2018), with permission from Elsevier

the opposite of conventional design of the microwaveassisted apparatus. A household microwave oven must be placed on a tray that can rotate $360^{\circ}$ clockwise followed by reversing the direction of rotation to the counterclockwise to not affect the outside connections. Meanwhile, a reaction flask was fixed to a central pipe, which is extended outside the microwave oven through a port and fixedly attached to the support frame as illustrated in Fig. 11. Consequently, the magnetron was rotated around the fixed flask allowing the target to be contacted evenly with microwave generated. The port was covered by a metal tube according to the instructions of Mingos and Baghurst (1991), resulting in a 


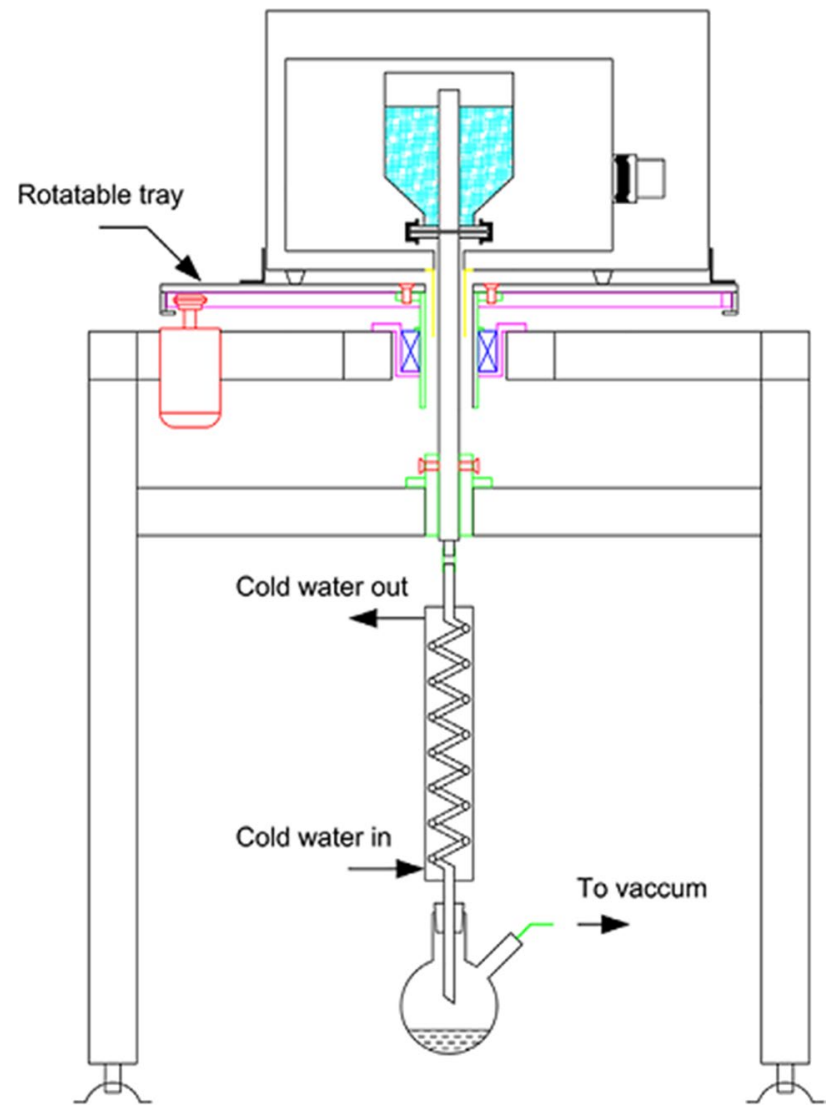

Fig. 11 Turntable multimode microwave device for solvent-free extraction of essential oil. Note that the setup was developed from a household microwave oven so that the magnetron can be rotated around the fixed flask resulting in a uniform distribution of electromagnetic field. Reprinted with permission from (Nguyen et al. 2019), Copyright (2019) John Wiley and Sons

low microwave leakage that was reported to be below the safety limit of $5 \mathrm{~mW} / \mathrm{cm}^{2}$ (Schiffmann and Steiner 2012). Although the modified setup was originally employed for the solvent-free microwave-assisted extraction, it can be practically developed to a novel microwave-enhanced reformer in the future.

\section{Catalysts}

Since microwave-assisted DRM requires microwave irradiation as the thermal source to drive the endothermic reaction, the degree of microwave interaction governed by the dielectric attributes of materials related to the corresponding structural and physical features is crucial (Hamzehlouia et al. 2018). However, various gaseous materials possess intrinsic dielectric properties that are not appreciably favouring the microwave interaction. From the above reasons, the exploration and development has been mainly focused on the solid material, namely catalyst and microwave receptor (C/
MR), which can act as a catalyst for reforming reaction and simultaneously dissipate the absorbed microwave irradiation to thermal energy in the form of heat for microwave-assisted DRM (Fidalgo et al. 2008; Hamzehlouia et al. 2018). Hence, apart from the ability of resistance towards the carbonaceous deposition and metal sintering on catalyst surface, the catalyst and microwave receptor performance for improving the conversion of microwave radiation to heat source depending on types of microwave-absorbing material used is also essential.

The general catalysts employed in microwave-assisted DRM are similar to methane dry reforming, including noble metal catalyst, i.e. Pt- and Ru-based catalyst (Gangurde et al. 2018; Zhang et al. 2003) and non-noble metal catalysts (i.e. Ni- and Fe-based catalyst) (Odedairo et al. 2016; Zhang et al. 2018a, b, c; Herminio et al. 2020; Qin et al. 2020) as their mechanisms are fundamentally alike. However, considering the microwave selective heating mechanism governs the reforming performance, microwave-absorbing materials with significant dielectric properties are extensively investigated as catalyst for microwave-assisted DRM. Additionally, numerous studies about the development of novelty catalyst, such as coating or mixing metal catalysts with microwaveabsorbing materials, have recently conducted to enhance the reforming performance with low carbonaceous deposits and excellent energy conversion of microwave irradiation to heat generation. The performance of catalyst and microwave receptor reported in literature is summarized in Table 5.

\section{Carbon-based catalysts}

In heterogeneous catalysis systems, carbon-containing materials, i.e. carbon blacks, activated carbon and chars from biomass residues, are widely evaluated as support or as catalyst in reactions due to their thermal durability, availability, great porosity, low cost and oxygen surface groups improving the catalytic performance and product selectivities (RodriguezReinoso 1998; Titirici et al. 2015; Balajii and Niju 2019; Hassan et al. 2020). Particularly, in comparison with metalbased catalysts, carbon-based catalysts possess excellent ability in microwave absorption, known as good microwave receptors appropriate for microwave-assisted DRM (Fidalgo et al. 2010; Li et al. 2017). Since the degree of microwave interaction to produce heat is highly reliant on type of microwave-absorbing materials, several parameters including dielectric constant, loss tangent and loss factor are employed to measure the strength of their dielectric attributes, where dielectric constant $\left(\varepsilon^{\prime}\right)$ and loss factor $\left(\varepsilon^{\prime \prime}\right)$ represent the corresponding capability of material in absorption of electromagnetic wave and the capability of material for dissipating the absorbed wave into heat), whereas loss tangent $(\tan \delta)$ is the $\varepsilon^{\prime \prime} / \varepsilon^{\prime}$ ratio describing the efficiency of the absorbed microwave convert into thermal energy (Hamzehlouia et al. 
Table 5 Catalytic performance of different catalysts recently applied in microwave-assisted dry reforming of methane (DRM)

\begin{tabular}{|c|c|c|c|c|c|c|c|c|}
\hline \multirow{2}{*}{$\begin{array}{l}\text { Catalysts and microwave recep- } \\
\text { tors (C/MR) }\end{array}$} & \multirow{2}{*}{$\begin{array}{l}\mathrm{CH}_{4} / \mathrm{CO}_{2} \\
\text { ratio }\end{array}$} & \multirow[t]{2}{*}{$\mathrm{T}\left({ }^{\circ} \mathrm{C}\right)$} & \multirow{2}{*}{$\begin{array}{l}\text { VHSV } \\
\left(\mathrm{ml} \mathrm{g}_{\text {cat }}{ }^{-1} \mathrm{~h}^{-1}\right)\end{array}$} & \multirow[b]{2}{*}{ TOS (min) } & \multicolumn{3}{|c|}{ Reforming performance } & \multirow[t]{2}{*}{ References } \\
\hline & & & & & $\begin{array}{l}\mathrm{CH}_{4} \\
\text { conversion } \\
(\%)\end{array}$ & $\begin{array}{l}\mathrm{CO}_{2} \\
\text { conversion } \\
(\%)\end{array}$ & $\overline{\mathrm{H}_{2} / \mathrm{CO} \text { ratio }}$ & \\
\hline \multicolumn{9}{|l|}{ Carbon-based catalysts } \\
\hline Char $^{\mathrm{a}}$ & $1 / 1$ & 800 & 332 & 120 & 82 & 98 & 0.66 & $\begin{array}{l}\text { Domínguez et al. (2007a, } \\
\text { b) }\end{array}$ \\
\hline $\begin{array}{l}\text { Activated carbon (filtracarb } \\
\text { FY5) }\end{array}$ & $1 / 1$ & 800 & 320 & 300 & 70 & 79 & 0.80 & Fidalgo et al. (2008) \\
\hline FY5 & $1.2 / 1$ & 800 & 290 & 150 & 60 & 80 & - & Fidalgo et al. (2010) \\
\hline BPL & $1 / 1$ & 800 & 320 & 150 & 10 & 7 & - & Fidalgo et al. (2010) \\
\hline CQ & $1 / 1$ & 800 & 680 & 150 & 1 & 6 & - & Fidalgo et al. (2010) \\
\hline Activated carbon (FY5-63) & $1 / 1$ & 800 & 320 & 300 & 65 & 91 & - & Fidalgo et al. (2010) \\
\hline Activated carbon $(\mathrm{FY} 5 \mathrm{ox})^{\mathrm{c}}$ & $1.2 / 1$ & 800 & 290 & 150 & 13 & 3 & - & Fidalgo et al. (2010) \\
\hline Bio-char $^{\mathrm{d}}$ & $1 / 1$ & 800 & 1200 & 120 & 12 & 4 & - & Fidalgo et al. (2008) \\
\hline \multicolumn{9}{|l|}{ Metal-based catalysts } \\
\hline $40 \% \mathrm{Ni} / \mathrm{CeO}_{2}$ & $1 / 1$ & 850 & 10,200 & 840 & 68 & - & 1.47 & Odedairo et al. (2016) \\
\hline $2 \% \mathrm{Cr}-40 \% \mathrm{Ni} / \mathrm{CeO}_{2}$ & $1 / 1$ & 850 & 10,200 & 840 & 76 & - & 1.45 & Odedairo et al. (2016) \\
\hline $2 \% \mathrm{Ta}-40 \% \mathrm{Ni} / \mathrm{CeO}_{2}$ & $1 / 1$ & 850 & 10,200 & 840 & 74 & - & 1.47 & Odedairo et al. (2016) \\
\hline $2 \% \mathrm{Fe}-40 \% \mathrm{Ni} / \mathrm{CeO}_{2}$ & $1 / 1$ & 850 & 10,200 & 840 & 71 & - & 1.40 & Odedairo et al. (2016) \\
\hline $4 \% \mathrm{Fe} / \mathrm{Al}_{2} \mathrm{O}_{3}-\mathrm{SiC}$ & $1 / 1$ & 750 & 1200 & - & 63 & 59 & 0.93 & Zhang et al. (2018a, b, c) \\
\hline $8 \% \mathrm{Fe} / \mathrm{Al}_{2} \mathrm{O}_{3}-\mathrm{SiC}$ & $1 / 1$ & 750 & 1200 & - & 87 & 88 & 0.96 & Zhang et al. (2018b) \\
\hline $12 \% \mathrm{Fe} / \mathrm{Al}_{2} \mathrm{O}_{3}-\mathrm{SiC}$ & $1 / 1$ & 750 & 1200 & - & 93 & 92 & 0.98 & Zhang et al. (2018b) \\
\hline $16 \% \mathrm{Fe} / \mathrm{Al}_{2} \mathrm{O}_{3}-\mathrm{SiC}$ & $1 / 1$ & 750 & 1200 & - & 89 & 90 & 0.96 & Zhang et al. (2018b) \\
\hline $\mathrm{Ni}_{0.491} \mathrm{Mg}_{0.258} \mathrm{Al}_{0.250} \mathrm{O}$ & $1 / 1$ & 600 & 120,000 & 600 & 38 & 51 & 1.08 & Ojeda-Niño et al. (2019) \\
\hline $\mathrm{Ni}_{0.429} \mathrm{Mg}_{0.286} \mathrm{Al}_{0.286} \mathrm{Pr}_{0.005} \mathrm{O}$ & $1 / 1$ & 600 & 120,000 & 600 & 44 & 57 & 1.18 & Ojeda-Niño et al. (2019) \\
\hline $\mathrm{Ni}_{0.433} \mathrm{Mg}_{0.289} \mathrm{Al}_{0.278} \mathrm{Pr}_{0.025} \mathrm{O}$ & $1 / 1$ & 600 & 120,000 & 600 & 38 & 52 & 1.10 & Ojeda-Niño et al. (2019) \\
\hline $\mathrm{Ni}_{0.550} \mathrm{Mg}_{0.212} \mathrm{Al}_{0.238} \mathrm{Pr}_{0.055} \mathrm{O}$ & $1 / 1$ & 600 & 120,000 & 600 & 50 & 61 & 1.25 & Ojeda-Niño et al. (2019) \\
\hline \multicolumn{9}{|c|}{ Mixing metal catalysts with microwave-absorbing materials } \\
\hline $\mathrm{FY} 5+\mathrm{Ni} / \mathrm{Al}_{2} \mathrm{O}_{3}$ & $1 / 1$ & 800 & 1500 & 180 & 90 & 98 & - & Fidalgo et al. (2011) \\
\hline $\mathrm{CQ}+\mathrm{Ni} / \mathrm{Al}_{2} \mathrm{O}_{3}$ & $1 / 1$ & 800 & 1500 & 180 & 84 & 92 & - & Fidalgo et al. (2011) \\
\hline $\mathrm{Ni} / \mathrm{FY} 5$ & $1 / 1$ & 800 & 1500 & 180 & 85 & 100 & - & Fidalgo et al. (2011) \\
\hline $\mathrm{FY} 5+\mathrm{eFe}^{\mathrm{e}}$ & $1 / 1$ & 800 & 680 & 160 & 72 & 93 & - & Bermudez et al. (2012) \\
\hline $\mathrm{CQ}+\mathrm{eFe}^{\mathrm{e}}$ & $1 / 1$ & 800 & 680 & 160 & 42 & 70 & - & Bermudez et al. (2012) \\
\hline $5 \% \mathrm{Ni} /$ bio-char $^{\mathrm{d}}$ & $1 / 1$ & 800 & 1200 & 120 & 83 & 87 & - & Li et al. (2017) \\
\hline $10 \% \mathrm{Ni} /$ bio-char $^{\mathrm{d}}$ & $1 / 1$ & 800 & 1200 & 120 & 84 & 89 & 0.54 & Li et al. (2017) \\
\hline $15 \%$ Ni/bio-char ${ }^{\mathrm{d}}$ & $1 / 1$ & 800 & 1200 & 120 & 80 & 89 & - & Li et al. (2017) \\
\hline $20 \% \mathrm{Ni} /$ bio-char $^{\mathrm{d}}$ & $1 / 1$ & 800 & 1200 & 120 & 79 & 88 & - & Li et al. (2017) \\
\hline $\mathrm{Char}+\mathrm{Na}$ & $1 / 1$ & 975 & 2400 & - & 73 & 93 & - & Li et al. (2018a, b) \\
\hline Char $+\mathrm{K}$ & $1 / 1$ & 975 & 2400 & - & 73 & 92 & - & Li et al. (2018a, b) \\
\hline $\mathrm{Char}+\mathrm{Ca}$ & $1 / 1$ & 975 & 2400 & - & 79 & 83 & - & Li et al. (2018a, b) \\
\hline Char $+\mathrm{Mg}$ & $1 / 1$ & 975 & 2400 & - & 80 & 82 & - & Li et al. (2018a, b) \\
\hline $\mathrm{Char}+\mathrm{Ni}$ & $1 / 1$ & 975 & 2400 & - & 87 & 93 & - & Li et al. (2018a, b) \\
\hline $5 \% \mathrm{Fe}-\mathrm{C}$ & $1 / 1$ & 900 & 7200 & 20 & 95 & 99 & 1.01 & Li et al. (2019) \\
\hline $10 \% \mathrm{Fe}-\mathrm{C}$ & $1 / 1$ & 900 & 7200 & 20 & 98 & 100 & 1.02 & Li et al. (2019) \\
\hline $20 \% \mathrm{Fe}-\mathrm{C}$ & $1 / 1$ & 900 & 7200 & 20 & 93 & 100 & 0.93 & Li et al. (2019) \\
\hline
\end{tabular}

$C Q$ metallurgical coke, BPL bituminous coal-based activated carbon, FY5 coconut shell-derived activated carbon, VHSV volume hourly space velocity

${ }^{\mathrm{a}}$ Char was compose of ash (24.4 wt \%), volatile matter (12.3 wt \%) and fixed carbon $(63.3 \mathrm{wt} \%)$

${ }^{\mathrm{b}}$ Coconut shell-derived activated carbon (FY5) after $\mathrm{CO}_{2}$ activation up to a burn-off degree of $63 \%$

${ }^{c}$ Coconut shell-derived activated carbon (FY5) after oxidation in $\left(\mathrm{NH}_{4}\right)_{2} \mathrm{~S}_{2} \mathrm{O}_{8} / \mathrm{H}_{2} \mathrm{SO}_{4}$ solution

${ }^{\mathrm{d}}$ Bio-char was made of $\mathrm{K}$ (36.4 wt \%), Fe (9.04 wt\%), Ca (11.37 wt\%), Mg (13.12 wt\%), Al (14.43 wt\%) and Na (15.64 wt\%)

${ }^{\mathrm{e}} \mathrm{Fe}$-rich steel-making slag (eFe) was composed of $\mathrm{CaO}$ (41.7 wt $\left.\%\right), \mathrm{Fe}_{2} \mathrm{O}_{3}(21.7 \mathrm{wt} \%), \mathrm{SiO}_{2}(15.0 \mathrm{wt} \%), \mathrm{MgO}(3.7 \mathrm{wt} \%), \mathrm{MnO}(3.5 \mathrm{wt} \%)$ and $\mathrm{Al}_{2} \mathrm{O}_{3}(2.3 \mathrm{wt} \%)$ 
2018; Menéndez et al. 2010). Table 4 summarizes the dielectric attributes of recent reported carbon materials.

In the study of electric heating and microwave heating dry reforming of methane over the char produced from coffee hulls via pyrolysis, Domínguez et al. (2007a, b) found that microwave heating approach significantly enhanced the $\mathrm{CH}_{4}$ and $\mathrm{CO}_{2}$ conversions by achieving $82 \%$ and $98 \%$, respectively (Domínguez et al. 2007a, b). However, a noticeable reduction in $\mathrm{CH}_{4}$ conversion was observed for microwave heating case after few minutes indicating the severe blockage of active sites by carbonaceous species, carbon nanofibres as evident by scanning electron microscopy (SEM) analyses (Fig. 12). Interestingly, unlike the trend observed for $\mathrm{CH}_{4}$ conversion, the $\mathrm{CO}_{2}$ conversion consistently maintained at around of $98 \%$ with time-on-stream due to the high potassium content (40.3 wt\%) existed in char catalysing the carbon gasification reaction at high reaction temperature. From the above results, a 2 steps reaction pathways were proposed for microwave-assisted DRM, in which $\mathrm{CH}_{4}$ decomposition (Eq. 10) followed by carbon gasification by $\mathrm{CO}_{2}$ where the carbon source was reportedly not only originated from $\mathrm{CH}_{4}$ (Eq. 11) but also contributed by the certain type of carbon
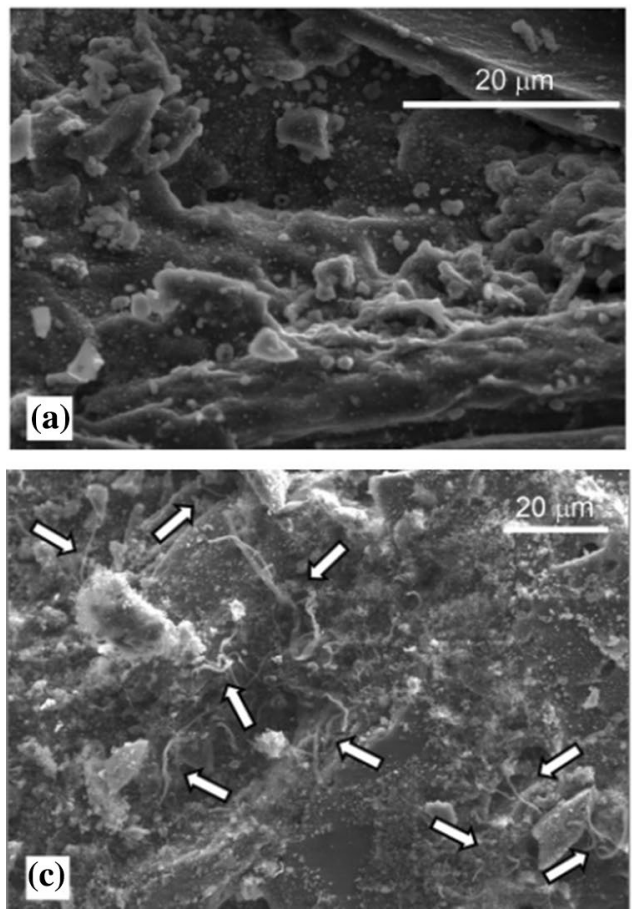

Fig. 12 Scanning electron microscopy (SEM) micrographs of chars after reactions for $2 \mathrm{~h}$-on-stream at temperature of $800{ }^{\circ} \mathrm{C}$ : a deposited coke on char surface after methane cracking in electrical heating; b nanofibres after $\mathrm{CH}_{4}$ cracking in microwave heating; c surface of char after dry reforming of methane in microwave heating (arrows point at nanofibres location); $\mathbf{d}$ nanofibres after dry reforming of methane in microwave heating. The deposition of carbon
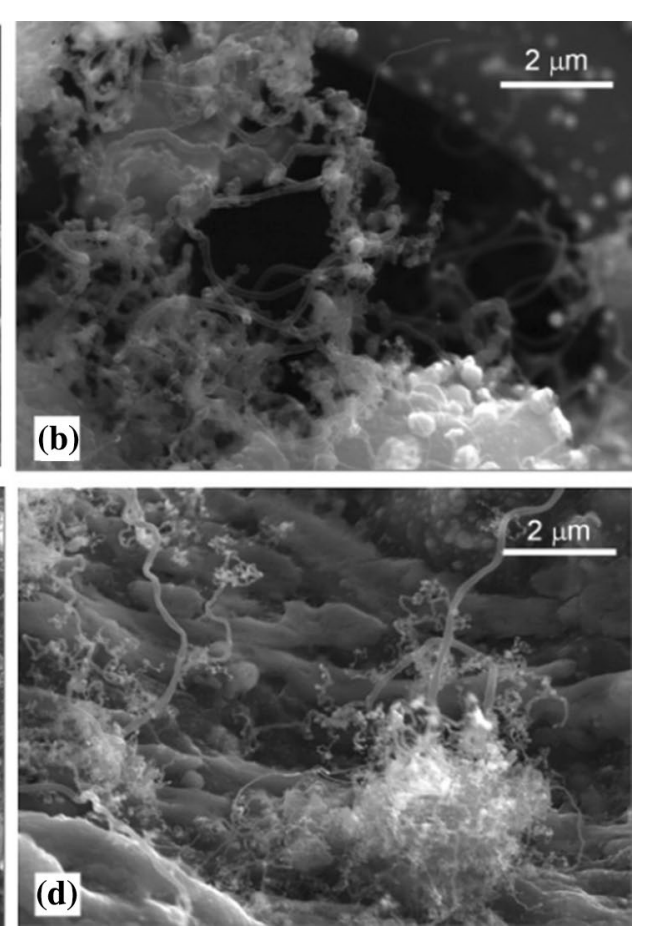

content presented in the char catalyst (Eq. 12) (Domínguez et al. 2007a, b).

$$
\begin{aligned}
& \mathrm{CH}_{4} \rightarrow \mathrm{C}+2 \mathrm{H}_{2} \\
& \mathrm{C}_{\left(\mathrm{CH}_{4}\right)}+\mathrm{CO}_{2} \rightarrow 2 \mathrm{CO} \\
& \mathrm{C}_{(\mathrm{Char})}+\mathrm{CO}_{2} \rightarrow 2 \mathrm{CO}
\end{aligned}
$$

To investigate the influence of various carbon materials on microwave-assisted DRM performance, Fidalgo et al. (2010) had synthesized metallurgical coke (CQ) and various activated carbons, including bituminous coal-based activated carbon (BPL), coconut shell-derived activated carbon (FY5), as well as FY5s prepared with various conditions such as activated carbon (FY5-63) and activated carbon (FY5ox), as given in Table 5. The reactant conversions declined in the following order activated carbon (FY5-63) $>$ coconut shell-derived activated carbon (FY5) $>$ activated carbon $(\mathrm{FY} 50 x)>$ bituminous coal-based activated carbon $(\mathrm{BPL})>$ metallurgical coke (CQ) catalysts. From the study, they discovered that catalytic performance of carbon

nanofibres inevitably grows on char surface, as a result of accelerated $\mathrm{CH}_{4}$ decomposition under the employment of microwave heating dry reforming of methane even though this approach appreciably improves the catalytic activity. This is the main factor leading to the catalyst deactivation within minutes due to severe clogging of active sites of the char. Reprinted with permission from Domínguez et al. (2007a, b). Copyright (2007) American Chemical Society 
materials associated with microwave selective heating mechanism crucially depended on their oxygen surface groups and porosity. Amongst carbonaceous materials employed, coconut shell-derived activated carbon possessed the highest reactant conversion owing to its excellent microporosity capturing the $\mathrm{CO}_{2}$ reactants. Interestingly, oxidized activated carbon (FY5ox) owned a similarly micropores as coconut shell-derived activated carbon, but it did not favour microwave-assisted DRM performance under microwave assistance. Fidalgo et al. (2010) assigned this behaviour to the difficulty in the dissipation of adsorbed microwave into thermal energy due to the presence of electronegative oxygen restraining their mobility for promoting microwave heating (Fidalgo et al. 2010). Theoretically, during microwave heating, the delocalized $\pi$-electrons of carbon materials prone to pair the electric component phase changes associated with electromagnetic field for heat dissipation (Fig. 13). However, oxygen surface groups from oxidized materials are electronwithdrawing resulting in a restriction to the mobility of partial $\pi$-electrons and hence, confining the heat dissipation (Hashisho et al. 2009; Fidalgo et al. 2010).

\section{Metal-based catalysts}

Similar to common the dry reforming of methane, the employment of metals for easing the $\mathrm{CH}_{4}$ activation, improving dispersion of hosting metal and hindering the metal agglomeration and sintering plays an essential role in microwave-assisted DRM process with respect to stability, reactant conversions and product selectivity. Evaluation of a series of metals for microwave-assisted DRM has been conducted based on their inherent nature and numerous main selection criterions. As reported in literature, since formation of carbonaceous species is inevitable in microwaveassisted DRM and carbon is also known as a good microwave receptor, addition of several metals could enhance the dispersion of hosting metal and simultaneously promote the carbon formation accelerating the microwave selective heating mechanism (Odedairo et al. 2016).

In the investigation of metal impact on $\mathrm{Ni} / \mathrm{CeO}_{2}$ catalysts for microwave-assisted DRM, Odedairo et al. (2016) prepared three different $\mathrm{Ni}$ catalysts promoted by several metals, namely, $2 \% \mathrm{Ta}-40 \% \mathrm{Ni} / \mathrm{CeO}_{2}, 2 \% \mathrm{Cr}-40 \% \mathrm{Ni} / \mathrm{CeO}_{2}$ and $2 \% \mathrm{Fe}-40 \% \mathrm{Ni} / \mathrm{CeO}_{2}$ via co-impregnation approach (Odedairo et al. 2016). The incorporation of $\mathrm{Ta}$ and $\mathrm{Cr}$ to $\mathrm{Ni} / \mathrm{CeO}_{2}$ catalysts reportedly inhibited $\mathrm{NiO}$ agglomeration and increased reducibility of Ni catalysts owing to strengthened interaction between support and metal during synthesis. The $\mathrm{CH}_{4}$ conversion in microwave-assisted DRM followed the order: $2 \% \mathrm{Cr}-40 \% \mathrm{Ni} / \mathrm{CeO}_{2}>2 \% \mathrm{Ta}-40 \% \mathrm{Ni} / \mathrm{CeO}_{2} 2 \% \mathrm{Fe}-40 \% \mathrm{Ni} /$ $\mathrm{CeO}_{2}>\mathrm{Ni} / \mathrm{CeO}_{2}$. In fact, the structure of carbon formed during microwave-assisted DRM also has a substantial impact on the reforming activity. Transmission electron

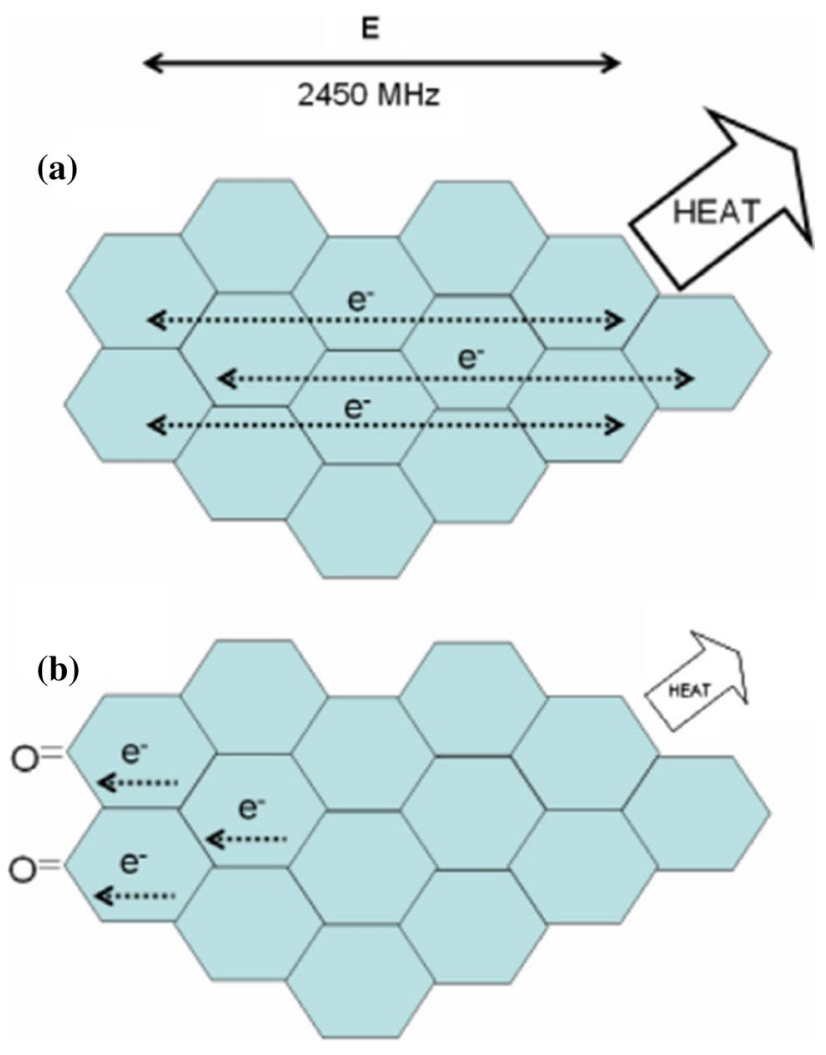

Fig. 13 Effects in microwave heating of carbonaceous materials: a microwave heating induced by the Maxwell-Wagner effect (Interfacial polarization), the delocalized p-electrons pairing electric component phase changes of the electromagnetic field's heat dissipation; b oxygen surface groups are electron-extracting which restrain the movement of partial p-electrons of the basal planes and thus limiting dissipation of heat. This theory explains the disparity in catalytic performance of different carbon materials associated with their corresponding oxygen surface groups and porosity, which impactfully affect their microwave selective heating mechanism in the degree of conversion of adsorbed microwave into thermal energy for microwave-assisted dry reforming of methane (DRM). Reprinted from (Fidalgo et al. 2010), Copyright (2010), with permission from Elsevier

microscopy (TEM) results confirmed the presence of multiwalled carbon nanotubes/layered graphene composite (M/ GR) on $2 \% \mathrm{Cr}-40 \% \mathrm{Ni} / \mathrm{CeO}_{2}$ (Fig. 14) while multi-walled carbon nanotubes/cup-stacked carbon nanotubes composite (M/CSCNT) and multi-walled carbon nanotubes/graphitic nanofibre/graphene (3-phase composite) were found on $2 \% \mathrm{Ta}-40 \% \mathrm{Ni} / \mathrm{CeO}_{2}$ (Fig. 15 ) and $2 \% \mathrm{Fe}-40 \% \mathrm{Ni} / \mathrm{CeO}_{2}$ (Fig. 16), respectively after reaction. Amongst the catalysts, $2 \% \mathrm{Cr}-40 \% \mathrm{Ni} / \mathrm{CeO}_{2}$ possessed the most graphene content on its surface. According to Menéndez et al. (2010), graphene owns plentiful of $s p^{2} \pi$ electrons that able to absorb microwave effectively and transform the subsequent absorbed microwave into microplasmas or hot spots (Menéndez et al. 2010). Hence, Odedairo et al. (2016) suggested that the good catalyst activity of Cr- and Ta-doped catalysts could 
Fig. 14 Transmission electron microscopy (TEM) images of multi-walled carbon nanotubes/ layered graphene (M/GR) obtained on $2 \% \mathrm{Cr}-40 \% \mathrm{Ni} / \mathrm{CeO}_{2}$ after $14 \mathrm{~h}$-on-stream reaction. The graphene and multi-walled carbon nanotubes and metal nanoparticles are evidently dispersed on the transparent and wrinkled layered graphene and multi-walled carbon nanotubes. Graphene was crumpling into many overlapped regions owing to the strong Van der Waals interactions amongst layers. The metal nanoparticles are found at the tip of a multi-walled carbon nanotube and coated with carbonaceous shell could be a result of the $\mathrm{CH}_{4}$ decomposition. Reprinted from Odedairo et al. (2016), Copyright (2015), with permission from Elsevier (a)

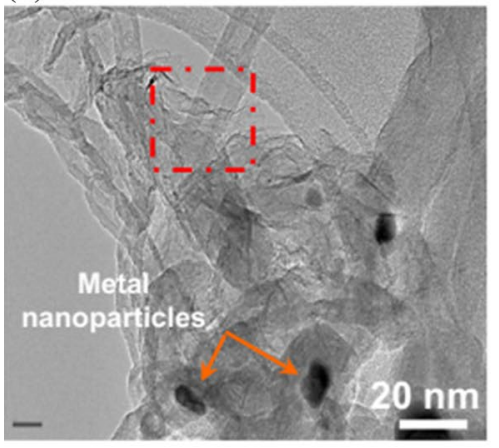

(c)

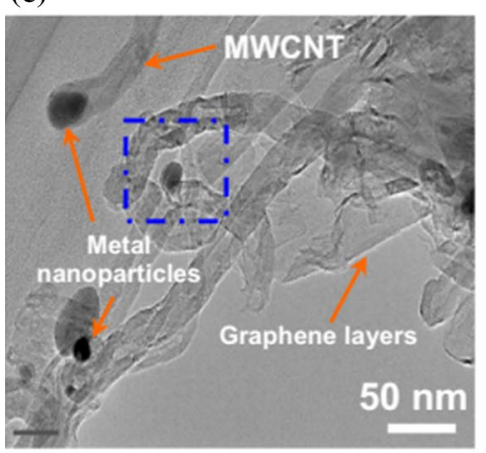

(e)

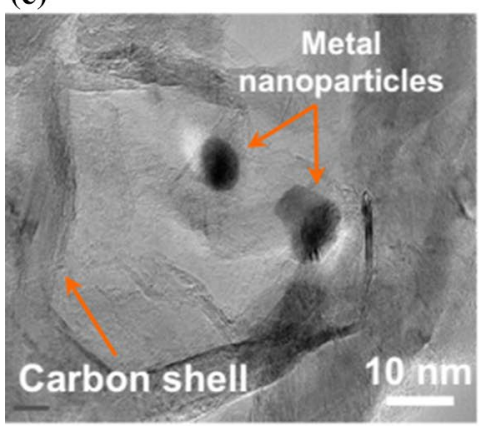

(b)

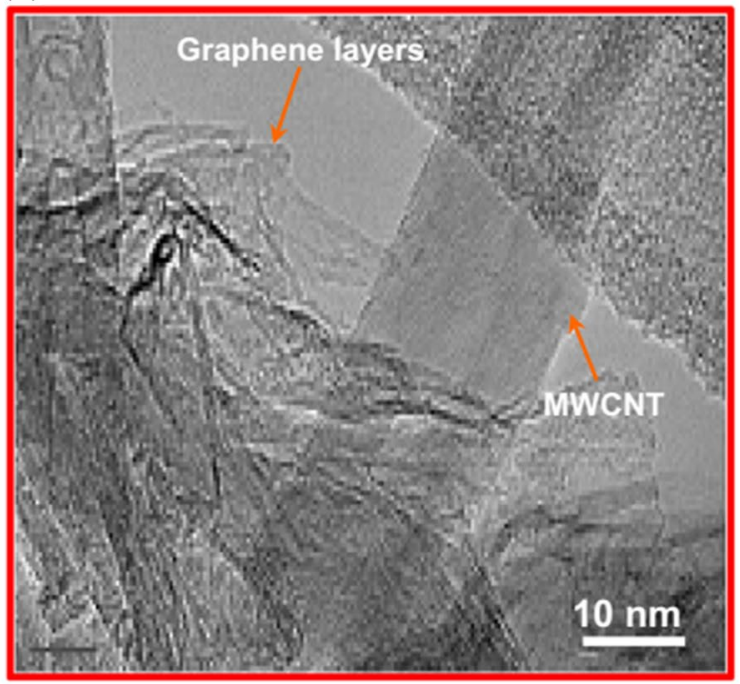

(d)

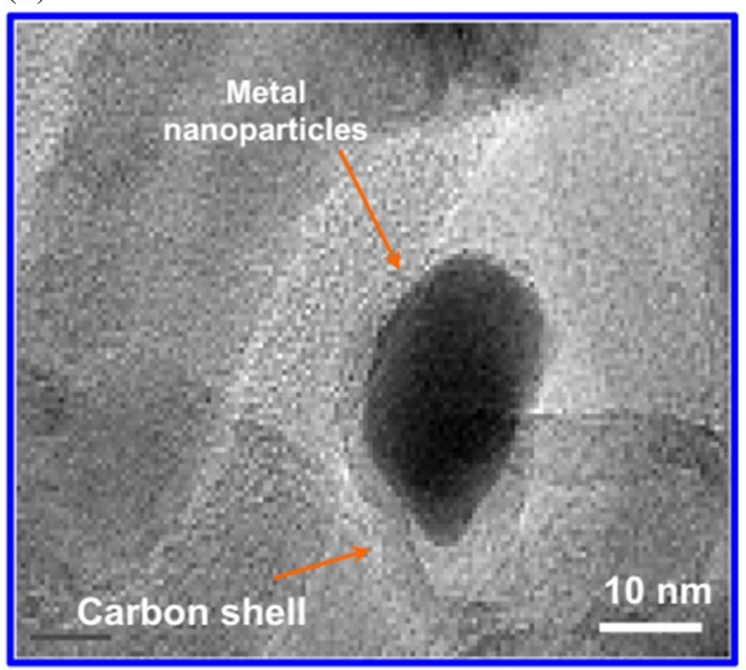

be attributed to the in situ grown graphene on catalyst surface which sustainably released heat to the neighbouring $\mathrm{Ni}$ particles under microwave irradiation and thus, facilitating the microwave selective heating mechanism for microwaveassisted DRM process (Odedairo et al. 2016).

Zhang et al. (2018b) assessed the factors, i.e. catalyst carriers, microwave power, active component contents and space velocity, affecting catalytic performance of $\mathrm{Al}_{2} \mathrm{O}_{3}-\mathrm{SiC}$ supported catalysts for microwave-assisted DRM. They found that an increase in active Fe content rapidly enhanced the catalytic activity from Fe loading of $4-12 \mathrm{wt} \%$ but an insignificant decline in catalytic activity was discerned at $\mathrm{Fe}$ content of $16 \mathrm{wt} \%$. With the optimal content of $\mathrm{Fe}(12 \mathrm{wt} \%)$, the highest $\mathrm{CO}_{2}$ and $\mathrm{CH}_{4}$ conversion about of $92 \%$ and $93 \%$ were achieved. As reported by Zhang et al. (2018b), active Fe component below $12 \mathrm{wt} \%$ was insufficient to disperse finely over the whole support surface providing sufficient active sites for microwave-assisted DRM while Fe content above $12 \mathrm{wt} \%$ easily led to metal sintering at high temperature. In contrast with the discussion of Zhang et al. (2018b), Odedairo et al. (2016) suggested that carbon deposit was indeed active in the existence of microwave irradiation but it was also favourable to the side reactions causing a drop in reforming performance (Zhang et al. 2018b).

In the study of microwave-assisted DRM activity with respect to the stability, Ojeda-Niño et al. (2019) found that the incorporation of Pr not only significantly enhance the thermal stability for the $\mathrm{Ni}-\mathrm{Mg}-\mathrm{Al}$ catalysts at hightemperature microwave-assisted DRM but also promote the $\mathrm{CO}_{2}$ adsorption in a capture-release reversible dynamic depending on the basicity strength. Overall, they discovered that the Pr loading did not has a direct correlation 
Fig. 15 Transmission electron microscopy (TEM) images of multi-walled carbon nanotubes/ graphitic nanofibre/layered graphene (3-phase composite) obtained on $2 \% \mathrm{Ta}-40 \% \mathrm{Ni} / \mathrm{CeO}_{2}$ after $14 \mathrm{~h}$-on-stream reaction. Graphene layers with metal nanoparticles encapsulated by carbon shell can be observed. This is probably due to the nucleation of crystalline carbon forming the multi-walled carbon nanotubes which catalysed by Ni particles. Reprinted from Odedairo et al. (2016), Copyright (2015), with permission from Elsevier (a)

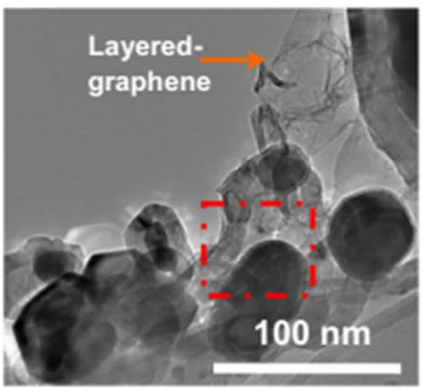

(b)

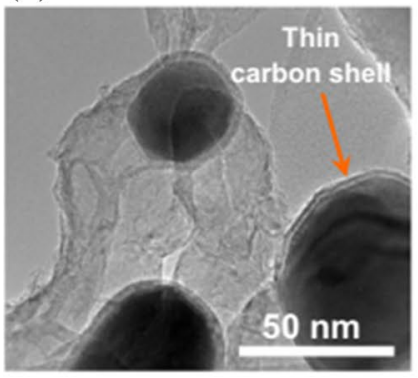

(e)

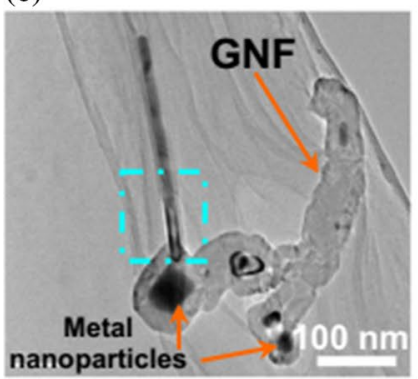

(f)

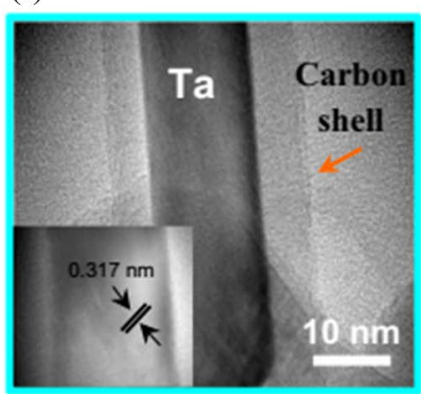

(c)

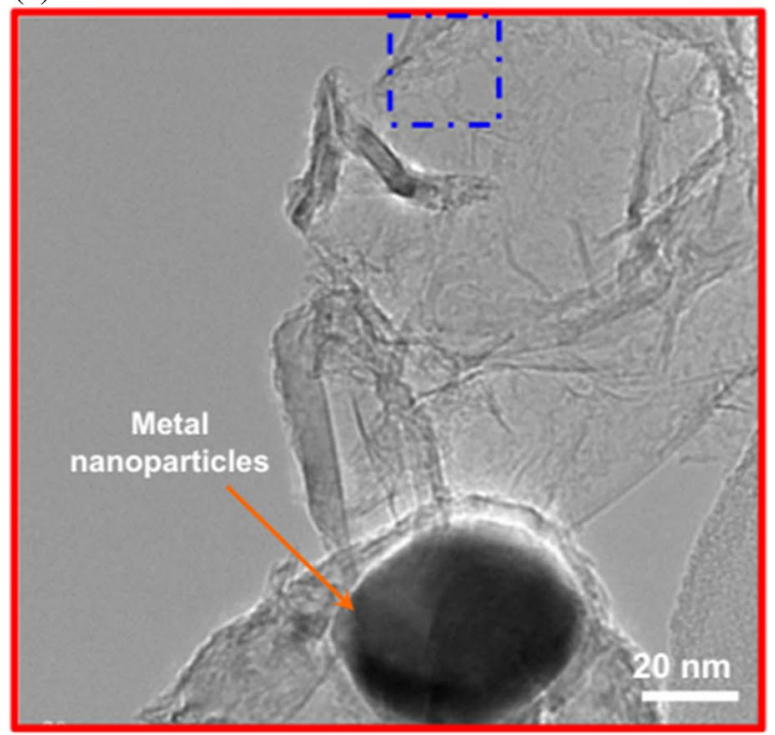

(d)

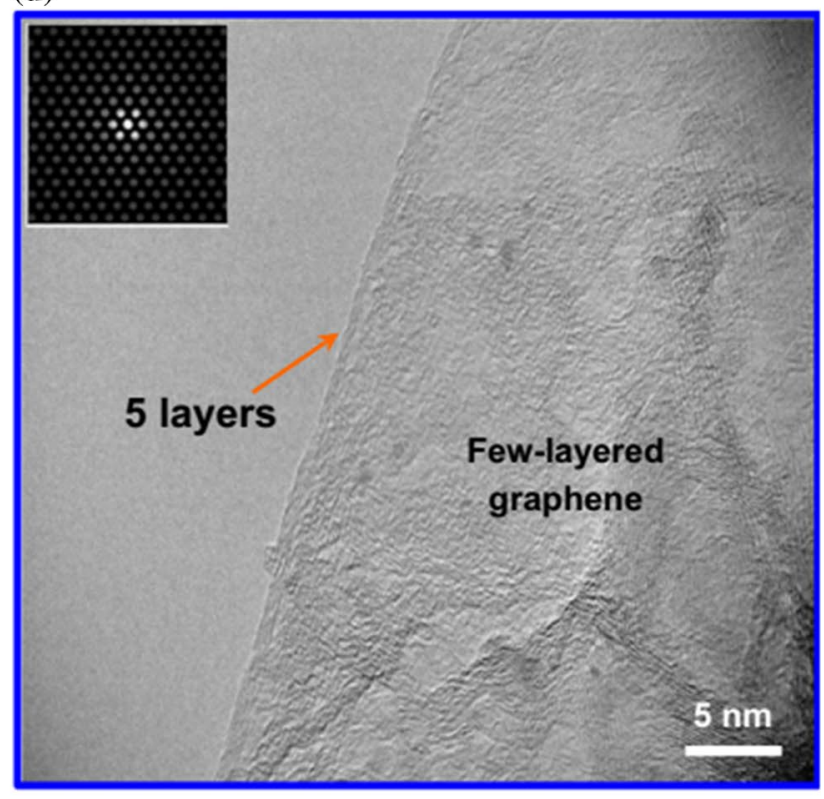

towards the catalytic performance for the reaction but it considerably influences catalytic stability. With respect to the resistibility towards carbon formation, Pr reportedly improved the dispersity of metallic Ni particles resulting in the reduction of their particle sizes on catalyst surface and thus, suppressing the growth of carbonaceous deposits and metal sintering. As a result, the increasing Pr loading led to a decline in ratio of $\mathrm{H}_{2}$ to $\mathrm{CO}$ due to the facilitated gasification process of carbon producing a $\mathrm{CO}$-rich atmosphere.

\section{Mixing metal catalysts with microwave-absorbing materials}

Since microwave-assisted DRM process is a heterogeneous catalytic reaction involving conventional reaction mechanism and concomitant presence of microwave selective heating mechanism, the synergistic effect of mixture comprising of carbon materials and active metals for novel microwave-assisted DRM catalyst is significantly important for maximizing catalytic activity, stability and product yields at extreme operating conditions. 
Fig. 16 Transmission electron microscopy (TEM) images of multi-walled carbon nanotubes/ cup-stacked carbon nanotubes (M/CSCNT) obtained on $2 \% \mathrm{Fe}-40 \% \mathrm{Ni} / \mathrm{CeO}_{2}$ after $14 \mathrm{~h}$-on-stream reaction. The cup-stacked carbon nanotubes have various sizes and lengths with large hollow tubular structure and open ends, which can continuously grow via decomposition of carbon-containing gases on a metal catalyst. Since Fe reportedly produces tubular carbon nanofibres, the formation of multi-walled carbon nanotubes/cup-stacked carbon nanotubes on $2 \% \mathrm{Fe}-40 \% \mathrm{Ni} /$ $\mathrm{CeO}_{2}$ is predictable. Reprinted from Odedairo et al. (2016), Copyright (2015), with permission from Elsevier (a)

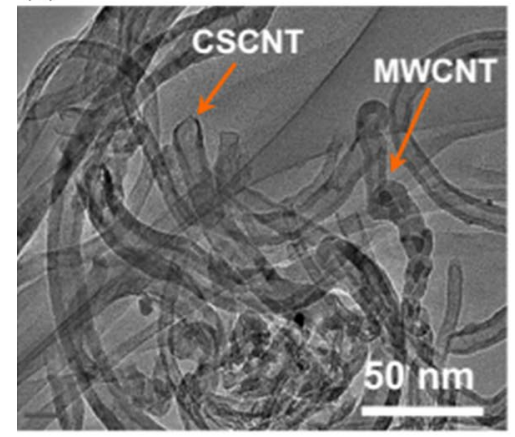

(c)

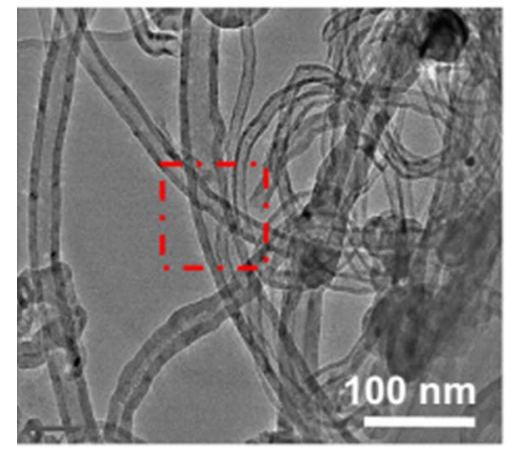

(d)

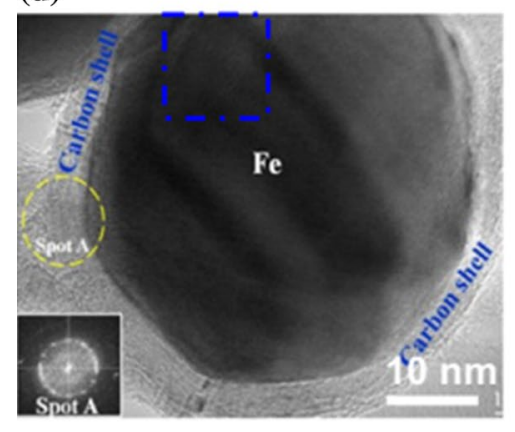

(b)

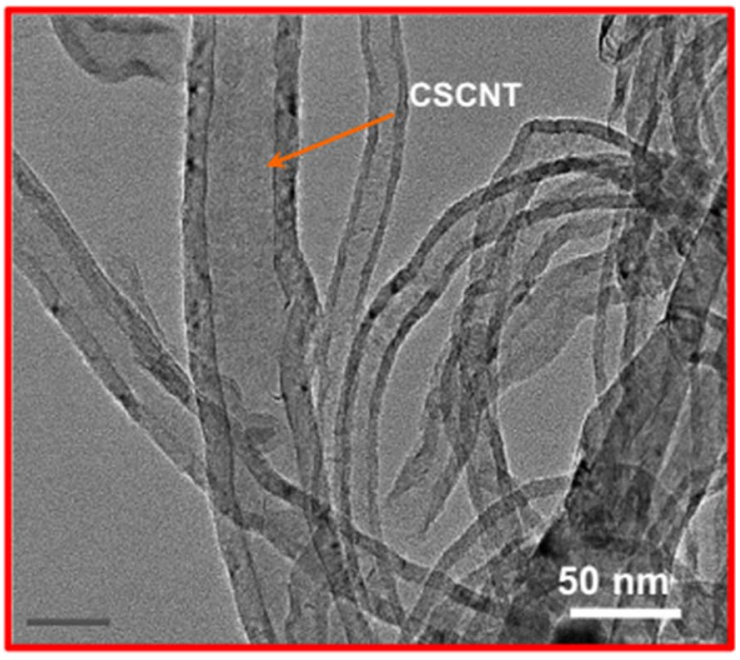

(e)

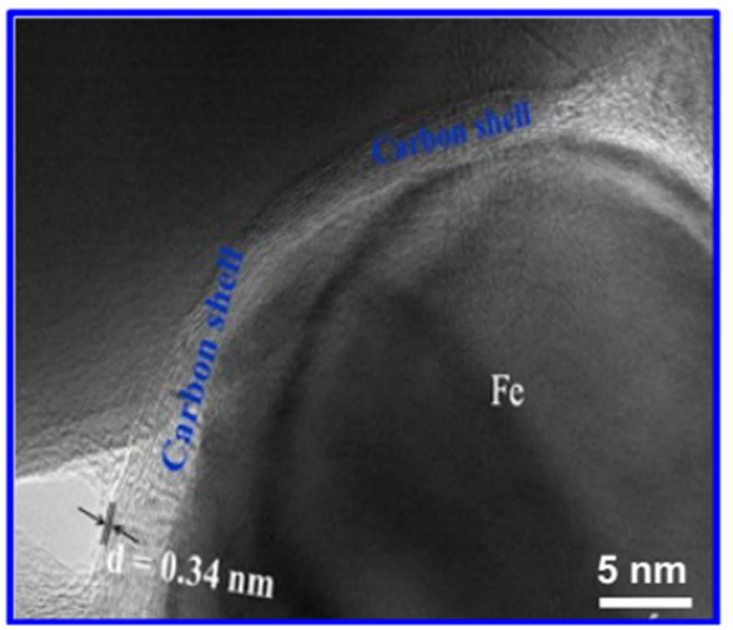

In the investigation of microwave-assisted DRM performance over different carbon-mixed $\mathrm{Ni} / \mathrm{Al}_{2} \mathrm{O}_{3}$ catalysts, Fidalgo et al. (2011) reported that coconut shell-derived activated carbon $+\mathrm{Ni} / \mathrm{Al}_{2} \mathrm{O}_{3}$ exhibited greater reactant conversions in comparison with that of metallurgical coke $(\mathrm{CQ})+\mathrm{Ni} / \mathrm{Al}_{2} \mathrm{O}_{3}$ under microwave irradiation owing to its greater dielectric properties promotes microwave heating process (Fidalgo et al. 2011). Apart from dielectric properties of material employed, poor microporosity of metallurgical coke (CQ) was also one of the key elements contributed to low catalytic performance of metallurgical coke (CQ) $+\mathrm{Ni} / \mathrm{Al}_{2} \mathrm{O}_{3}$. Additionally, $\mathrm{Ni} /$ coconut shell-derived activated carbon (FY5) was synthesized to further examine the synergistic influence of coconut shell-derived activated carbon (FY5) support and metallic Ni phase on microwaveassisted DRM and Fidalgo et al. (2011) noticed that reactant conversions achieved by $\mathrm{Ni} /$ coconut shell-derived activated carbon (FY5) were superior and more stable than that of coconut shell-derived activated carbon (FY5) alone. However, Ni/coconut shell-derived activated carbon (FY5) exhibited a lower $\mathrm{CH}_{4}$ conversion in comparison with coconut shell-derived activated carbon (FY5) $+\mathrm{Ni} / \mathrm{Al}_{2} \mathrm{O}_{3}$ possibly owing to the aggregation of $\mathrm{Ni}$ particles and active sites clogging induced by deposited carbon. From the results, for carbonaceous material $+\mathrm{Ni} / \mathrm{Al}_{2} \mathrm{O}_{3}$, Fidalgo et al. (2011) suggested that formation of spinel associated with metallic $\mathrm{Ni}$ form and $\mathrm{Al}_{2} \mathrm{O}_{3}$ support was responsible for the inhibition of $\mathrm{Ni}$ sintering and carbon formation, leading to good catalytic performance.

The promotional effects of different carbonaceous species, i.e. metallurgical coke (CQ) and coconut shell-derived activated carbon (FY5), on the catalytic performance of steel-making slag $(\mathrm{eFe})$ catalysts for microwave-assisted DRM were evaluated by Bermudez et al. (2012) at $800{ }^{\circ} \mathrm{C}$ and the stoichiometric feed composition. Comparable to the findings of Fidalgo et al. (2011), they found that mixture of 
steel-making slag (eFe) and coconut shell-derived activated carbon (FY5) exhibited greater and steadier catalytic activity with time-on-stream compared to those attained using activated carbon alone. Bermudez et al. (2012) also conducted microwave-assisted DRM over a mixture of carbon + steelmaking slag and carbon $+\mathrm{Ni} / \mathrm{Al}_{2} \mathrm{O}_{3}$ at various $\mathrm{VSHV}$ in order to examine their catalytic activity with different metals. They discovered that the reactant conversions over carbon $+\mathrm{Ni} / \mathrm{Al}_{2} \mathrm{O}_{3}$ catalyst was independent from VSHV. This catalyst mixture could surprisingly achieve reactant conversions approximate to $100 \%$ with the increasing VSHV up to

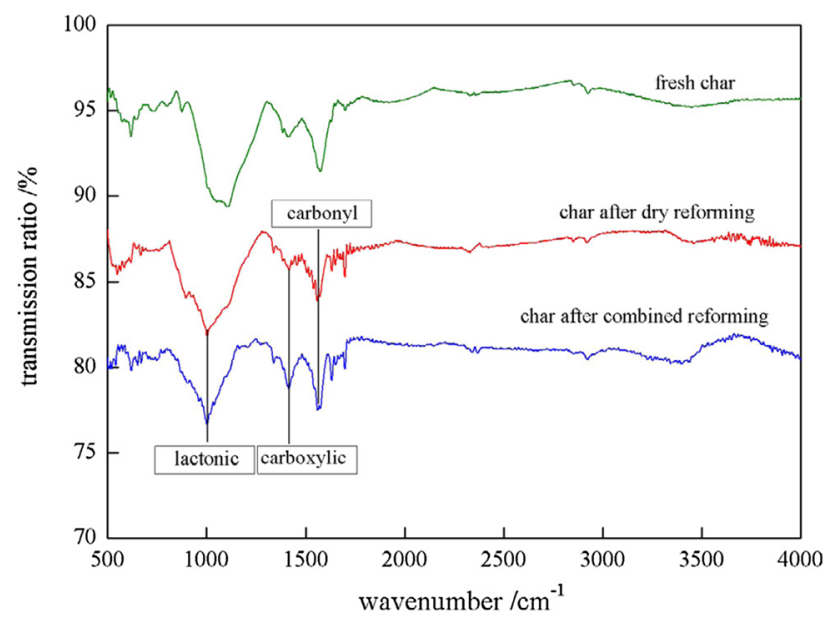

Fig. 17 Fourier transform infrared spectroscopy (FTIR) spectra of biochar before and after reaction. The detection of carbonyl and carboxylic groups confirm the presence of carbonaceous deposits on the char surface after reaction, which is responsible for the active site blockage of bio-char catalyst and hence resulting in the poor reforming activity. Reprinted from Li et al. (2016), Copyright (2016), with permission from Elsevier sixfold than that employed for activated carbon alone (Bermudez et al. 2012).

Li et al. (2017) prepared the Ni/bio-char catalysts with varying Ni loading of $0-20 \mathrm{wt} \%$ to study the synergetic influence on their catalytic performance for microwaveassisted DRM at temperature of $800{ }^{\circ} \mathrm{C}$ ( $\mathrm{Li}$ et al. 2017). The addition of $\mathrm{Ni}$ (from 0 to $20 \mathrm{wt} \%$ ) could significantly enhance the bio-char's catalytic performance and the optimal value was achieved at $10 \% \mathrm{Ni} /$ bio-char respecting reactant conversions and catalytic stability. With the employment of $\mathrm{Ni}$ loading at $10 \mathrm{wt} \%$ and below, the equilibrium between carbon consumption and carbon deposition rate could be achieved, and hence, recovery of active sites led to higher $\mathrm{CH}_{4}$ conversion and better stability (Li et al. 2017). While the Ni/bio-char with Ni loading beyond $10 \mathrm{wt} \%$ experienced severe deactivation probably due to the active site blockage induced by metal sinterization and deposition of carbonaceous species, as evidenced by the post-reaction Fourier transform infrared spectroscopy (FTIR, Fig. 17) and scanning electron microscopy (SEM, Fig. 18) measurements. It is worth noting that the conversion of $\mathrm{CO}_{2}$ was always greater than $\mathrm{CH}_{4}$ and the decrease in $\mathrm{CO}_{2}$ conversion was insignificant with growing Ni loading. This behaviour was possibly due to the gasification of carbon presented in bio-char and the reverse water-gas shift. From this study, Li et al. (2017) found that in the process of the carbon removal with $\mathrm{CO}_{2}$, the activeness of carbon from bio-char was much higher than carbon deposits in accordance with Fidalgo et al. (2008).

Apart from transition metal-based catalyst, Li et al. (2018a, b) had prepared several alkaline metal-based catalysts and assessed their catalytic performance for microwave-assisted DRM. Interestingly, the advantages of employing alkaline metal were pronounced to the improvement in $\mathrm{CO}_{2}$ conversion, indicating the enhancement in
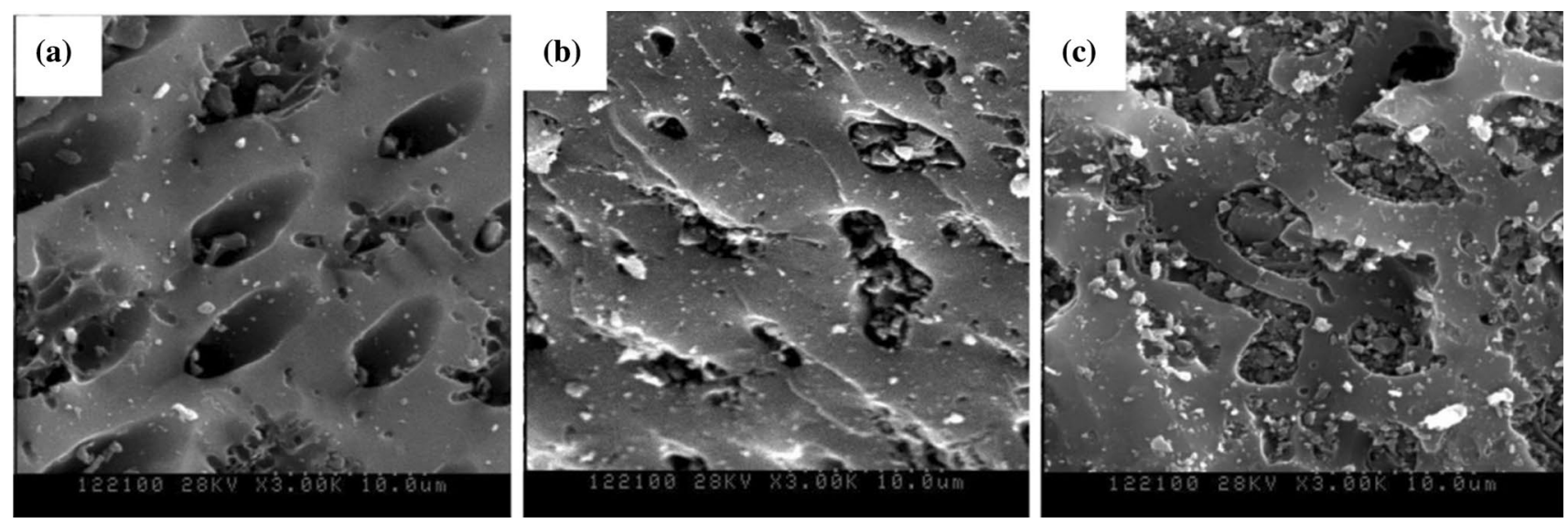

Fig. 18 Scanning electron microscopy (SEM) micrographs of the fresh and spent bio-char (a fresh char; $\mathbf{b}$ char after combined reforming; $\mathbf{c}$ char after dry reforming). The porosity of bio-char is evidently blocked and deposited by carbonaceous species, which is the main factor causing the rapid loss in catalytic activity of bio-char during reaction. Reprinted from Li et al. (2016), Copyright (2016), with permission from Elsevier 
gasification of carbonaceous deposits possibly owing to the extent of alkalinity of catalyst. In comparison with original bio-char, the embedment of $\mathrm{K}$ and $\mathrm{Na}$ improved the conversion of $\mathrm{CO}_{2}$ by 10.8 and $12.1 \%$, respectively, while the embedment of $\mathrm{Mg}$ and $\mathrm{Ca}$ unexpectedly promote the rate of $\mathrm{CH}_{4}$ decomposition. Considering the economic feasibility, applicability and availability, Li et al. (2019) continuously study the microwave-assisted DRM process over the Fe-rich biomass-derived chars. They found that $\mathrm{Fe}$ addition appreciably enhance the activity of methane reforming compared to original char. However, at Fe content beyond 10\%, a drop in $\mathrm{CH}_{4}$ conversion was observed owing to the metal sintering at higher temperature. Conversely, the $\mathrm{CO}_{2}$ conversion was unaffected over different Fe content bio chars. This behaviour was attributed to the acceleration of both gasification of carbon and reverse water-gas shift contributing to the high consumption of $\mathrm{CO}_{2}$ reactant.

\section{Effect of operating conditions}

Apart from catalyst property, the process variables such as volume hourly space velocity (VHSV), reaction temperature and reactant partial pressure also play essential role to formulate the inherent kinetic models for catalyst based on elementary steps since the reaction kinetics are fundamentally affected by resistances of mass and heat transfer associated with process variables (Abdullah et al. 2017). Hence, wide-ranging investigations of process variable on microwave-assisted DRM were conducted to describe the correlation between operating conditions and the corresponding catalytic performance meanwhile determine the appropriate optimization of microwave-assisted DRM process conditions (Fidalgo et al. 2008; Gangurde et al. 2018; Odedairo et al. 2016). Catalytic performance of catalysts under varying process variables reported in literature is listed in Table 6.

\section{Reaction temperature}

The increase in reaction temperature profoundly offers positive effects to the microwave-assisted DRM since the reaction is intrinsically possessing endothermic nature. However, analogous to other reforming processes, catalyst deactivation caused by metal sinterization and carbon deposits was the unavoidable encountered setback at extreme temperature condition. Thus, numerous researches were to determine the appropriate temperature range for performing microwaveassisted DRM in terms of excellent reforming performance and insignificant carbonaceous deposition.

Fidalgo et al. (2008) examined the temperature impact on microwave-assisted DRM performance over activated carbon at reaction temperature of $600-900{ }^{\circ} \mathrm{C}$. They found that the temperature range $700-800{ }^{\circ} \mathrm{C}$ was appropriate for maximizing the reforming performance due to the existence of microplasmas facilitating the heterogeneous catalytic reactions, namely, $\mathrm{CH}_{4}$ dissociation and $\mathrm{CO}_{2}$ gasification. However, higher temperatures accelerated the growth of carbonaceous species encapsulating active sites of catalyst while lower temperatures only achieved low $\mathrm{CH}_{4}$ conversion (36\%) and $\mathrm{CO}_{2}$ conversion (25\%). Similarly, Domínguez et al. $(2007 \mathrm{a}, \mathrm{b})$ found that increasing reforming temperature could generate microplasmas during microwave heating approach which appreciably improved the $\mathrm{CH}_{4}$ conversion of activated carbon from 11 to $70 \%$ at VSHV of $160 \mathrm{ml} \mathrm{g}_{\text {cat }}{ }^{-1} \mathrm{~h}^{-1}$ (Domínguez et al. 2007a, b). However, the reactant conversions declined with reaction duration owing to the pore blockage of catalyst induced by carbon deposition, as evidenced by the reduction in micropore volumes and BET surface area. Additionally, Lim and Chun (2017) and Zhang et al. (2018b) stated that growth in reactant conversions with increasing temperature was mainly ascribed to the endothermicity of microwave-assisted DRM (Lim and Chun 2017; Zhang et al. 2018b). From the study, Zhang et al. (2018b) discovered that as temperature increased, $\mathrm{CH}_{4}$ conversion was lower than $\mathrm{CO}_{2}$ conversion under microwave irradiation, indicating the predominance of reverse Boudouard reaction and water-gas shift reaction.

From the investigation of transition metal-promoted, i.e. $\mathrm{Ta}, \mathrm{Cr}$ and $\mathrm{Fe}$, Ni catalysts for microwave-assisted DRM with different microwave heating powers, Odedairo et al. (2016) concluded that a growth in temperature from 770 to $940{ }^{\circ} \mathrm{C}$ could greatly influence the coke formation and improve the catalytic activity. However, this behaviour was enormously depending on the ability of microwave absorption for material employed and the carbonaceous species formed on catalyst surface. Odedairo et al. (2016) assigned the superior catalytic performance of $2 \% \mathrm{Cr}-40 \% \mathrm{Ni} / \mathrm{CeO}_{2}$ and $2 \% \mathrm{Ta}-40 \% \mathrm{Ni} / \mathrm{CeO}_{2}$ to the formation of graphene at suitable reaction temperatures associated with the microwave heating power. The subsequent in situ graphene could further enhance the heat dissipation from microwave and locally heated the neighbouring Ni particles and thus improvement of catalytic activity. Hamzehlouia et al. (2018) synthesized a carbon-coated $\mathrm{SiO}_{2}$ catalyst and examined at varying operating temperatures from 650 to $900{ }^{\circ} \mathrm{C}$ (Hamzehlouia et al. 2018). The reactant conversions were in accordance with the microwave-assisted DRM endothermic nature, in which $\mathrm{CO}_{2}$ and $\mathrm{CH}_{4}$ conversions were improved up to $85 \%$ and $91 \%$, correspondingly by increasing the reaction temperature (Fig. 19). With the employment of microwave heating, the reactant conversions achieved were reportedly greater than thermodynamically predicted equilibrium values reported in literature. Hence, Hamzehlouia et al. (2018) proposed that the microwave selective heating mechanism not only enhanced the reforming performance via sustainably maintain the temperature gradient on catalyst surface 
Table 6 Effects of process variables on the catalytic performance for microwave-assisted dry reforming of methane (DRM) reaction with different catalysts

\begin{tabular}{|c|c|c|c|c|c|c|c|}
\hline \multirow{2}{*}{$\begin{array}{l}\text { Catalysts and } \\
\text { microwave } \\
\text { receptors (C/ } \\
\mathrm{MR})\end{array}$} & \multicolumn{3}{|l|}{ Operating conditions } & \multirow{2}{*}{$\begin{array}{l}\mathrm{CH}_{4} \text { conversion } \\
(\%)\end{array}$} & \multirow{2}{*}{$\begin{array}{l}\mathrm{CO}_{2} \text { conversion } \\
(\%)\end{array}$} & \multirow[t]{2}{*}{$\mathrm{H}_{2} / \mathrm{CO}$ ratio } & \multirow[t]{2}{*}{ References } \\
\hline & $\mathrm{CH}_{4} / \mathrm{CO}_{2}$ ratio & $\begin{array}{l}\text { Temperature } \\
\left({ }^{\circ} \mathrm{C}\right)\end{array}$ & $\begin{array}{l}\text { VHSV } \\
\left(\mathrm{Ml} \mathrm{g}_{\text {cat }}{ }^{-1} \mathrm{~h}^{-1}\right)\end{array}$ & & & & \\
\hline \multirow{3}{*}{$\begin{array}{l}\text { Activated carbon } \\
\text { (filtracarb } \\
\text { FY5) }\end{array}$} & $1 / 1.5$ & $600-800$ & 400 & $36-100$ & $25-100$ & $0.90-0.70$ & \multirow{3}{*}{$\begin{array}{l}\text { Fidalgo et al. } \\
\qquad(2008)\end{array}$} \\
\hline & $0.4-0.65 / 0.6-0.35$ & 800 & 160 & $100-31$ & $100-65$ & $0.70-1.40$ & \\
\hline & $1 / 1$ & 800 & $320-920$ & $70-38$ & $80-44$ & $0.80-0.70$ & \\
\hline \multirow{2}{*}{$\begin{array}{l}\text { Activated carbon } \\
\text { (filtracarb } \\
\text { FY5) }\end{array}$} & - & $700-900$ & 160 & $11-70$ & - & - & \multirow{2}{*}{$\begin{array}{l}\text { Domínguez et al. } \\
(2007 \mathrm{a}, \mathrm{b})\end{array}$} \\
\hline & - & 800 & $160-720$ & $80-20$ & - & - & \\
\hline \multirow[t]{2}{*}{ Sludge char ${ }^{\mathrm{a}}$} & $1 / 1$ & $800-1000$ & 300 & $61-76$ & $74-88$ & $1.03-1.58$ & \multirow{2}{*}{$\begin{array}{l}\text { Lim and Chun } \\
\text { (2017) }\end{array}$} \\
\hline & $1 / 1$ & 900 & $300-1300$ & $72-35$ & $77-35$ & $1.24-1.42$ & \\
\hline $\mathrm{C}-\mathrm{SiO}_{2}$ & $1 / 1$ & $650-900$ & - & $76-91$ & $57-85$ & - & $\begin{array}{l}\text { Hamzehlouia } \\
\text { et al. (2018) }\end{array}$ \\
\hline \multirow{2}{*}{$\begin{array}{l}8 \% \mathrm{Pt} / 20 \% \mathrm{CeO}_{2} / \\
\gamma-\mathrm{Al}_{2} \mathrm{O}_{3}\end{array}$} & $1 / 1$ & $450-800$ & 7200 & 29-92 & $38-91$ & $0.53-0.96$ & \multirow{2}{*}{$\begin{array}{l}\text { Zhang et al. } \\
\text { (2003) }\end{array}$} \\
\hline & $3-1 / 1-3$ & 650 & 7200 & $36-89$ & $95-48$ & $1.19-0.53$ & \\
\hline $\mathrm{Ni} / \mathrm{CeO}_{2}$ & $1 / 1$ & $770-940$ & 10,200 & $45-78$ & - & - & $\begin{array}{l}\text { Odedairo et al. } \\
\text { (2016) }\end{array}$ \\
\hline $\begin{array}{l}2 \% \mathrm{Ta}-40 \% \mathrm{Ni} / \\
\mathrm{CeO}_{2}\end{array}$ & $1 / 1$ & $770-940$ & 10,200 & $55-81$ & - & - & $\begin{array}{l}\text { Odedairo et al. } \\
\text { (2016) }\end{array}$ \\
\hline $\begin{array}{l}2 \% \mathrm{Fe}-40 \% \mathrm{Ni} / \\
\mathrm{CeO}_{2}\end{array}$ & $1 / 1$ & $770-940$ & 10,200 & $48-69$ & - & - & $\begin{array}{l}\text { Odedairo et al. } \\
\text { (2016) }\end{array}$ \\
\hline $\begin{array}{l}2 \% \mathrm{Cr}-40 \% \mathrm{Ni} / \\
\mathrm{CeO}_{2}\end{array}$ & $1 / 1$ & $770-940$ & 10,200 & $82-90$ & - & - & $\begin{array}{l}\text { Odedairo et al. } \\
\text { (2016) }\end{array}$ \\
\hline \multirow{2}{*}{$\begin{array}{l}12 \% \mathrm{Fe} / \mathrm{Al}_{2} \mathrm{O}_{3}- \\
\quad \mathrm{SiC}\end{array}$} & $1 / 1$ & $427-773$ & $200^{\mathrm{b}}$ & $0-95$ & $0-97$ & - & \multirow{2}{*}{$\begin{array}{l}\text { Zhang et al. } \\
\text { (2018b) }\end{array}$} \\
\hline & $1 / 1$ & 750 & $200-800^{\mathrm{b}}$ & $96-80$ & $94-82$ & $1.23-1.07$ & \\
\hline \multirow[t]{3}{*}{$7 \% \mathrm{Ru} / \mathrm{SrTiO}_{3}$} & $1 / 1$ & $415-1068$ & 3000 & $12-81$ & $16-78$ & $0.60-0.86$ & \multirow{3}{*}{$\begin{array}{l}\text { Gangurde et al. } \\
\text { (2018) }\end{array}$} \\
\hline & $0.55-0.4 / 0.45-0.6$ & 1068 & 3000 & 69-94 & $95-85$ & $0.97-0.81$ & \\
\hline & $0.45 / 0.55$ & $\geq 1068$ & $3000-13,500$ & $90-54$ & $89-65$ & $0.88-0.86$ & \\
\hline $10 \% \mathrm{Fe}-\mathrm{C}$ & $2-0.5 / 1$ & 800 & 7200 & $84-99$ & $95-99$ & $1.72-0.48$ & (Li et al. 2019) \\
\hline
\end{tabular}

${ }^{a}$ Sludge char was composed of $\mathrm{SiO}_{2}(28.35 \mathrm{wt} \%), \mathrm{P}_{2} \mathrm{O}_{5}(24.76 \mathrm{wt} \%), \mathrm{Al}_{2} \mathrm{O}_{3}(13.09 \mathrm{wt} \%), \mathrm{CaO}(12.06 \mathrm{wt} \%), \mathrm{Fe}_{2} \mathrm{O}_{3}(8.98 \mathrm{wt} \%), \mathrm{MgO}(4.55 \mathrm{wt} \%)$, $\mathrm{K}_{2} \mathrm{O}(2.64 \mathrm{wt} \%), \mathrm{SO}_{3}(2.05 \mathrm{wt} \%), \mathrm{ZnO}(0.56 \mathrm{wt} \%), \mathrm{CuO}(0.35 \mathrm{wt} \%), \mathrm{BaO}(0.20 \mathrm{wt} \%), \mathrm{MnO}(0.16 \mathrm{wt} \%), \mathrm{SrO}(0.07 \mathrm{wt} \%)$ and $\mathrm{NiO}(0.04 \mathrm{wt} \%)$

${ }^{\mathrm{b}}$ The volume hourly space velocity (VHSV) unit was $\mathrm{h}^{-1}$

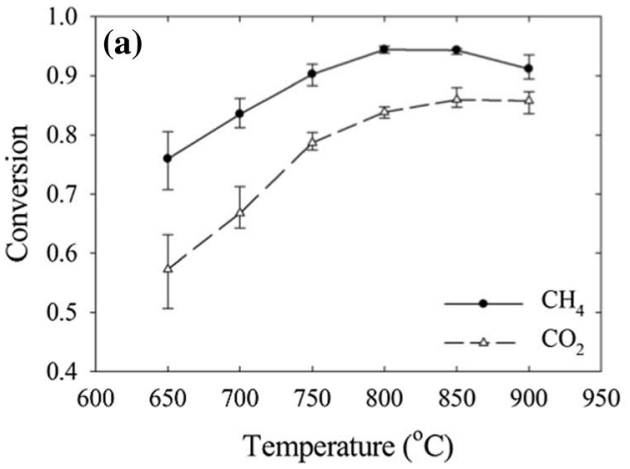

Fig. 19 a Reactant conversion and b product selectivity at temperature ranging from 650 to $900{ }^{\circ} \mathrm{C}$. The reactant conversion and product selectivities are enormously enhanced with the employment of microwave heating compared to conventional electric heating method. This indicates that microwave selective heating mechanism not only

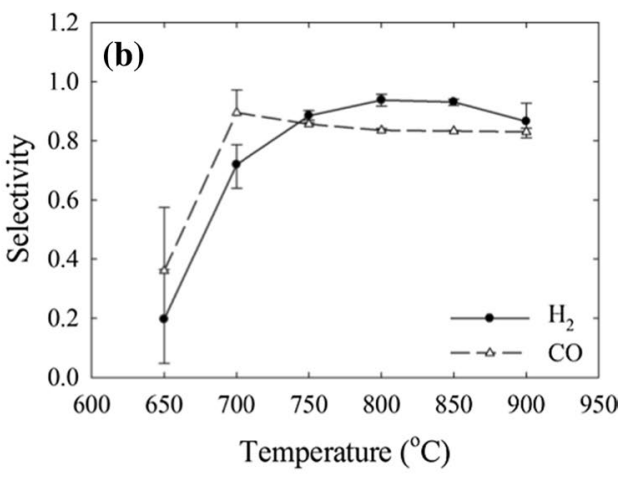

improves the reforming performance by retaining the temperature gradient on catalyst surface but also greatly hinders the occurrence of secondary gas-phase reactions. Adapted from Hamzehlouia et al. (2018) 
but also highly inhibited the occurrence of secondary gasphase reactions to achieve the remarkable $\mathrm{H}_{2}$ and $\mathrm{CO}$ selectivities (Fig. 19).

\section{Gas hourly space velocity}

Apart from the reaction temperature, mass transport of reactants also play a substantial role to the derivation of kinetic models associated with elementary steps. The conversions of reactant can be straightforwardly ascribed to the fundamental kinetics of the catalysts if the mass transport resistance is negligible (Abdullah et al. 2017). Hence, in order to diminish mass transport resistance, evaluation of volume hourly space velocity is necessary for determining the independence of reactant conversions to volume hourly space velocity after reaching a steady-state (Kathiraser et al. 2015).

Domínguez et al. (2007a, b) scrutinized the volume hourly space velocity effect on the catalyst behaviour for microwave-assisted DRM by using FY5 at $800{ }^{\circ} \mathrm{C}$ with $120 \mathrm{~min}$ and revealed that growing VSHV from 160 to $720 \mathrm{ml} \mathrm{g}_{\text {cat }}{ }^{-1} \mathrm{~h}^{-1}$ resulted in a decline in $\mathrm{CH}_{4}$ conversion from 80 to $20 \%$. This observation was ascribed to the short contact time between methane gaseous reactant and active sites on activated carbon surface during the microwaveassisted DRM (Domínguez et al. 2007a, b). Moreover, Fidalgo et al. (2008) described analogous findings of the negative effect of increasing volume hourly space velocity on $\mathrm{CH}_{4}$ conversion over sludge char catalysts owing to the reduced retention time for heterogeneous catalytic reaction. They suggested that longer retention time favoured the carbon gasification by $\mathrm{CO}_{2}$ and $\mathrm{CH}_{4}$ decomposition, leading to a decrease in reactant conversions while $\mathrm{H}_{2} / \mathrm{CO}$ ratio was retained (Fidalgo et al. 2008). In the study of influential factors for microwave-assisted DRM over Fe catalysts, Zhang et al. (2018b) also found that a rise in VSHV ranging of 200-800 h${ }^{-1}$ resulted in the $\mathrm{CH}_{4}$ and $\mathrm{CO}_{2}$ conversion declined by $15.2 \%$ and $13.1 \%$ in this order. This observation was ascribed to the drop in the reactants' retention time on the surface of catalyst with rising VSHV (Zhang et al. 2018b). Nevertheless, they reported that $\mathrm{H}_{2} / \mathrm{CO}$ of syngas generated was not significantly affected with rising volume hourly space velocity in line with the findings obtained by Fidalgo et al. (2008) and Gangurde et al. (2018).

\section{Reactant partial pressure}

The microwave-assisted DRM reaction is an endothermic reforming process which is capable to generate syngas with fraction of $\mathrm{H}_{2}$ to $\mathrm{CO}$ less than unity at temperature range of $700-1100{ }^{\circ} \mathrm{C}$ under microwave irradiation. In fact, ratio of $\mathrm{H}_{2} / \mathrm{CO}$ less than 1 is a valuable feedstock favoured for downstream Fischer-Tropsch (FT) synthesis and methanol production (Abdullah et al. 2017; Siang et al. 2018). Thus, evaluation of various reactant feed composition effect on microwave-assisted DRM is exceptionally important for tuning appropriate $\mathrm{H}_{2} / \mathrm{CO}$ ratios with respect to industrial necessity.

Zhang et al. (2003) inspected the impact of feed composition on the conversions and product selectivities at $650{ }^{\circ} \mathrm{C}$ with $\mathrm{CO}_{2} / \mathrm{CH}_{4}$ ratios ranging of 1:3-3:1 for both microwave heating and conventional approaches. They noticed that growing $\mathrm{CO}_{2} / \mathrm{CH}_{4}$ ratio resulted in a rise in $\mathrm{CH}_{4}$ conversion but reduced the $\mathrm{CO}_{2}$ conversion. A comparable conversion value of $\mathrm{CH}_{4}$ and $\mathrm{CO}_{2}$ was attained at $\mathrm{CO}_{2} / \mathrm{CH}_{4}$ ratio around 1.2 due to the evolution of secondary reaction associated with $\mathrm{CO}_{2}$ at $\mathrm{CO}_{2}$-rich environment. However, $\mathrm{H}_{2} / \mathrm{CO}$ ratio was declined from 1.19 to 0.53 with rising $\mathrm{CO}_{2}$ reactant implying that reverse water-gas shift was dominant. In the study of microwave-assisted DRM, Fidalgo et al. (2008) stated that influence of $\mathrm{CO}_{2}$ partial pressure in feed gas on reforming performance was significant than that of reaction temperature. Similar to results attained by Zhang et al. (2003), the reactant conversions increased with growing $\mathrm{CO}_{2} / \mathrm{CH}_{4}$ ratio. Additionally, a drop in reactant conversions was obtained at low $\mathrm{CO}_{2}$ concentration, possibly due to the deficiency of regenerated catalyst active sites of via carbon gasification by $\mathrm{CO}_{2}$ (Zhang et al. 2003). Gangurde et al. (2018) also reported analogous findings and proposed that an increase in $\mathrm{CO}_{2}$ gaseous reactant in feed gas could lead to an acceleration in deposited carbon gasification and thus facilitating the regeneration of active sites and improving the reactant conversions (Gangurde et al. 2018).

Li et al. (2019) have conducted microwave-assisted DRM over Fe-rich biomass-derived char under different feedstock ratios to determine the correlation between the feed composition and $\mathrm{Fe}$ content presented on catalysts. As $\mathrm{CH}_{4} / \mathrm{CO}_{2}$ ratio increased, an observed decline in catalytic activity implying the predominance of carbon deposition originated from $\mathrm{CH}_{4}$ decomposition at $\mathrm{CH}_{4}$-rich environment. Notably, the $\mathrm{CO}_{2}$ conversion obtained was stable and was higher than $\mathrm{CH}_{4}$ conversion regardless the reactant partial pressure. This observation reveals that the rates of both gasification of carbonaceous deposits and reverse water-gas shift were accelerated with the presenting Fe content in char compared to original char. This evolution could explain the decline in $\mathrm{H}_{2} / \mathrm{CO}$ ratio (from 1.72 to 0.48 ) at lower ratio of $\mathrm{CH}_{4}$ to $\mathrm{CO}_{2}$ due to the excessive $\mathrm{CO}$ gas produced from the parallel side reactions.

As partial conclusions, the employment of natural gas in chemical and energy industries has driven exceptional impacts on the world in terms of economic and environmental outlooks. However, the development of efficient approach to sustainably convert natural gas to value-added syngas product with low capital cost is always a challenging topic. The microwave-assisted DRM offers environmental advantages since it consumes anthropogenic $\mathrm{CO}_{2}$ greenhouse gas 
leading to a reduction in global $\mathrm{CO}_{2}$ emission. In addition, by utilizing the intrinsic dielectric property of material with microwave interaction, strong thermal gradients could be generated between the gaseous reactants and catalyst with the existence of microwave irradiation promoting the syngas selectivity and concurrently retaining the reactant conversions and eliminating the occurrence of secondary gas-phase reactions.

Nevertheless, catalyst deactivation induced by carbonaceous deposition is one of major drawbacks to reforming technologies for industrial implementation. microwaveassisted DRM over carbon-containing catalysts, combining catalytic and dielectric attributes with microwave irradiation to substantially improve the rate of catalytic heterogeneous reaction and reforming performance. Hence, future study in this realm is possibly to highlight on the exploration of appropriate materials combined as catalyst and microwave receptors possessing high surface areas to accommodate the catalyst active sites.

Numerous studies on microwave-assisted DRM showed very promising catalytic performance owing to its selective mechanism with existing microwave heating. Additionally, the influence of microwave heating on thermodynamic equilibrium, activation energy and kinetic parameters exhibits valuable information to understand the reaction mechanistics and formation of intermediate compounds. Substantial evolutions have been evidenced in the last years but further studies are still necessitated in future works in order to develop the best-fitted kinetic modelling fundamentally derived from mechanistic reaction pathways.

\section{Energy consumption comparison}

The capability of the microwave energy for non-contact, rapid, and selective heating promoted its application in distinct research disciplines across the globe in the last couple of decades (Bermudez et al. 2015). As comprehensively validated in previous sections of this review, it has been extensively applied in dry reforming of methane too. However, comparative assessment on energy consumption of conventional and microwave heating in the dry reforming of methane is seldom done. The total publications with and without energy efficiency conclusion during the last decades is summarized in Fig. 20 (Scopus ${ }^{\circledR}$ data were used). It depicts that despite the increasing interest in dry reforming of methane technology for industrialization, minimal research works dedicated to energy efficiency have been performed, in precise less than $1 \%$ amongst around 2300 research works considered for this comparison. The energy efficiency of the conventional furnace is even less ominously studied compared to those with plasma or microwave-assisted heating, yet they are inconclusive.
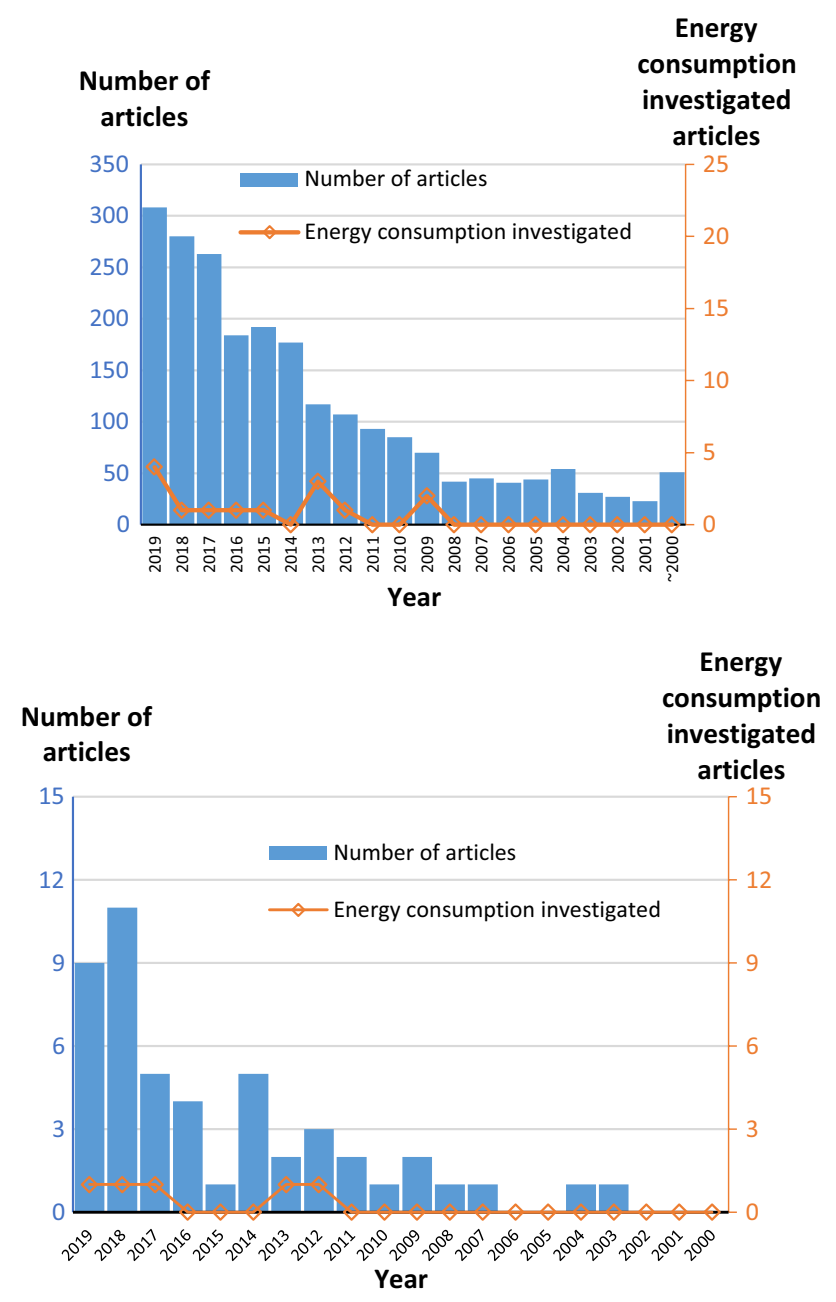

Fig. 20 Publication distribution in the history of the dry reforming of methane to produce syngas. Top: methane reforming with and without energy consumption conclusion; bottom: microwave-assisted methane reforming with and without energy consumption conclusion. It is evident that minimal research works dedicated to energy efficiency studies. (Source: Scopus®)

It is evidently confirmed that microwave heating excelled in $\mathrm{CH}_{4}-\mathrm{CO}_{2}$ conversion performance compared to conventional furnace heating in terms of energy consumption and heating rates (Fidalgo et al. 2008; Gangurde et al. 2018). Hence, the microwave energy directly transfers to the microwave receptor/catalysts and enhances the internal temperature with precisely uniform distribution, eluding the energy wastage by heating the environs and reactor wall. However, a comprehensive comparison study between conventional and microwave heating is yet to be done. Fidalgo and Menéndez (2012) inspected the energy consumption in a microwave pilot plant and scaled up the results to compare energy efficiency with industrially established processes. They estimated that $50 \% \mathrm{FY} 5+50 \% \mathrm{Ni} / \mathrm{Al}_{2} \mathrm{O}_{3}$ catalyst consumed $4.6 \mathrm{~kW} \mathrm{~h} / \mathrm{m}^{3}$ of $\mathrm{H}_{2}$ produced; FY5 means coconut 
shell-derived activated carbon. Tian et al. (2019) reported that the energy consumption for $\mathrm{CO}_{2}$ utilization in a conventional furnace reactor is $682 \mathrm{~kJ} / \mathrm{mol}$. Table 7 compares the energy consumption in the dry reforming of methane with different heating sources. A comparison within the bibliographic data is almost impossible as their experimental conditions are far different.

Scaling up of dry reforming process is inevitable in the coming years. Hence, the relevance of microwave-assisted dry reforming of methane in the large scale over conventional methods is yet to prove on a case-to-case basis, considering equipment design, radiation frequency, mode of heating, specific power, energy balance, and energy losses through the reactor wall (Bermudez et al. 2015). It could be suggested to start with simulation studies using basic tools such as ASPEN in order to compare mass and energy balance of the conventional dry reforming of methane and microwave-assisted DRM. PINCH analysis could be also used to optimize and compare energy consumption of these reforming processes. Microwave heating exhibits exclusive advantages over conventional heating. However, it is worth to consider that the energy saving in microwave-assisted catalytic synthesis reactions are connected to the shortened reaction time, not any of the microwave features (Razzaq and Kappe 2008). Hence, such shortening of reaction time in the reforming experiments has many challenges. It demands to develop suitable catalysts capable of reforming feed gases at high flow rates too. All the while, the energy consumption in the microwave-assisted reforming is reliant on the efficiency of microwave susceptor (Razzaq and Kappe 2008). So, the development of efficient susceptor capable of stable feed conversion at high flow would be a breakthrough in the industrialization of microwave reforming.

\section{Conclusion}

As an alternative to the steam reforming of methane which is a well-established industrial process for syngas production, the dry reforming of methane has shown various environmental benefits since it converts greenhouse gases, especially non-combustible $\mathrm{CO}_{2}$, into syngas as high-value platform chemicals. However, in order to be more competitive, the dry reforming of methane system must be improved both in terms of energy consumption and catalytic performance. Being assisted by microwave heating, which exhibits exclusive advantages over conventional one, the dry reforming of methane has given rise to promising results, thus deserved to be investigated deeply. There are several potential avenues to explore further microwave-assisted DRM; thus, the following outlooks are pointed out:

Table 7 A comparison on energy consumption in methane dry reforming with various heating sources

\begin{tabular}{|c|c|c|c|c|c|c|}
\hline Catalyst/MW susceptor & Heating source & Feed flow & $\mathrm{H}_{2}: \mathrm{CO}$ ratio & Supplied power & Energy consumption & References \\
\hline FY5 & Microwave & $0.72 \mathrm{~kg} / \mathrm{h}^{\mathrm{a}}$ & $2: 3$ & $84.4 \mathrm{~kW}$ & $44.4 \mathrm{~kW} \mathrm{~h} / \mathrm{m}^{3 \mathrm{~b}}$ & $\begin{array}{l}\text { Fidalgo and Menéndez } \\
\text { (2012) }\end{array}$ \\
\hline $\mathrm{FY} 5+\mathrm{Ni} / \mathrm{Al}_{2} \mathrm{O}_{3}$ & Microwave & $0.72 \mathrm{~kg} / \mathrm{h}$ & $1: 1$ & $8.3 \mathrm{~kW}$ & $4.6 \mathrm{~kW} \mathrm{~h} / \mathrm{m}^{3 \mathrm{~b}}$ & $\begin{array}{l}\text { Fidalgo and Menéndez } \\
\text { (2012) }\end{array}$ \\
\hline Bio-char & Microwave & $1 \mathrm{~m}^{3} / \mathrm{h}^{\mathrm{a}}$ & $1: 1.1$ & $13.2 \mathrm{~kW}$ & $4.14 \mathrm{~kW} \mathrm{~h} / \mathrm{m}^{3 \mathrm{c}}$ & Li et al. $(2018 a, b)$ \\
\hline HyProGen R-70 & Microwave & $30 \mathrm{~L} / \mathrm{min}$ & $0.25: 1.5$ & $3 \mathrm{~kW}$ & $59.1 \mathrm{~g} / \mathrm{kWh}^{\mathrm{b}}$ & Chun et al. (2019) \\
\hline Ni/bio-char & Microwave & $1.2 \mathrm{~L} / \mathrm{h} / \mathrm{g}$ & $1: 1.5$ & $12.8 \mathrm{~kW} / \mathrm{kg}$ & $7.9 \mathrm{~kW} / \mathrm{hm}^{3 \mathrm{c}}$ & Li et al. (2017) \\
\hline- & $\begin{array}{l}\text { Microwave plasma } \\
\text { torch }\end{array}$ & & $1: 1$ & $6 \mathrm{~kW}$ & $41.4 \mathrm{~g} / \mathrm{kWh}^{\mathrm{b}}$ & Chun et al. (2017) \\
\hline- & $\begin{array}{l}\text { Gliding arc discharge } \\
\text { plasma }\end{array}$ & 12.7 SL/min & $1: 1$ & $5.91 \mathrm{kV}$ & $3.2 \mathrm{eV}$ & Bo et al. (2008) \\
\hline $\mathrm{CaO}-\mathrm{Ni}$ (looping) & Electric furnace & - & $1: 0.9$ & - & $534.8 \mathrm{~kJ} / \mathrm{mol}$ & Tian et al. (2019) \\
\hline $\mathrm{CaO}-\mathrm{Ni}$ & Electric furnace & - & $1: 1$ & - & $682 \mathrm{~kJ} / \mathrm{mol}^{\mathrm{d}}$ & Tian et al. (2019) \\
\hline- & Plasma & $50 \mathrm{~mL} / \mathrm{min}$ & - & $30 \mathrm{~W}$ & $0.14 \mathrm{mmol} / \mathrm{kJ}$ & Tu and Whitehead (2012) \\
\hline $\mathrm{Ni} /-\mathrm{Al}_{2} \mathrm{O}_{3}$ & Plasma & $50 \mathrm{~mL} / \mathrm{min}$ & - & $30 \mathrm{~W}$ & $0.32 \mathrm{mmol} / \mathrm{kJ}$ & Tu and Whitehead (2012) \\
\hline- & DBD & $200 \mathrm{~mL} / \mathrm{min}$ & - & $50 \mathrm{~W}$ & $5.47 \mathrm{~g} / \mathrm{kWh}^{\mathrm{b}}$ & Dors et al. (2012) \\
\hline
\end{tabular}

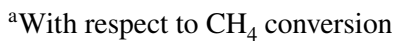

${ }^{\mathrm{b}}$ With respect to produced $\mathrm{H}_{2}$

${ }^{\mathrm{c}}$ With respect to produced syn-gas

${ }^{\mathrm{d}}$ With respect to $\mathrm{CO}_{2}$ conversion 
(1) The existence of microplasmas was found to be responsible for facilitating some preferred catalytic reactions, such as $\mathrm{CH}_{4}$ dissociation and $\mathrm{CO}_{2}$ gasification. Although it is well-established that the main reactions of the dry reforming of methane are favourable at high temperature, low pressure and a low molar ratio of $\mathrm{CH}_{4} / \mathrm{CO}_{2}$, there is a need to develop the thermodynamic equilibrium models which take into account the formation of hotspots or microplasmas to provide improved estimates of overall efficiencies.

(2) Many studies on the microwave-assisted DRM have been focused on the carbon-based catalysts due to their reasonable catalytic and dielectric properties. However, the formation of coke which causes severe blockage of active sites and disappearance of carbonaceous catalytic materials due to the $\mathrm{CO}_{2}$ gasification reaction seems to be unavoidable during the reforming process. Thus, there remains scope to further increase the performance and stability of carbon-based catalysts by altering the operational conditions so that carbon produced will be consumed immediately.

(3) Due to its high magnetic loss tangent and well-established catalytic properties towards the dry reforming of methane, Ni-based catalysts deserve to be studied more thoroughly. Although metal is classified as a microwave reflector, it can be effectively heated by microwave as long as its particle is fine enough compared to its penetration depths. Since most of microwave susceptors have low surface area whereas porous supports are transparent, it also worth noting that a transparent material will become more lossy to be able to absorb microwaves at a higher temperature. Therefore, there is some potential to maximize the performance of Ni-based catalysts on microwave-assisted DRM: (1) increasing the amount of fine (nano-size) Ni particles coated on the micro- or mesoporous materials, which have been widely employed as the effective supports for the conventional dry reforming of methane, as much as possible to improve their microwave absorbing ability; (2) mixing any effective Ni-based catalyst with high lossy materials such as $\mathrm{SiC}$; and (3) combining these two approaches to form a two-way heating: conventional heating from the surface by susceptor-generated thermal radiation and microwave heating from the centre, resulting in more uniform heating.

(4) Any material that can act efficiently as both catalyst for the conventional dry reforming of methane and microwave susceptor may exhibit excellent activity for microwave-assisted DRM. High lossy materials such as metal carbides, perovskites and ferrites, which have been proved to have outstanding catalytic activity and stability for the dry reforming of methane, deserve to be employed in microwave-assisted DRM according to this approach.

(5) The prospect of actual application of an alternative technology depends on many factors that are inherently related to the equipment design and process optimization, such as the energy efficiency, the potential scalability, and the benefits of the alternative technology compared to the conventional one. The development of microwave equipment for different heating purposes is in progress, ranging from the commercial to the conceptual stage. Drawing from this related area may lead to an approach for improving the design and scale-up of a microwave-assisted reforming system.

(6) Further simulation and experimental works need to be done to optimize and compare energy consumption as well as the overall efficiency of the conventional and microwave-assisted reforming processes. It could be suggested to start with simulation studies using basic tools such as ASPEN in order to compare mass and energy balance of the conventional dry reforming of methane and microwave-assisted DRM. PINCH analysis could be also used to optimize and compare the energy consumption of these reforming processes. Comparison should be experimentally validated on a case-to-case basis, keeping the same operating conditions such as, reactor design, catalysts used, reaction temperature, gas hourly space velocity, and reactant composition.

Acknowledgements A part of this work is funded by Vietnam National Foundation for Science and Technology Development (NAFOSTED) under Grant Number "104.05-2019.344" for the project entitled "Syngas generation from bi-reforming of biomass-derived feedstocks using microwave-enhanced reactor". A part of this work was financially supported by The Japan Society for the Promotion of Science (JSPS) for Grant-Aid for Challenging Research (Pioneering) (17H06225). The authors are also grateful to the Cooperative Research Program of Network Joint Research Center for Materials and Devices that has been supported by Ministry of Education, Culture, Sports, Science, and Technology (MEXT), Japan.

\section{References}

Abdullah B, Abd Ghani NA, Vo DVN (2017) Recent advances in dry reforming of methane over Ni-based catalysts. J Clean Prod 162:170-185. https://doi.org/10.1016/j.jclepro.2017.05.176

Abdulrasheed A, Jalil AA, Gambo Y, Ibrahima M, Hambali HU, Hamid HYS (2019) A review on catalyst development for dry reforming of methane to syngas: recent advances. Renew Sustain Energy Rev 108:175-193. https://doi.org/10.1016/j.rser.2019.03.054

Alia S, Khader MM, Almarri MJ, Abdelmoneim AG (2020) Ni-based nano-catalysts for the dry reforming of methane. Catal Today 343:26-37. https://doi.org/10.1016/j.cattod.2019.04.066

Antunes E, Jacob MV, Brodie G, Schneider PA (2018) Microwave pyrolysis of sewage biosolids: dielectric properties, microwave 
susceptor role and its impact on biochar properties. J Anal Appl Pyrol 129:93-100. https://doi.org/10.1016/j.jaap.2017.11.023

Aramouni NAK, Touma JG, Tarboush BA, Zeaiter J, Ahmad MN (2018) Catalyst design for dry reforming of methane: analysis review. Renew Sustain Energy Rev 82:2570-2585. https://doi. org/10.1016/j.rser.2017.09.076

Aravind S, Kumar PS, Kumar NS, Siddarth N (2020) Conversion of green algal biomass into bioenergy by pyrolysis. A review. Environ Chem Lett 18:829-849. https://doi.org/10.1007/s1031 1-020-00990-2

Arora S, Prasad R (2016) An overview on dry reforming of methane: strategies to reduce carbonaceous deactivation of catalysts. RSC Adv 6:108668-108688. https://doi.org/10.1039/C6RA20450C

Atwater J, Wheeler R (2004) Temperature dependent complex permittivities of graphitized carbon blacks at microwave frequencies between 0.2 and $26 \mathrm{GHz}$. J Mater Sci 39:151-157. https://doi. org/10.1023/B:JMSC.0000007739.07797.08

Balajii M, Niju S (2019) Biochar-derived heterogeneous catalysts for biodiesel production. Environ Chem Lett 17:1-23. https://doi. org/10.1007/s10311-019-00885-x

Barbosa-Canovas GV, Ibarz A (2014) Introduction to food process engineering. CRC Press, Boca Raton

Benedito A, Galindo B, Hare C, Morgan L, Bayerl T, Mitschang P (2012) Selective heating applications for the processing of polymer-polymer materials. In: Proceedings of the 15th European conference on composite materials (ECCM-15), Venice, Italy

Beneroso D, Fidalgo B (2016) Microwave technology for syngas production from renewable sources. In: Myers R (ed) Syngas: production, emerging technologies and ecological impacts. Nova Science Publishers, Hauppauge, NY (USA), pp 117-152

Benrabaa R, Löfberg A, Rubbens A, Bordes-Richard E, Vannier RN, Barama A (2013) Structure, reactivity and catalytic properties of nanoparticles of nickel ferrite in the dry reforming of methane. Catal Today 203:188-195. https://doi.org/10.1016/j.catto d.2012.06.002

Bermudez JM, Fidalgo B, Arenillas A, Menéndez JA (2012) Mixtures of steel-making slag and carbons as catalyst for microwaveassisted dry reforming of $\mathrm{CH}_{4}$. Chin J Catal 33:1115-1118. https ://doi.org/10.1016/S1872-2067(11)60386-0

Bermudez JM, Beneroso D, Rey-Raap N, Arenillas A, Menéndez JA (2015) Energy consumption estimation in the scaling-up of microwave heating processes. Chem Eng Process Process Intensif 95:1-8. https://doi.org/10.1016/j.cep.2015.05.001

Bhaskar A, Chang TH, Chang HY, Cheng SY (2007) Low-temperature crystallization of sol-gel-derived lead zirconate titanate thin films using $2.45 \mathrm{GHz}$ microwaves. Thin Solid Films 515:28912896. https://doi.org/10.1016/j.tsf.2006.08.044

Bhattacharya M, Basak T (2016) A review on the susceptor assisted microwave processing of materials. Energy 97:306-338. https:// doi.org/10.1016/j.energy.2015.11.034

Bo Z, Yan J, Li X, Chi Y, Cen K (2008) Plasma assisted dry methane reforming using gliding arc gas discharge: effect of feed gases proportion. Int J Hydrog Energy 33:5545-5553. https://doi. org/10.1016/j.ijhydene.2008.05.101

BP Statistical Review of World Energy (2019) 68th edition. https:// www.bp.com/en/global/corporate/energy-economics/statistica l-review-of-world-energy.html. Accessed 15 June 2020

Cao Z, Yoshikawa N, Taniguchi S (2010) Microwave heating behaviors of $\mathrm{Si}$ substrate materials in a single-mode cavity. Mater Chem Phys 124:900-903. https://doi.org/10.1016/j.matchemphy s.2010.08.004

Chein RY, Chen YC, Yu CT, Chung JN (2015) Thermodynamic analysis of dry reforming of $\mathrm{CH}_{4}$ with $\mathrm{CO}_{2}$ at high pressures. J Nat Gas Chem 26:617-629. https://doi.org/10.1016/j.jngse.2015.07.001

Chen MQ, Wang J, Zhang MX, Chen MG, Zhu XF, Min FF, Tan ZC (2008) Catalytic effects of eight inorganic additives on pyrolysis of pine wood sawdust by microwave heating. J Anal Appl Pyrol 82:145-150. https://doi.org/10.1016/j.jaap.2008.03.001

Chen W, Sheng W, Cao F, Lu Y (2012) Microfibrous entrapment of Ni/ $\mathrm{Al}_{2} \mathrm{O}_{3}$ for dry reforming of methane: heat/mass transfer enhancement towards carbon resistance and conversion promotion. Int $\mathrm{J}$ Hydrog Energy 37(23):18021-18030. https://doi.org/10.1016/j. ijhydene.2012.09.080

Cheng J, Roy R, Agrawal D (2001) Experimental proof of major role of magnetic field losses in microwave heating of metal and metallic composites. J Mater Sci Lett 20:1561-1563. https://doi. org/10.1023/A:1017900214477

Cheng J, Roy R, Agrawal D (2002) Radically different effects on materials by separated microwave electric and magnetic fields. Mater Res Innov 5:170-177. https://doi.org/10.1007/s1001 9-002-8642-6

Chun SM, Hong YC, Choi DH (2017) Reforming of methane to syn-gas in a microwave plasma torch at atmospheric pressure. J CO2 Util 19:221-229. https://doi.org/10.1016/j.jcou.2017.03.016

Chun SM, Shin DH, Ma SH, Yang GW, Hong YC (2019) $\mathrm{CO}_{2}$ Microwave plasma-catalytic reactor for efficient reforming of methane to syngas. Catalysts 9(3):292. https://doi.org/10.3390/catal90302 92

De Caprariis B, De Filippis P, Petrullo A, Scarsella M (2015) Methane dry reforming over nickel perovsikite catalysts. Chem Eng Trans 43:991-996. https://doi.org/10.3303/CET1543166

Domínguez A, Fernández Y, Fidalgo B, Pis JJ, Menéndez JA (2007a) Biogas to syngas by microwave-assisted dry reforming in the presence of char. Energy Fuels 21:2066-2071. https://doi. org/10.1021/ef070101j

Domínguez A, Fidalgo B, Fernández Y, Pis JJ, Menéndez JA (2007b) Microwave-assisted catalytic decomposition of methane over activated carbon for $\mathrm{CO}_{2}$-free hydrogen production. Int $\mathrm{J}$ Hydrog Energy 32:4792-4799. https://doi.org/10.1016/j.ijhyd ene.2007.07.041

Dors M, Izdebski T, Berendt A, Mizeraczyk J (2012) Hydrogen production via biomethane reforming in DBD reactor. Int J Plasma Environ Sci Technol 6:93-97. https://doi.org/10.34343/ijpes t.2012.06.02.093

Durka T, Van Gerven T, Stankiewicz A (2009) Microwaves in heterogeneous gas-phase catalysis: experimental and numerical approaches. Chem Eng Technol 32:1301-1312. https://doi. org/10.1002/ceat.200900207

Durka T, Stefanidis GD, Van Gerven T, Stankiewicz AI (2011) Microwave-activated methanol steam reforming for hydrogen production. Int J Hydrog Energy 36:12843-12852. https://doi. org/10.1016/j.jjhydene.2011.07.009

Ellison C, McKeown M, Trabelsi S, Boldor D (2017) Dielectric properties of biomass/biochar mixtures at microwave frequencies. Energies 10:502. https://doi.org/10.3390/en10040502

Eskilsson CS, Björklund E (2000) Analytical-scale microwaveassisted extraction. J Chromatogr A 902(1):227-250. https:// doi.org/10.1016/S0021-9673(00)00921-3

Estel L, Poux M, Benamara N, Polaert I (2017) Continuous flowmicrowave reactor: Where are we? Chem Eng Proc Proc Intensif 113:56-64. https://doi.org/10.1016/j.cep.2016.09.022

Fidalgo B, Menéndez JA (2012) Study of energy consumption in a laboratory pilot plant for the microwave-assisted $\mathrm{CO}_{2}$ reforming of $\mathrm{CH}_{4}$. Fuel Proc Technol 95:55-61. https://doi.org/10.1016/j. fuproc.2011.11.012

Fidalgo B, Menéndez JA (2013) Syngas production by $\mathrm{CO}_{2}$ reforming of $\mathrm{CH}_{4}$ under microwave heating-challenges and opportunities. In: Indarto A, Palguandi J (eds) Syngas: production, applications and environmental impact. Nova Science Publisher, New York, pp 121-149

Fidalgo B, Domínguez A, Pis J, Menéndez JA (2008) Microwave-assisted dry reforming of methane. Int J Hydrog 
Energy 33(16):4337-4344. https://doi.org/10.1016/j.ijhyd ene.2008.05.056

Fidalgo B, Arenillas A, Menéndez JA (2010) Influence of porosity and surface groups on the catalytic activity of carbon materials for the microwave-assisted $\mathrm{CO}_{2}$ reforming of $\mathrm{CH}_{4}$. Fuel 89:40024007. https://doi.org/10.1016/j.fuel.2010.06.015

Fidalgo B, Arenillas A, Menéndez JA (2011) Mixtures of carbon and $\mathrm{Ni} / \mathrm{Al}_{2} \mathrm{O}_{3}$ as catalysts for the microwave-assisted $\mathrm{CO}_{2}$ reforming of $\mathrm{CH}_{4}$. Fuel Proc Technol 92:1531-1536. https://doi. org/10.1016/j.fuproc.2011.03.015

Fischer VF, Tropsch H (1928) Conversion of methane into hydrogen and carbon monoxide. Brennstoff-Chemie 3(9):39-46

Gabriel C, Gabriel S, Grant EH, Grant EH, Halstead BSI, Mingos DMP (1998) Dielectric parameters relevant to microwave dielectric heating. Chem Soc Rev 27:213-224. https://doi.org/10.1039/ A827213Z

Gangurde LS, Sturm GS, Devadiga TJ, Stankiewicz AI, Stefanidis AD (2017) Complexity and challenges in noncontact high temperature measurements in microwave-assisted catalytic reactors. Ind Eng Chem Res 56:13379-13391. https://doi.org/10.1021/acs. iecr.7b02091

Gangurde LS, Sturm GSJ, Valero-Romero MJ, Mallada R, Santamaria J, Stankiewicz AI, Stefanidisad GD (2018) Synthesis, characterization, and application of ruthenium-doped $\mathrm{SrTiO}_{3}$ perovskite catalysts for microwave-assisted methane dry reforming. Chem Eng Proc Proc Intensif 127:178-190. https://doi.org/10.1016/j. cep.2018.03.024

Giguere RJ, Bray TL, Duncan SM, Majetich G (1986) Application of commercial microwave ovens to organic synthesis. Tetrahedron Lett 27(41):4945-4948. https://doi.org/10.1016/S0040 $-4039(00) 85103-5$

Grouset D, Ridart C (2018) Lowering energy spending and costs for hydrogen transportation and distribution. In: Azzaro-Pantel C (ed) Hydrogen supply chain: design, deployment and operation, 1st edn. Elsevier, Academic Press, pp 207-270. https://doi. org/10.1016/B978-0-12-811197-0.00006-3

Guler M, Dogu T, Varisli D (2017) Hydrogen production over molybdenum loaded mesoporous carbon catalysts in microwave heated reactor system. Appl Catal B Environ 219:173-182. https://doi. org/10.1016/j.apcatb.2017.07.043

Gündüz S, Dogu T (2015) Hydrogen by steam reforming of ethanol over $\mathrm{Co}-\mathrm{Mg}$ incorporated novel mesoporous alumina catalysts in tubular and microwave reactors. Appl Catal B Environ 168169:497-508. https://doi.org/10.1016/j.apcatb.2015.01.006

Gupta M, Leong EWW (2008) Microwaves and metals. Wiley, Hoboken

Hamzehlouia S, Jaffer SA, Chaouki J (2018) Microwave heatingassisted catalytic dry reforming of methane to syngas. Sci Rep 8:8940. https://doi.org/10.1038/s41598-018-27381-6

Haneishi N, Tsubaki S, Maitani MM, Suzuki E, Fujii S, Wada Y (2017) Electromagnetic and heat-transfer simulation of the catalytic dehydrogenation of ethylbenzene under microwave irradiation. Ind Eng Chem Res 56:7685-7692. https://doi.org/10.1021/acs. iecr.7b01413

Haque KE (1999) Microwave energy for mineral treatment processes-a brief review. Int J Miner Proc 57:1-24. https://doi.org/10.1016/ S0301-7516(99)00009-5

Hashisho Z, Rood MJ, Barot S, Bernhard J (2009) Role of functional groups on the microwave attenuation and electric resistivity of activated carbon fiber cloth. Carbon 47:1814-1823. https://doi. org/10.1016/j.carbon.2009.03.006

Hassan NS, Jalil AA, Hitam CNC, Vo DVN, Nabgan W (2020) Biofuels and renewable chemicals production by catalytic pyrolysis of cellulose: a review. Environ Chem Lett. https://doi.org/10.1007/ s10311-020-01040-7
Hawangchu Y, Atong D, Sricharoenchaikul V (2010) Enhanced microwave induced thermochemical conversion of waste glycerol for syngas production. Int J Chem React Eng. https://doi. org/10.2202/1542-6580.2187

Herminio T, Cesário MR, Silva VD, Simões TA, Medeiros ES, Macedo DA, Tidahy HL, Gennequin C, Abi-Aad E (2020) $\mathrm{CO}_{2}$ reforming of methane to produce syngas using anti-sintering carbon-resistant $\mathrm{Ni} / \mathrm{CeO}_{2}$ fibers produced by solution blow spinning. Environ Chem Lett 18:1-9. https://doi.org/10.1007/s10311-020-00968-0

Higman C (2017) GSTC Syngas Database: 2017 Update. In: Gasification \& Syngas Technologies Conference, Colorado Springs. https://www.globalsyngas.org/uploads/downloads/keynote\%20 tuesday $\% 20$ eve $\% 20$ Higman.pdf. Accessed 22 July 2020

Hogan PF, Mori T (1990) Development of a method of continuous temperature measurement for microwave denture processing. Dental Mater J 9:1-11. https://doi.org/10.4012/dmj.9.1

Hoogenboom R, Schubert US (2007) Microwave-assisted polymer synthesis: Recent developments in a rapidly expanding field of research. Macromol Rapid Commun 28:368-386. https://doi. org/10.1002/marc.200600749

Horikoshi S, Sumi T, Serpone N (2012) Unusual effect of the magnetic field component of the microwave radiation on aqueous electrolyte solutions. J Microw Power Electromagn Energy 46:215-228. https://doi.org/10.1080/08327823.2012.11689838

Horikoshi S, Schiffmann RF, Fukushima J, Serpone N (2018) Microwave chemical and materials processing. Springer, Berlin

Hotta M, Hayashi M, Lanagan MT, Agrawal DK, Nagata K (2011) Complex permittivity of graphite, carbon black and coal powders in the ranges of X-band frequencies (8.2 to $12.4 \mathrm{GHz})$ and between 1 and $10 \mathrm{GHz}$. ISIJ Int 51:1766-1772. https://doi. org/10.2355/isijinternational.51.1766

Jain S, Newman D, Nzihou A, Dekker H, Le Feuvre H, Richter H, Gobe F, Morton C, Thompson R (2019) Global potential of biogas. World Biogas Association, London

Janezic MD, Paulter N, Blendell J (2001) Dielectric and conductorloss characterization and measurements on electronic packaging materials. NIST technical note, vol 1520

Jang WJ, Jshim JO, Kim HM, Yoo SY, Roh HS (2019) A review on dry reforming of methane in aspect of catalytic properties. Catal Today 324:15-26. https://doi.org/10.1016/j.cattod.2018.07.032

Jones DA, Lelyveld T, Mavrofidis S, Kingman S, Miles N (2002a) Microwave heating applications in environmental engineering-a review. Res Conserv Recycl 34(2):75-90. https://doi. org/10.1016/S0921-3449(01)00088-X

Jones DA, Lelyveld TP, Mavrofidis SD, Kingman SW, Miles NJ (2002b) Microwave heating applications in environmental engineering-a review. Res Conserv Recycl 34:75-90. https://doi. org/10.1016/S0921-3449(01)00088-X

Julian I, Pedersen CM, Achkasov K, Hueso JL, Hellstern HL, Silva H, Mallada R, Davis ZJ, Santamaria J (2019) Overcoming stability problems in microwave-assisted heterogeneous catalytic processes affected by catalyst coking. Catalysts 9:867. https:// doi.org/10.3390/catal9100867

Kathiraser Y, Oemar U, Saw ET, Li Z, Kawi S (2015) Kinetic and mechanistic aspects for $\mathrm{CO}_{2}$ reforming of methane over $\mathrm{Ni}$ based catalysts. Chem Eng J 278:62-78. https://doi.org/10.1016/j. cej.2014.11.143

Kingman SM, Jackson K, Bradshaw SM, Rowson NA, Greenwood R (2004) An investigation into the influence of microwave treatment on mineral ore comminution. Powder Technol 146:176184. https://doi.org/10.1016/j.powtec.2004.08.006

Komarneni S, Roy R, Li QH (1992) Microwave-hydrothermal synthesis of ceramic powders. Mater Res Bull 27:1393-1405. https://doi. org/10.1016/0025-5408(92)90004-J 
Lavoie JM (2014) Review on dry reforming of methane, a potentially more environmentally-friendly approach to the increasing natural gas exploitation. Front Chem 2:1-17. https://doi.org/10.3389/ fchem.2014.00081

Li Y, Wang Y, Zhang X, Mi Z (2008) Thermodynamic analysis of autothermal steam and $\mathrm{CO}_{2}$ reforming of methane. Int $\mathrm{J}$ Hydrog Energy 33:2507-2514. https://doi.org/10.1016/j.ijhyd ene.2008.02.051

Li L, Song Z, Li Z, Zhao X, Ma C (2011) Microwave-assisted reforming of $\mathrm{CH}_{4}$ with $\mathrm{CO}_{2}$ over activated carbon. In: 2011 Asia-Pacific power and energy engineering conference, pp 1-4

Li L, Jiang X, Wang H, Wang J, Song Z, Zhao X, Ma C (2017) Methane dry and mixed reforming on the mixture of bio-char and nickel-based catalyst with microwave assistance. J Anal Appl Pyrol 125:318-327. https://doi.org/10.1016/j.jaap.2017.03.009

Li L, Chen J, Yan K, Qin X, Feng T, Wang J, Wang F, Song Z (2018a) Methane dry reforming with microwave heating over carbonbased catalyst obtained by agriculture residues pyrolysis. J CO2 Util 28:41-49. https://doi.org/10.1016/j.jcou.2018.09.010

Li L, Yang Z, Chen J, Qin X, Jiang X, Wang F, Song Z, Ma C (2018b) Performance of bio-char and energy analysis on $\mathrm{CH}_{4}$ combined reforming by $\mathrm{CO}_{2}$ and $\mathrm{H}_{2} \mathrm{O}$ into syngas production with assistance of microwave. Fuel 215:655-664. https://doi.org/10.1016/j. fuel.2017.11.107

Li L, Yan K, Chen J, Feng T, Wang F, Wang J, Song Z, Ma C (2019) Fe-rich biomass derived char for microwave-assisted methane reforming with carbon dioxide. Sci Total Environ 657:13571367. https://doi.org/10.1016/j.scitotenv.2018.12.097

Lim MS, Chun YN (2017) Biogas to syngas by microwave-assisted reforming in the presence of char. Energy Fuels 31:1376113768. https://doi.org/10.1021/ef070101j

Liu K, Song C, Subramani V (2009) Hydrogen and syngas production and purification technologies. Wiley, Hoboken

Liu S, Zhang Y, Tuo K, Wang L, Chen G (2018) Structure, electrical conductivity, and dielectric properties of semi-coke derived from microwave-pyrolyzed low-rank coal. Fuel Proc Technol 178:139147. https://doi.org/10.1016/j.fuproc.2018.05.028

Lovell EC, Scott J, Amal R (2015) $\mathrm{Ni}-\mathrm{SiO}_{2}$ catalysts for the carbon dioxide reforming of methane: varying support properties by flame spray pyrolysis. Molecules 20:4594-4609. https://doi. org/10.3390/molecules20034594

Mandal V, Mohan Y, Hemalatha S (2007) Microwave assisted extraction-an innovative and promising extraction tool for medicinal plant research. Pharmacogn Rev 1(1):7-18

McMillan P, Partridge G (1972) The dielectric properties of certain $\mathrm{ZnO}-\mathrm{Al}_{2} \mathrm{O}_{3}-\mathrm{SiO}_{2}$ glass-ceramics. J Mater Sci 7:847-855. https ://doi.org/10.1007/BF00550431

Meloni E, Martino M, Palma V (2020) A short review on Ni based catalysts and related engineering issues for methane steam reforming. Catalysts 10(3):352. https://doi.org/10.3390/catal10030352

Menéndez JA, Arenillas A, Fidalgo B, Fernández Y, Zubizarreta L, Calvo EG, Bermúdez JM (2010) Microwave heating processes involving carbon materials. Fuel Proc Technol 91:1-8. https:// doi.org/10.1016/j.fuproc.2009.08.021

Meredith RJ (1998) Engineers' handbook of industrial microwave heating. IET, The Institution of Electrical Engineers, London

Metaxas AC, Meredith RJ (1983) Industrial microwave heating. IET, London

Mingos DMP, Baghurst DR (1991) Applications of microwave dielectric heating effects to synthetic problems in chemistry, microwave-enhanced chemistry. Chem Soc Rev 20:1-47. https://doi. org/10.1039/CS9912000001

Motasemi F, Afzal MT (2013) A review on the microwave-assisted pyrolysis technique. Renew Sustain Energy Rev 28:317-330. https://doi.org/10.1016/j.rser.2013.08.008
Muraza O, Galadima A (2015) A review on coke management during dry reforming of methane. Int J Energy Res 39(9):1196-1216. https://doi.org/10.1002/er.3295

Nematollahi B, Rezaei M, Lay EN, Khajenoori M (2012) Thermodynamic analysis of combined reforming process using Gibbs energy minimization method: in view of solid carbon formation. J Nat Gas Chem 21:694-702. https://doi.org/10.1016/S1003 -9953(11)60421-0

Nguyen PHD, Le Nguyen KT, Nguyen TTN, Duong NL, Hoang TC, Pham TTP, Vo DVN (2019) Application of microwave-assisted technology: a green process to produce ginger products without waste. J Food Proc Eng 42:e12996. https://doi.org/10.1111/ jfpe. 12996

Nguyen HM, Sunarsoc J, Lia C, Pham GH, Phan C, Liu S (2020) Microwave-assisted catalytic methane reforming: a review. Appl Catal A Gen 599:117620. https://doi.org/10.1016/j.apcat a.2020.117620

Nightingale S (2001) Interfacial phenomena in microwave sintering. Ionics 7:327-331. https://doi.org/10.1007/BF02373566

Nikoo MK, Amin NAS (2011) Thermodynamic analysis of carbon dioxide reforming of methane in view of solid carbon formation. Fuel Process Technol 92:678-691. https://doi.org/10.1016/j. fuproc.2010.11.027

Nüchter M, Ondruschka B, Bonrath W, Gum A (2004) Microwave assisted synthesis-a critical technology overview. Green Chem 6(3):128-141. https://doi.org/10.1039/B310502D

Odedairo T, Ma J, Chen J, Wang S, Zhu Z (2016) Influences of doping $\mathrm{Cr} / \mathrm{Fe} / \mathrm{Ta}$ on the performance of $\mathrm{Ni} / \mathrm{CeO}_{2}$ catalyst under microwave irradiation in dry reforming of $\mathrm{CH}_{4}$. J Solid State Chem 233:166-177. https://doi.org/10.1016/j.jssc.2015.10.025

Ojeda-Niño OH, Gracia F, Daza C (2019) Role of Pr on Ni-Mg-Al mixed oxides synthesized by microwave-assisted self-combustion for dry reforming of methane. Ind Eng Chem Res 58:7909-7921. https://doi.org/10.1021/acs.iecr.9b00557

Pashchenko D (2017) Thermodynamic equilibrium analysis of combined dry and steam reforming of propane for thermochemical waste-heat recuperation. Int J Hydrog Energy 42:14926-14935. https://doi.org/10.1016/j.ijhydene.2017.04.284

Peng Z, Hwang JY, Kim BG, Mouris J, Hutcheon R (2012) Microwave absorption capability of high volatile bituminous coal during pyrolysis. Energy Fuels 26:5146-5151. https://doi.org/10.1021/ ef300914f

Peng K, Zhou J, Xu W, You Z, Long W, Xiang M, Luo M (2017) Microwave irradiation-selective catalytic reduction of $\mathrm{NO}$ to $\mathrm{N}_{2}$ by activated carbon at low temperature. Energy Fuels 31:73447351. https://doi.org/10.1021/acs.energyfuels.7b01102

Pham Minh D, Phan TS, Grouset D, Nzihou A (2018) Thermodynamic equilibrium study of methane reforming with carbon dioxide, water and oxygen. J Clean Energy Technol 6:309-313. https:// doi.org/10.18178/JOCET.2018.6.4.480

Pham Minh D, Hernandez Torres A, Rego de Vasconcelos B, Siang TJ, Vo DVN (2020) Conversion of biogas to syngas via catalytic carbon dioxide reforming reactions: an overview of thermodynamic aspects, catalytic design, and reaction kinetics. In: Nanda S, Vo DVN, Sarangi PK (eds) Biorefinery of alternative resources: targeting green fuels and platform chemicals. Springer, Berlin, pp 427-456. https://doi.org/10.1007/978-981-15-1804-1_18

Protasov ON, Mamonov NA, Mikhailov MN, Kustov LM (2012) Optimization of equilibrium carbon dioxide methane reforming parameters by the gibbs free energy minimization method. Russ $\mathbf{J}$ Phys Chem A 86:741-746. https://doi.org/10.1134/S003602441 2050305

Qin Z, Chen J, Xie X, Luo X, Su T, Ji H (2020) $\mathrm{CO}_{2}$ reforming of $\mathrm{CH}_{4}$ to syngas over nickel-based catalysts. Environ Chem Lett 18:1-21. https://doi.org/10.1007/s10311-020-00996-w 
Qiu J, Qiu T (2015) Fabrication and microwave absorption properties of magnetite nanoparticle-carbon nanotube-hollow carbon fiber composites. Carbon 81:20-28. https://doi.org/10.1016/j. carbon.2014.09.011

Raje AP, Davis BH (1997) Fischer-Tropsch synthesis over ironbased catalysts in a slurry reactor. Reaction rates, selectivities and implications for improving hydrocarbon productivity. Catal Today 36(3):335-345. https://doi.org/10.1016/S0920 $-5861(96) 00245-3$

Razzaq T, Kappe CO (2008) On the energy efficiency of microwaveassisted organic reactions. Chemsuschem 1:123-132. https://doi. org/10.1002/cssc. 200700036

Rodriguez-Reinoso F (1998) The role of carbon materials in heterogeneous catalysis. Carbon 36:159-175. https://doi.org/10.1016/ S0008-6223(97)00173-5

Rosa R, Veronesi P, Casagrande A, Leonelli C (2016) Microwave ignition of the combustion synthesis of aluminides and field-related effects. J Alloys Compd 657:59-67. https://doi.org/10.1016/j. jallcom.2015.10.044

Rossi AS, Faria MG, Pereira MS, Ataíde CH (2017) Kinetics of microwave heating and drying of drilling fluids and drill cuttings. Dry Technol 35:1130-1140. https://doi.org/10.1080/07373 937.2016.1233425

Roy R, Peelamedu R, Grimes C, Cheng J, Agrawal D (2002) Major phase transformations and magnetic property changes caused by electromagnetic fields at microwave frequencies. J Mater Res 17:3008-3011. https://doi.org/10.1557/JMR.2002.0437

Salema AA, Yeow YK, Ishaque K, Ani FN, Afzal MT, Hassan A (2013) Dielectric properties and microwave heating of oil palm biomass and biochar. Ind Crops Prod 50:366-374. https://doi. org/10.1016/j.indcrop.2013.08.007

Sarıyer M, Bozdağ AA, Sezgi NA, Doğu T (2019) Performance comparison of microwave and conventionally heated reactors for sorption enhanced reforming of ethanol over $\mathrm{Ni}$ impregnated SBA-15. Chem Eng J 377:120138. https://doi.org/10.1016/j. cej.2018.10.075

Schiffmann RF, Steiner R (2012) Inexpensive microwave leakage detectors-are they worth it? (A performance evaluation report). J Microw Power Electromagn Energy 46:128-138. https://doi. org/10.1080/08327823.2012.11689831

Shah YT, Gardner TH (2014) Dry reforming of hydrocarbon feedstocks. Catal Rev 56:476-536. https://doi.org/10.1080/01614 940.2014.946848

Sheshko TF, Kryuchkova TA, Serov YM, Chislova IV, Zvereva IA (2017) New mixed perovskite-type $\mathrm{Gd}_{2-x} \mathrm{Sr}_{1+x} \mathrm{Fe}_{2} \mathrm{O}_{7}$ catalysts for dry reforming of methane, and production of light olefins. Catal Ind 9:162-169. https://doi.org/10.1134/S207005041702009X

Siang TJ, Singh S, Omoregbe O, Bach LG, Phuc NHH, Vo DVN (2018) Hydrogen production from $\mathrm{CH}_{4}$ dry reforming over bimetallic $\mathrm{Ni}-\mathrm{Co} / \mathrm{Al}_{2} \mathrm{O}_{3}$ catalyst. J Energy Inst 91:683-694. https://doi. org/10.1016/j.joei.2017.06.001

Stefanidis GD, Munoz AN, Sturm GS, Stankiewicz A (2014) A helicopter view of microwave application to chemical processes: reactions, separations, and equipment concepts. Rev Chem Eng 30:233-259. https://doi.org/10.1515/revce-2013-0033

Sun J, Wang W, Yue Q (2016) Review on microwave-matter interaction fundamentals and efficient microwave-associated heating strategies. Materials 9:231. https://doi.org/10.3390/ma9040231

Thostenson ET, Chou TW (1999) Microwave processing: fundamentals and applications. Compos Part A Appl Sci Manuf 30:1055-1071. https://doi.org/10.1016/S1359-835X(99)00020-2

Tian S, Yan F, Zhang Z, Jiang J (2019) Calcium-looping reforming of methane realizes in situ $\mathrm{CO}_{2}$ utilization with improved energy efficiency. Sci Adv 5:EAAV5077. https://doi.org/10.1126/sciad v.aav5077
Titirici MM, White RJ, Brun N, Budarin VL, Su DS, del Monte F, Clark JH, MacLachlan MJ (2015) Sustainable carbon materials. Chem Soc Rev 44:250-290. https://doi.org/10.1039/C4CS0 0232F

Tsang S, Claridge J, Green M (1995) Recent advances in the conversion of methane to synthesis gas. Catal Today 23(1):3-15. https://doi. org/10.1016/0920-5861(94)00080-L

Tu X, Whitehead JC (2012) Plasma-catalytic dry reforming of methane in an atmospheric dielectric barrier discharge: understanding the synergistic effect at low temperature. Appl Catal B Environ 125:439-448. https://doi.org/10.1016/j.apcat b.2012.06.006

Védrine JC (2005) Natural gas as feedstock. In: Derouane EG, Parmon V, Lemos F, Ramôa Ribeiro F (eds) Sustainable strategies for the upgrading of natural gas Fundamentals, challenges, and opportunities. NATO science series II: mathematics, physics and chemistry, vol 191. Springer, Dordrecht, pp 403-412

Verma P, Samanta SK (2018) Microwave-enhanced advanced oxidation processes for the degradation of dyes in water. Environ Chem Lett 16:969-1007. https://doi.org/10.1007/s10311-018-0739-2

Wang Y, Yao L, Wang S, Mao D, Hu C (2018) Low-temperature catalytic $\mathrm{CO}_{2}$ dry reforming of methane on Ni-based catalysts: a review. Fuel Process Technol 169:199-206. https://doi. org/10.1016/j.fuproc.2017.10.007

Wang P, Liu PA, Ye S (2019) Preparation and microwave absorption properties of $\mathrm{Ni}(\mathrm{Co} / \mathrm{Zn} / \mathrm{Cu}) \mathrm{Fe}_{2} \mathrm{O}_{4} / \mathrm{SiC} @ \mathrm{SiO}_{2}$ composites. Rare Met. https://doi.org/10.1007/s12598-016-0752-1

Wen F, Zhang F, Liu Z (2011) Investigation on microwave absorption properties for multiwalled carbon nanotubes $/ \mathrm{Fe} / \mathrm{Co} / \mathrm{Ni}$ nanopowders as lightweight absorbers. J Phys Chem C 115:14025-14030. https://doi.org/10.1021/jp202078p

Westphal WB, Sils A (1972) Dielectric constant and loss data. Massachusetts Institute of Technology, Cambridge

Wiesbrock F, Hoogenboom R, Schubert US (2004) Microwave-assisted polymer synthesis: state-of-the-art and future perspectives. Macromol Rapid Commun 25:1739-1764. https://doi.org/10.1002/ marc. 200400313

Will H, Scholz P, Ondruschka B (2004) Microwave-assisted heterogeneous gas-phase catalysis. Chem Eng Technol 27:113-122. https ://doi.org/10.1002/ceat.200401865

Xiong L, Yu M, Liu J, Li S, Xue B (2017) Preparation and evaluation of the microwave absorption properties of template-free graphene foam-supported Ni nanoparticles. RSC Adv 7:14733-14741. https://doi.org/10.1039/C6RA27435H

Xu W, Hu X, Xiang M, Luo M, Peng R, Lan L, Zhou J (2017a) Highly effective direct decomposition of $\mathrm{H} 2 \mathrm{~S}$ into $\mathrm{H} 2$ and $\mathrm{S}$ by microwave catalysis over $\mathrm{CoS}-\mathrm{MoS}_{2} / \gamma-\mathrm{Al}_{2} \mathrm{O}_{3}$ microwave catalysts. Chem Eng J 326:1020-1029. https://doi.org/10.1016/j. cej.2017.06.027

Xu W, Luo M, Peng R, Xiang M, Hu X, Lan L, Zhou J (2017b) Highly effective microwave catalytic direct decomposition of $\mathrm{H}_{2} \mathrm{~S}$ into $\mathrm{H}_{2}$ and $\mathrm{S}$ over MeS-based $(\mathrm{Me}=\mathrm{Ni}, \mathrm{Co})$ microwave catalysts. Energy Conver Manag 149:219-227. https://doi.org/10.1016/j. enconman.2017.07.029

Xu Y, Du XH, Li J, Wang P, Zhu J, Ge FJ, Zhou J, Song M, Zhu WY (2019) A comparison of $\mathrm{Al}_{2} \mathrm{O}_{3}$ and $\mathrm{SiO}_{2}$ supported Ni-based catalysts in their performance for the dry reforming of methane. J Fuel Chem Technol 47:199-208. https://doi.org/10.1016/S1872 -5813(19)30010-6

Yin P, Deng Y, Zhang L, Li N, Feng X, Wang J, Zhang Y (2018) Facile synthesis and microwave absorption investigation of activated carbon@ $\mathrm{Fe}_{3} \mathrm{O}_{4}$ composites in the low frequency band. RSC Adv 8:23048-23057. https://doi.org/10.1039/C8RA04141E

York AP, Xiao T, Green ML (2003) Brief overview of the partial oxidation of methane to synthesis gas. Top Catal 22(3-4):345-358. https://doi.org/10.1023/A:1023552709642 
Yoshikawa N, Ishizuka E, Taniguchi S (2006) Heating of metal particles in a single-mode microwave applicator. Mater Trans 47:898902. https://doi.org/10.2320/matertrans.47.898

Zhang X, Hayward DO (2006) Applications of microwave dielectric heating in environment-related heterogeneous gas-phase catalytic systems. Inorg Chim Acta 359:3421-3433. https://doi. org/10.1016/j.ica.2006.01.037

Zhang X, Hayward DO, Mingos DMP (1999) Apparent equilibrium shifts and hot-spot formation for catalytic reactions induced by microwave dielectric heating. Chem Commun. https://doi. org/10.1039/A901245A

Zhang X, Hayward DO, Lee C, Mingos DMP (2001) Microwave assisted catalytic reduction of sulfur dioxide with methane over $\mathrm{MoS}_{2}$ catalysts. Appl Catal B Environ 33:137-148. https://doi. org/10.1016/S0926-3373(01)00171-0

Zhang X, Hayward DO, Mingos DMP (2002) Dielectric properties of $\mathrm{MoS}_{2}$ and Pt catalysts: effects of temperature and microwave frequency. Catal Lett 84(3-4):225-233. https://doi. org/10.1023/A:1021488222243

Zhang X, Lee CSM, Mingos DMP, Hayward DO (2003) Carbon dioxide reforming of methane with Pt catalysts using microwave dielectric heating. Catal Lett 88:129-139. https://doi. org/10.1023/A:1024049403422

Zhang Y, Zhang S, Zhang X, Qiu J, Yu L, Shi C (2015) Ni modified WCx catalysts for methane dry reforming. In: Jin F, He LN, Hu $\mathrm{YH}$ (eds) Advances in $\mathrm{CO} 2$ capture, sequestration, and conversion, vol 1194. American Chemical Society, Washington, pp 171-189. https://doi.org/10.1021/bk-2015-1194.ch008

Zhang F, Song Z, Zhu J, Liu L, Sun J, Zhao X, Mao Y, Wang W (2018a) Process of $\mathrm{CH}_{4}-\mathrm{CO}_{2}$ reforming over $\mathrm{Fe} / \mathrm{SiC}$ catalyst under microwave irradiation. Sci Total Environ 639:1148-1155. https://doi.org/10.1016/j.scitotenv.2018.04.364
Zhang F, Song Z, Zhu J, Sun J, Zhao X, Mao Y, Liu L, Wang W (2018b) Factors influencing $\mathrm{CH}_{4}-\mathrm{CO}_{2}$ reforming reaction over Fe catalyst supported on foam ceramics under microwave irradiation. Int J Hydrog Energy 43:9495-9502. https://doi. org/10.1016/j.ijhydene.2018.03.171

Zhang YJ, Wang ZJ, Chen YN, Zhang ZD (2018c) Crystallization kinetics of $\mathrm{PbTiO}_{3}$ ferroelectric films: comparison of microwave irradiation with conventional heating. J Eur Ceram Soc 38:105-111. https://doi.org/10.1016/j.jeurceramsoc.2017.08.030

Zhao B, Shao G, Fan B, Zhao W, Chen Y, Zhang R (2015) Facile synthesis of crumpled $\mathrm{ZnS}$ net-wrapped $\mathrm{Ni}$ walnut spheres with enhanced microwave absorption properties. RSC Adv 5:98069814. https://doi.org/10.1039/C4RA15411H

Zhu YJ, Chen F (2014) Microwave-assisted preparation of inorganic nanostructures in liquid phase. Chem Rev 114:6462-6555. https ://doi.org/10.1021/cr400366s

Zhu H, He J, Yang Q, Yang Y, Huang K (2017) A rotary radiation structure of microwave reactor for advanced materials processing. In: 2017 international conference on information, communication and engineering (ICICE), pp 404-407

Zlotorzynski A (1995) The application of microwave radiation to analytical and environmental chemistry. Crit Rev Anal Chem 25:43-76. https://doi.org/10.1080/10408349508050557

Publisher's Note Springer Nature remains neutral with regard to jurisdictional claims in published maps and institutional affiliations. 